\title{
DIGITALLY-CONTROLLED DEEP BRAIN STIMULATION LEAD IMPLANT SYSTEM
}

A Master's Thesis presented to

the Faculty of California Polytechnic State University,

San Luis Obispo

In Partial Fulfillment of the Requirements for the Degree

Master of Science in Mechanical Engineering

by

Matthew Joseph Phillips

December 2011 
(C) 2011

Matthew Joseph Phillips

ALL RIGHTS RESERVED 
TITLE:

AUTHOR:

DATE SUBMITTED:

COMMITTEE CHAIR:

COMMITTEE MEMBER:

COMMITTEE MEMBER:
Digitally-Controlled Deep Brain Stimulation Lead Implant System

Matthew Joseph Phillips

December 2011

Peter J. Schuster, Ph.D., P.E., Professor of Mechanical Engineering

James M. Meagher, Ph.D., P.E., Professor of Mechanical Engineering

Saeed B. Niku, Ph.D., P.E., Professor of Mechanical Engineering 


\section{ABSTRACT \\ Digitally-Controlled Deep Brain Stimulation Lead Implant System Matthew Joseph Phillips}

Deep brain stimulation, the treatment of disorders by applying electrical stimulation to brain tissue, is a relatively new field of medicine with great potential to provide cures for neurological disorders. It utilizes a system very similar to a cardiac pacemaker and lead to electrically stimulate brain tissue. This electrical stimulation is programmed to disrupt or mask aberrant brain signals while not impeding the normal function of the brain. The advances in implantable pulse generators designed for deep brain stimulation have been remarkable, and the applications for deep brain stimulation continue to grow including multiple sclerosis (Berk, et al. 2002), severe psychiatric disorders (Kopell, Greenberg and Rezai 2004), and depression (Mayberg, et al. 2005). The da Vinci® Surgical System developed by Intuitive Surgical $\Theta$ has shown that providing surgeons with digital control of an advanced robotic surgical assistance device to be highly advantageous, however there has been minimal effort to develop a system that would provide similar advantages to deep brain stimulation surgeons. This thesis is focused on the design and utilization of a digital robotic system that will advance the safety and efficacy of the deep brain stimulation implant surgery. This is accomplished by employing current technology and custom software to control a mechanical system thereby improving relative accuracy during the deep brain stimulation lead implant procedure and providing focalized electrical stimulation. The first is achieved through digital control of motors to drive the implant procedure resulting in lead placement accuracy on a micron level and supported by computation and by FEA analysis. The latter is realized by providing the surgeon with the ability to generate curvilinear lead implant orientations which in turn concentrate electrical stimulation in a small volume of tissue with the goal of minimizing stimulation of healthy tissue and increasing battery life and supported by an electro-thermal FEA analogy. 


\section{NOTE:}

It should be noted that the Food and Drug Administration governs all aspects of a medical device to ensure safety. Hence all approvals associated with an active implantable device must be obtained before such a device can be used in clinical trials. This thesis is not intended to be used as a reference or evidence for any such device, but solely as an academic assessment of possible improvements which are yet to be realized in deep brain stimulation. 


\section{Table of Contents}

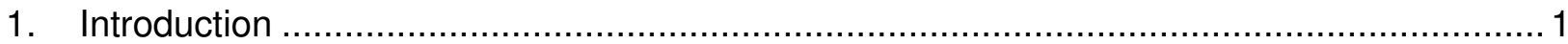

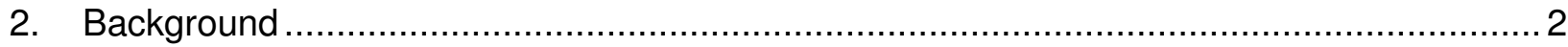

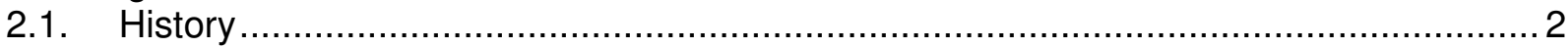

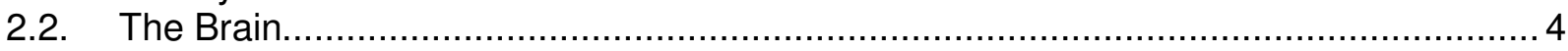

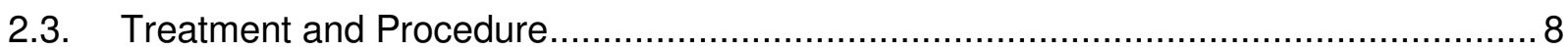

2.4. Existing Technology \& Procedures ................................................................ 10

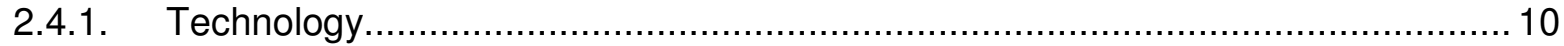

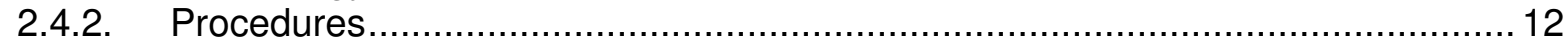

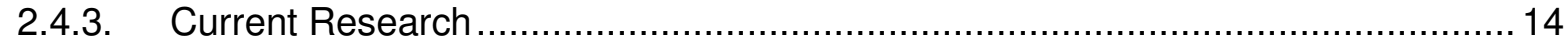

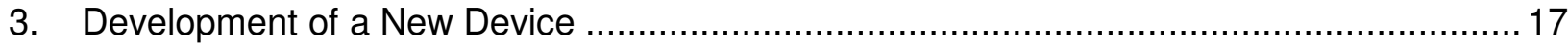

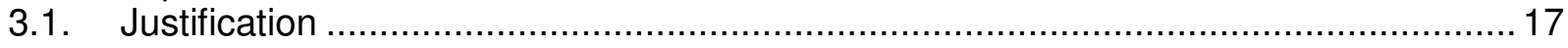

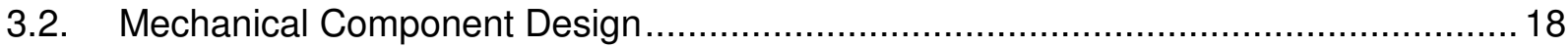

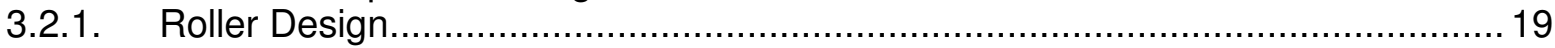

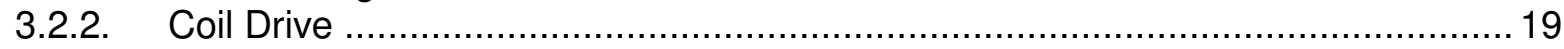

3.2.3. Dual Rollers / Conveyor Concepts......................................................... 20

3.2.4. Collet Concepts / Pencil Mechanism ........................................................... 21

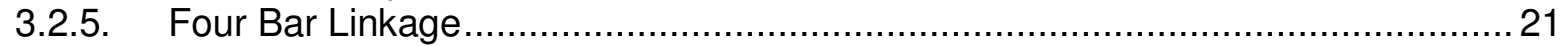

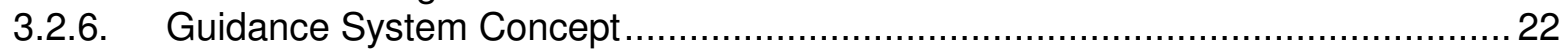

3.2.7. Overview of Combined System Functionality ........................................... 23

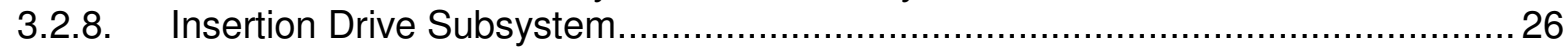

3.2.9. Advance \& Retract Lead Inputs ............................................................ 28

3.2.10. Advance \& Retract Equations................................................................ 29

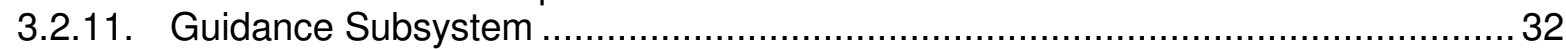

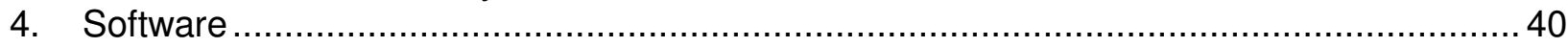

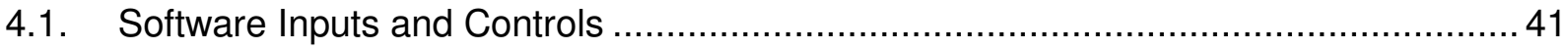

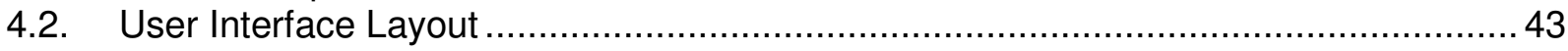

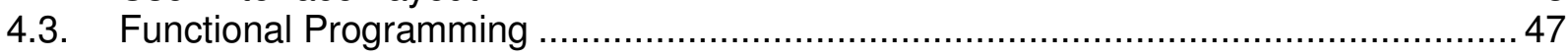

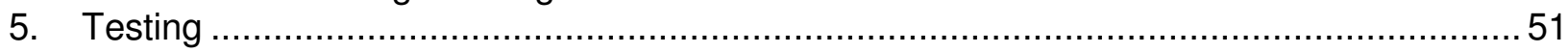

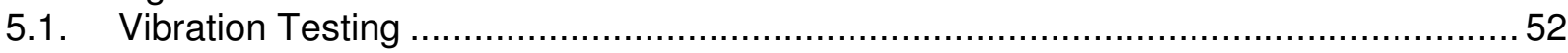

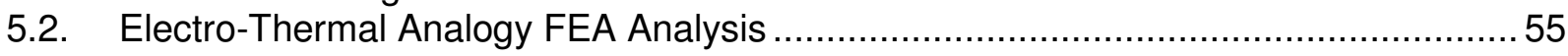

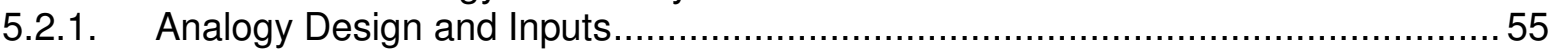

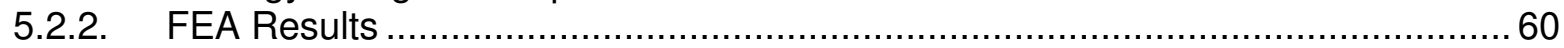

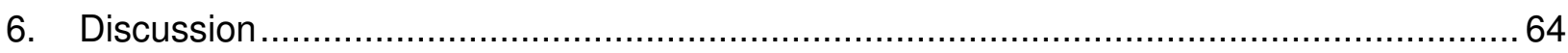

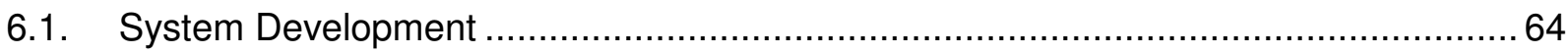

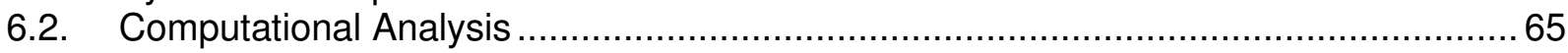

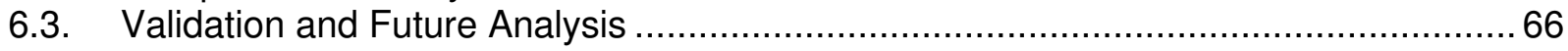

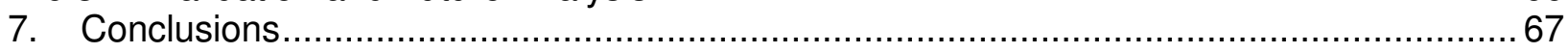

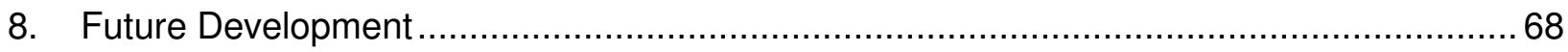

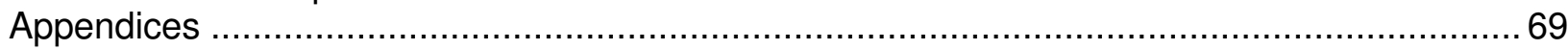

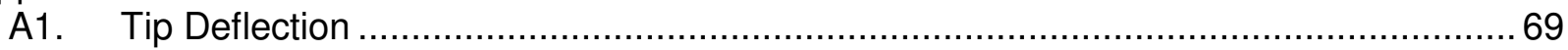

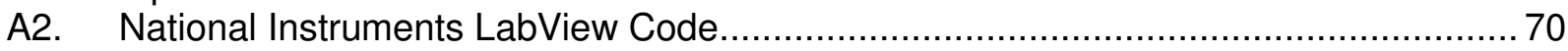

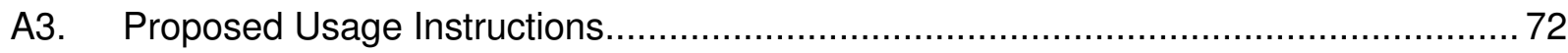

A4. Failure Mode and Effects Analysis (FMEA) …............................................ 75

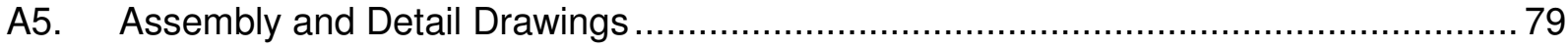

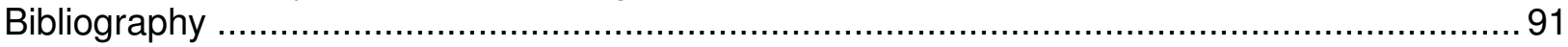




\section{List of Tables}

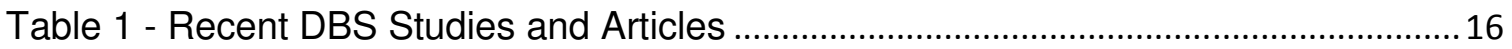

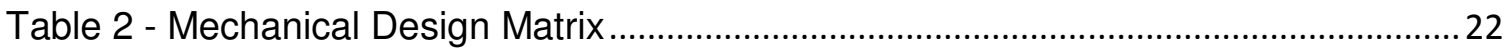

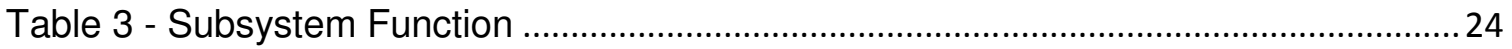

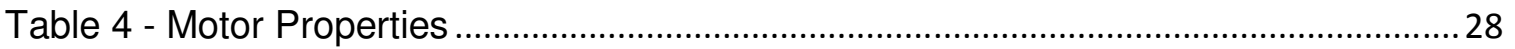

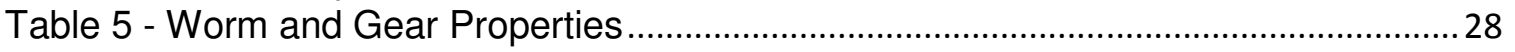

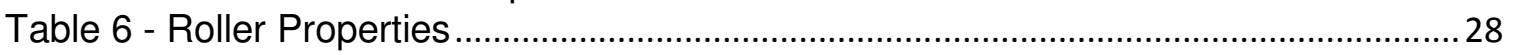

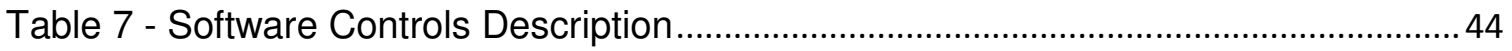

Table 8 - Leksell Arc Natural Modes of Vibration Convergence Study...............................52

Table 9 - FEA Vibration Model Properties............................................................................5

Table 10 - Leksell Arc with Additional Point Mass and Moments of Inertia ........................54

Table 11 - Harmonics of Maximum Driving Frequency ........................................................55

Table 12 - Electro-Thermal Component Definitions...............................................................56

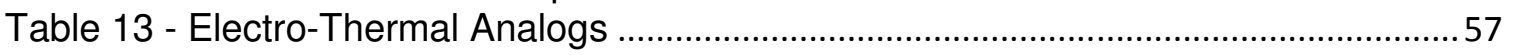

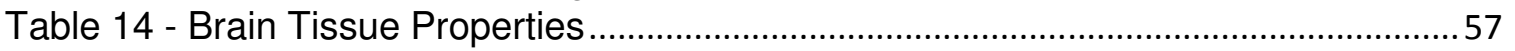

Table 15 - FEA Electro-thermal Analogy Model Properties..................................................58

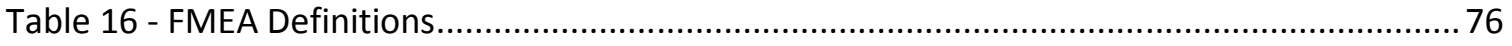

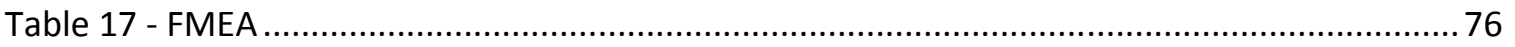

\section{Table of Figures}

Figure 1 - Spiegel et al.' stereotactic apparatus (Speigal, et al. 1947) ................................. 3

Figure 2 - Architecture of the Brain: The Forebrain, Midbrain, and Hindbrain (The

National Institute of Neurological Disorders and Stroke 2010) .........................................5

Figure 3 - Artist rendering of a cross section of the human brain (Oscar-Berman and

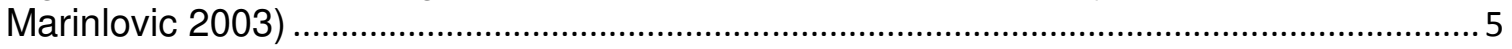

Figure 4 - MRI derived computer model of an implanted DBS lead (Butson, et al. 2007) 6

Figure 5 - Artist rendering of a typical neuron cell (Young 2000) ....................................... 7

Figure 6 - Artist rendering of an implanted DBS system (WebMD 2002) ............................ 8

Figure 7 - Medtronic Activa PC Neurostimulator with Leads (Medtronic Inc 2010) ........... 9

Figure 8 - Cross-sectional view of lead extrusion .......................................................... 9

Figure 9 - Leksell Frame (Leksell 2008) ............................................................................. 11

Figure 10 - Implant frame and arc attached to patient before lead insertion

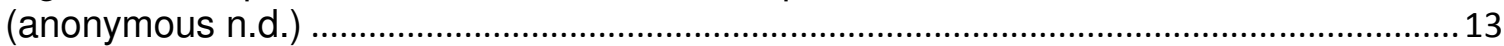

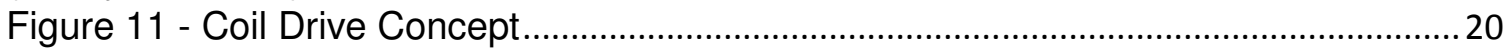

Figure 12 - Complete guidance/implant system mounted on Leksell Arc ...........................23

Figure 13 - Implant Coordinates .................................................................................. 25

Figure 14 - Complete Insertion Subsystem Mounted on Leksell Arc ..................................26

Figure 15 - Transparent View of Insertion Subsystem System..........................................27

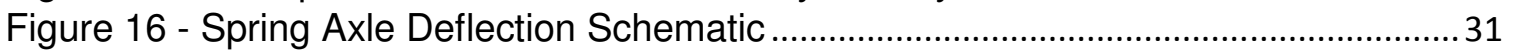

Figure 17 - Spring Axle Free Body Diagram ..................................................................... 31

Figure 18 - Transparent View of Complete Guidance Mechanism..................................... 32

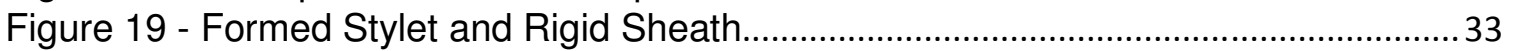

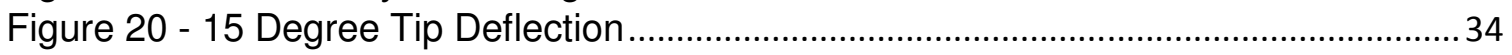

Figure 21 - Sheath Drive and Electrode Wiring Illustration................................................... 36

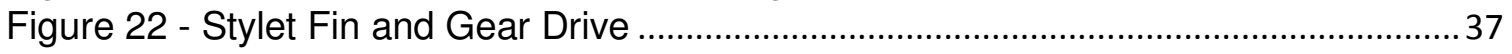

Figure 23 - Volume of Potential Implant Locations ............................................................. 38

Figure 24 - Close-up of Electrical Connections ................................................................. 38 


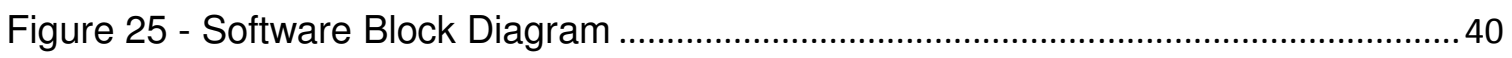

Figure 26 - Quadrants of User Interface Front Panel ....................................................... 41

Figure 27 - SpaceNavigator ${ }^{\mathrm{TM}}$ (3D Connexion (A Logitech Company) 2008) ...................... 42

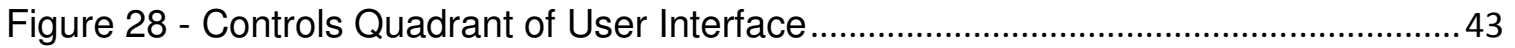

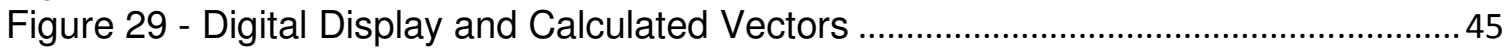

Figure 30 - Graphical Display of Lead Orientation and Proximity to Target Site .............46

Figure 31 - Graphical User Interface Displaying Correct Target Approach ...................... 47

Figure 32 - Functional Code for Initialization ................................................................. 48

Figure 33 - Functional Code for Graphical Display Database ............................................. 48

Figure 34 - Functional Code for Space Navigator Input Acquisition ................................... 49

Figure 35 - Functional Code for Keyboard Input Acquisition............................................... 49

Figure 36 - Functional Code for Stepper Motor Control ...................................................... 49

Figure 37 - Functional Code for Position and Orientation Computation............................... 50

Figure 38 - FEA Vibration Model .................................................................................. 53

Figure 39 - Volume of Tissue Activated by Deep Brain Stimulation (Butson, et al. 2007)

Figure 40 - Current Density Distribution for Axisymmetric Lead Implant............................61

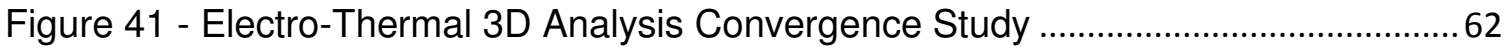

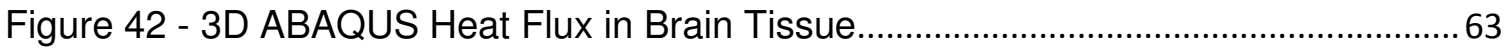

Figure 43 - 3D ABAQUS Heat Flux in Brain Tissue with DBS Lead Graphic ....................63

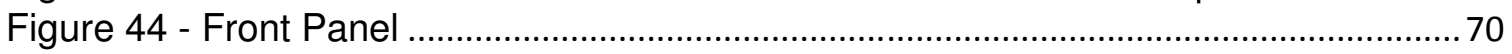

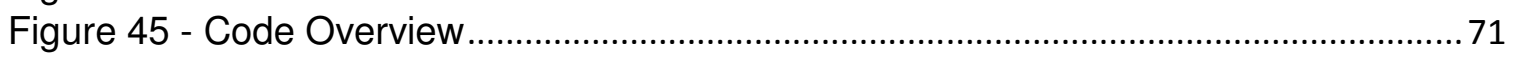




\section{Introduction}

Deep brain stimulation is the use of a surgically implanted electrical pulse generator and lead to deliver electrical stimulation to brain tissue in order to disrupt or mask abnormal signals generated or received by the brain. This thesis is focused on improving the procedure for implanting deep brain stimulation leads by developing a new implant system that gives the surgeon digital control over the insertion of the lead into the brain and the ability to fine tune the implant positioning, on a micron level, to ensure that the optimal implant orientation has been obtained. The following hypothesis will be tested through the development and simulation of this implant system: Digital control of the lead implant process will allow for asymmetric implant orientations and corresponding asymmetric electrical stimulation fields. Empirical data to support the calculations and simulations performed in this thesis can only be obtained through actual utilization of such a device in surgery. 


\section{Background}

\subsection{History}

Deep brain stimulation (DBS) is a very recently created branch of neurotechnology. Alternative procedures include prescribed medication, removal of portions of the brain via scalpel (e.g. thalamotomy - complete removal of the thalamus), radiosurgery (the use of x-ray beams to radiate and destroy target tissue), and thermal ablation (the use of intense heat or cold to thermally destroy target tissue). The benefits of deep brain stimulation must outweigh the risk and complexity of the procedure and the benefits associated with other treatments such as medication or therapy before it is attempted. However, there are several benefits to deep brain stimulation which cannot be realized with other forms of treatment. Deep brain stimulation targets the source of neurological disorders whereas therapy focuses on the symptoms. A properly performed implant procedure does not destroy the target tissue as does ablative surgery. Deep brain stimulation is also focused on a specific area of the brain unlike medication which is absorbed by a significantly larger portion of the body.

Electrical stimulation was first used as a mapping tool to determine what portions of the brain needed to be removed in 1951 and during the following decade research concerning therapy via deep brain stimulation commenced (Schawlb and Hamani 2008). Continual electrical stimulation allowed surgeons to treat the patient without causing irreparable damage to the brain tissue, and also allowed for modification or cessation of therapy if necessary. The U.S. Food and Drug Administration (FDA) approved the first deep brain stimulation treatment in 1997 for alleviating essential tremor, uncontrollable muscle spasms caused by involuntary commands generated by the brain (U.S. Department of Health and Human Services 1997). DBS has since been approved for treating Parkinson's disease in 2002 (National Institute of Neurological Disorders and 
Stroke 2007) and dystonia in 2003 (Schawlb and Hamani 2008). There are several other applications currently being investigated such as Tourette syndrome (Walkup 2005), obsessive compulsive disorder (Nuttin, et al. 1999), and clinical depression (Mayberg, et al. 2005).

The deep brain stimulation lead implant procedure has been based, since its inception, on stereotactic surgery. Stereotactic surgery is based on fundamental mathematics, vectors, and the axiom that a single line that can be drawn between two points. If a known desired implant site inside the brain is known, and can be referenced to a known point outside of the body, then a surgical procedure which follows an appropriate vector and proceeds the appropriate calculated depth will reach the desired target.

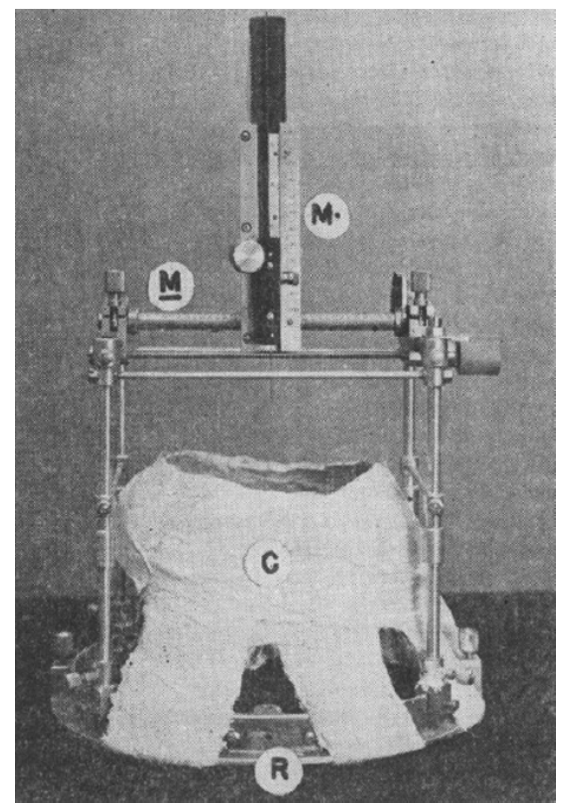

Figure 1 - Stereotactic Apparatus (Speigal, et al. 1947)

The above figure details one of the first designs of deep brain stimulation implant apparatuses. The following components are highlighted: C - cast of the patient's head formed with plaster of Paris, $R=$ ring which tethers the frame to plaster cast, $\underline{M}$ - a millimeter scale for movement in the sagittal direction (sagittal axis is from the front to the back of the patient), $\mathrm{M} \cdot$ a millimeter scale attached to 
the insertion needle. Although this appears to be simple trigonometry, it must be understood that this type of surgery is performed by adjustment of knobs and slides, the surgeon has no visual feedback on which to base the success or possible complications of the procedure. Feedback is derived from turning on the system, and the patient's response.

There have been several advancements in the design of the system used to insert the deep brain stimulation lead as well as the imaging tools and software used to map the brain and determine the target implant location. This is discussed in the "Existing Technology and Procedures" section of this thesis.

\subsection{The Brain}

The brain is the body's control center and the center of the nervous system for almost all animals. It is responsible for reception and processing of external input, logic and intelligence, emotion and feelings, as well as determining action and response. It was erroneously thought to be a "homogenous mass without discrete function" until 1864 (Schawlb and Hamani 2008). The brain is now known to be composed of several different discrete sections which perform unique tasks. Full functionality is achieved through the collaboration of these sections. The following is a brief overview of the brain and the currently known functionality of the specific regions. 

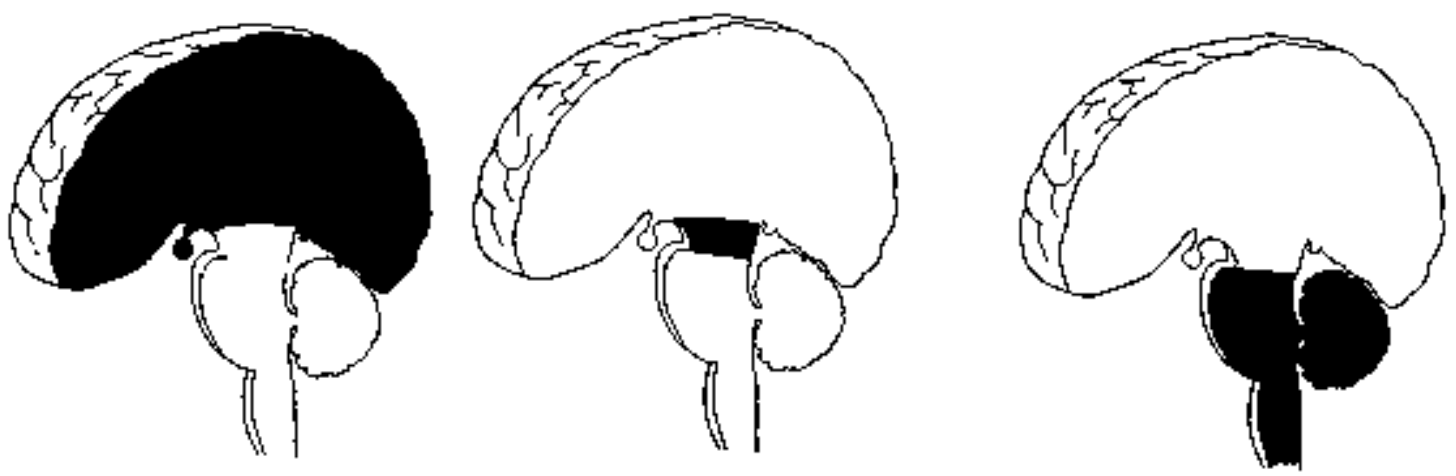

Figure 2 - Architecture of the Brain: The Forebrain, Midbrain, and Hindbrain (National Institute of Neurological Disorders and Stroke 2010)

The brain can be divided into three main sections with distinct functionality. The forebrain stores information, coordinates motion with the surrounding environment, and processes cognitive thought. The forebrain is split into two hemispheres. Each half performs unique tasks but communicates with the other via a bundle of nerves. The midbrain is directly linked to the eye and is thought to control reflex and other automatic responses. The hindbrain is composed of the brain stem and upper portion of the spinal cord. It is responsible for vital autonomous functionality such as breathing and heart contractions (National Institute of Neurological Disorders and Stroke 2010).

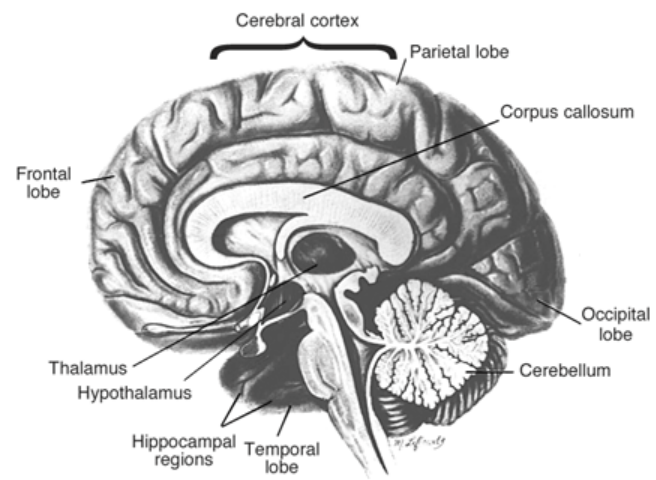

Figure 3 - Artist rendering of a cross section of the human brain (Oscar-Berman and Marinlovic 2003) Within the forebrain, the inner brain is contained. The thalamus, the hypothalamus, the hippocampus, and the basal ganglia constitute the inner brain, and like the forebrain, each of the components has a left and right half. This portion of the brain is a major 
component of what makes mankind unique. It is this section of the brain that allows man to act based on thought rather than instinct; "These structures not only determine our emotional state, they also modify our perceptions and responses depending on that state, and allow us to initiate movements that you make without thinking about them" (National Institute of Neurological Disorders and Stroke 2010). The following computer model derived from MRI images shows a DBS lead implanted through the thalamus (yellow) and subthalamic nucleus (green).

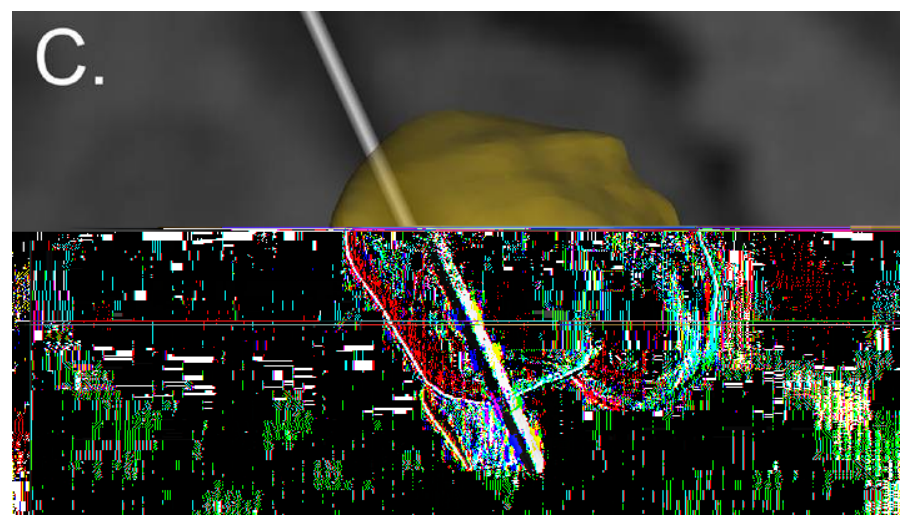

Figure 4 - MRI derived computer model of an implanted DBS lead (Butson, et al. 2007) Although the brain is composed of many different sections which have unique functions, the actual processing, on the cellular level, is done by the same type of cell, the neuron. The storage and recall of memories, analysis of input, and motor control of the body are all performed by these cells. Neurons are the cells responsible for the majority of electrical activity in the brain and they are supported by the neuroglia cells (or glial cells) which perform all of the processes required to sustain the organ. 


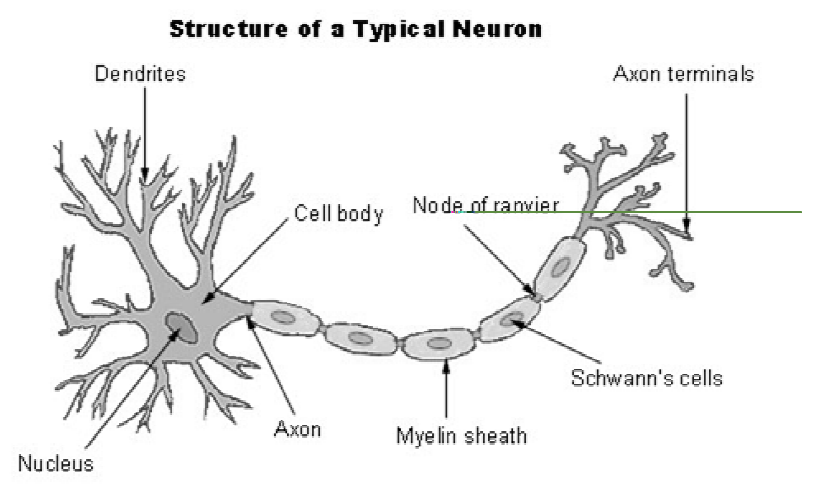

Figure 5 - Artist rendering of a typical neuron cell (Young 2000)

The neurons are the target cells of deep brain stimulation. They are fewer in number than the glial cells and do not undergo mitosis, and hence do not regenerate. Once they are lost, they cannot be replaced. The dendrite section of the neuron cell receives the input and the signal is transmitted along the axon to other cells via the axon terminals. The brain is a vast network of intra-connected neurons, with each neuron connecting to between one and ten thousand other neurons (Junqueira and Carneiro 2002).

Due to ability of a single neuron to transmit a signal to a large network of cells, stimulation must be as precise and as minimal as possible to minimize side effects caused by overstimulation or stimulation of the surrounding healthy neurons as errant stimulation of a single healthy neuron can affect a substantial number of connected cells.

Through the collaboration of surgeons and researchers, the main functions of different sections of the brain have been mapped. However, how the brain actually processes information, performs functions, and utilizes electro-chemical signals used to communicate with the rest of the body are still being studied. Currently, deep brain stimulation is only able to coarsely mask neurological ailments, rather than treat them. Although this provides therapeutic relief from the symptoms, if the stimulation is turned off, all symptoms will return. Once the functionality and manner in which the brain 
processes electrical input are understood, the algorithms used by deep brain stimulation systems can be modified to possibly correct or completely eliminate symptoms.

\subsection{Treatment and Procedure}

Deep brain stimulation system is composed of implanted leads connected to an implanted pulse generator. The pulse generator produces an electrical signal which is transmitted to the brain tissue via the lead.

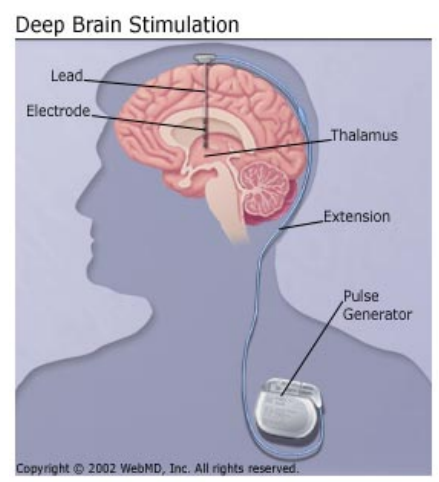

Figure 6 - Artist rendering of an implanted DBS system (WebMD 2002)

The implanted pulse generator is similar in most respects to a pacemaker. In most cases it is implanted far from the treatment target site and the electrical stimulation is delivered remotely by the lead. The lead is a conductive series of cables/coils that are individually isolated inside of a silicone or polyurethane tubing. These cables connect to conductive contacts on the exterior of the lead at both ends. The contacts on the proximal end of the lead are connected to the implanted pulse generator and the contacts on the distal end of the lead are used to stimulate the brain tissue. Software embedded in the implanted pulse generator allows the physician to select which contacts are "on" and the voltage and frequency of the stimulation signal. The frequency and magnitude of the electrical signal can be tuned and optimized for various locations in the brain, the severity of the disease being treated, and the preference of the individual being treated. This optimization of the electrical signal is commonly referred to as "current steering" and 
effectively gives the surgeon control over the direction and magnitude of the electrical signal as well as the size of the area affected by the electrical signal. Ultimately, this allows for an increase in the quality of treatment by allowing the surgeon to create a unique treatment for each patient using a standard lead and pulse generator. Current lead designs are very similar to the leads used in conjunction with cardiac pacemakers, as seen in the image below.

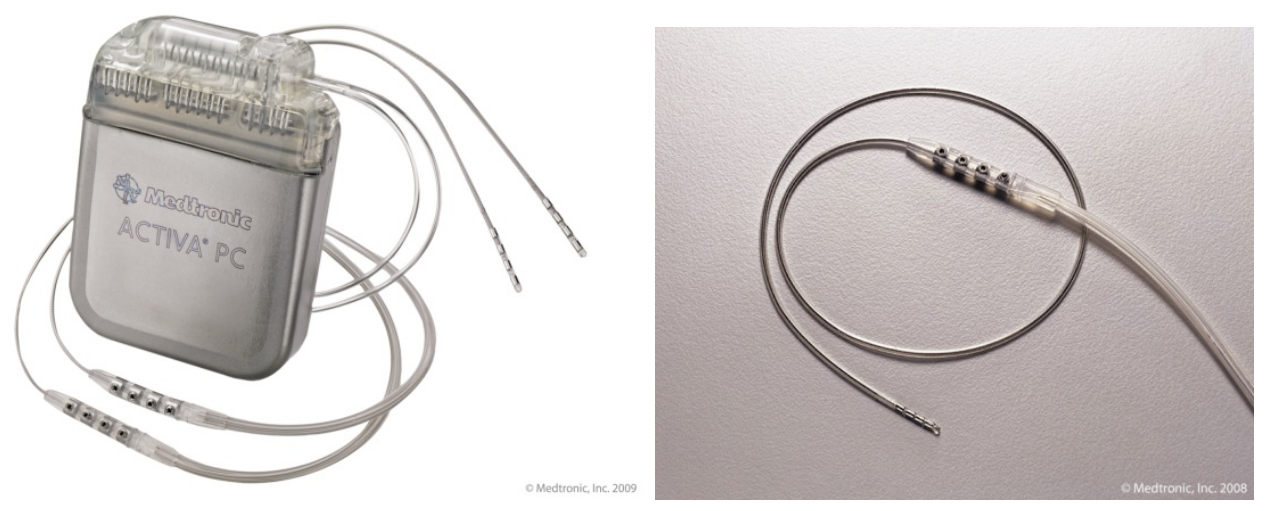

Figure 7 - Medtronic Activa PC Neurostimulator with Leads (Medtronic Inc 2010)

Each lead is composed of multiple cables electrically isolated by a silicone rubber or polyurethane multi-lumen tubing approximately $1.5 \mathrm{~mm}$ in diameter (See Figure 8). The lead also contains a central lumen that is vacant to allow for the use of guidewires or stylets.

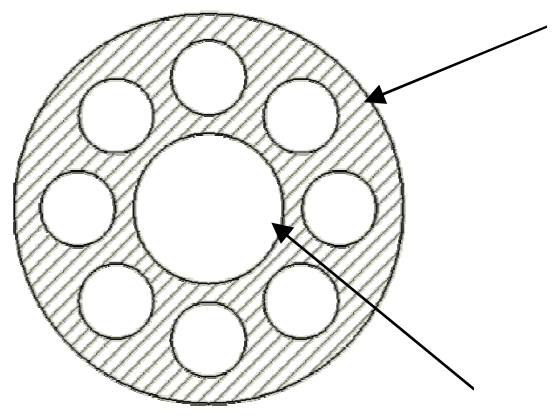

Lumens

Figure 8 - Cross-sectional view of lead extrusion 
The cables connect the electrodes in contact with the brain tissue with the pulse generator. The length of the lead as well as the number and spacing of the contacts are dependent on the manufacturer.

Deep brain stimulation leads are designed to only target a small section of the brain, but the actual volume of stimulated tissue depends on the farthest distance between activated contacts and the stimulation voltage. The size of the stimulation volume is relatively small to minimize stimulation of healthy tissue. Since various neurological disorders affect different areas of the brain, a unique implant location is required. The ability of the lead delivery system to be versatile in reference to implant site is crucial to expanding the range of diseases and syndromes that can be treated. For example, essential tremor and Parkinsonian tremors are treated by implanting the DBS leads in the thalamus. The thalamus is a major component of a person's motor control (Sommer 2003). Therefore, an improperly placed implant may negatively affect the patient's ability to control their muscles.

\subsection{Existing Technology \& Procedures}

\subsubsection{Technology}

There are several existing systems used for the implantation of deep brain stimulation leads. The most notable is the Leksell Stereotactic System sold by Elekta®. Elekta® was started in 1972 by Dr. Leksell, the surgeon and researcher who pioneered the development of the device that bears his name. Stereotactic refers to the utilization of a three-dimensional coordinate system to locate the desired implant site. As shown in the

picture below, the Leksell frame utilizes a spherical coordinate system $(r, \varphi, \theta)$ composed of an insertion mechanism (r-axis) which slides along an $\operatorname{arc}(\varphi)$ which pivots in reference to the frame $(\theta)$. 


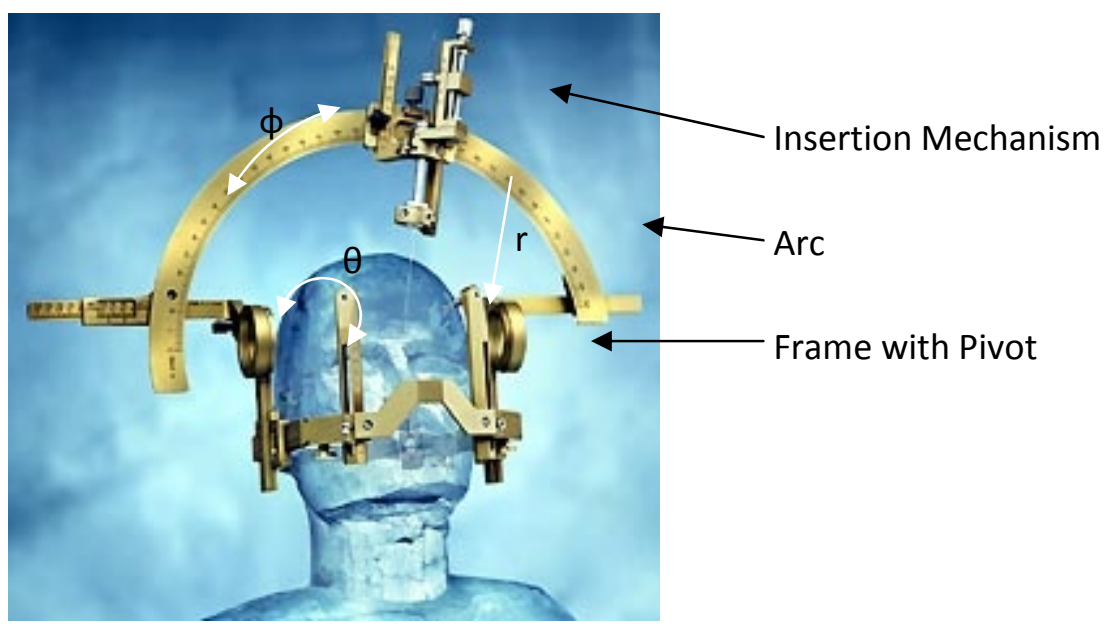

Figure 9 - Leksell Frame (Leksell 2008)

This frame has become the platform for most stereotactic-based neurosurgery

procedures. Elekta ${ }^{\circledR}$ currently sells a motorized lead advancement system designed to increase accuracy for deep implant sites. However this system only allows for straight implant contours and lacks any guidance capability.

At the time this thesis was initiated, there was no stereotactic product available to surgeons that allowed them to make a controlled deviation from a straight line while performing a deep brain lead implantation. This advancement would allow surgeons to implement stereotactic surgery for areas of the brain which have not yet been targeted for treatment, and provide new surgical implantation paths for already known target sites. This also allows for the deep brain stimulation lead to be placed in a curved profile. This curved profile focuses the electrical stimulation in the desired region. The benefits of these added abilities are discussed in Section 3 - Development of a New Device. 


\subsubsection{Procedures}

All procedures in use today follow the same initial patient preparation and setup. The patient is diagnosed with a disease or condition, and deep brain stimulation is either the recommended or only available treatment. The patient is then informed of the risks and potential benefits of deep brain stimulation and presented with a consent form. If the patient consents to surgery, a frame is rigidly attached to the patient's head. The patient's head with attached non-ferromagnetic frame, such as titanium, is scanned using magnetic resonance imaging (MRI) or computed tomography (CT). The images are used to target the implant location. Once chosen, the implant location for the deep brain stimulation lead is mapped in three dimensions and referenced to the stereotactic frame. The surgeon determines the best linear path for inserting the deep brain stimulation lead to the target site. An arc is then mounted on the frame. This arc can pivot on the frame to provide the surgeon with the desired stereotactic path. Once the arc has been rotated to the desired angle, it is rigidly locked to the frame and can then be used to support the required mechanical apparatus required for a craniotomy.

The patient is given a local anesthetic and the skull is breached using a surgical drill. The breaching apparatus is then removed and a lead insertion guide and/or motor assisted insertion device is attached. The arc is shown below with a lead advancement tool attached. 


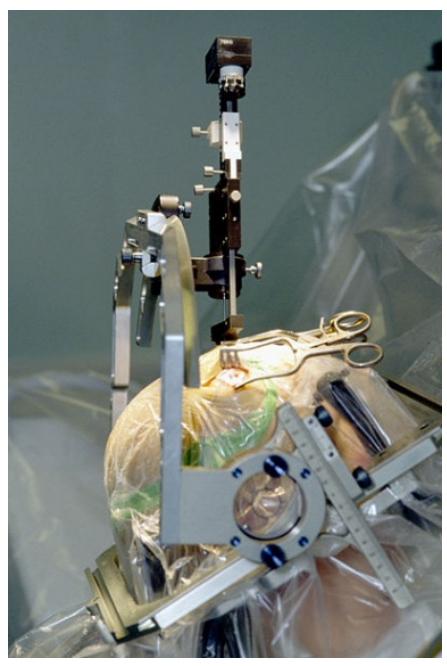

Figure 10 - Implant frame and arc attached to patient before lead insertion (anonymous n.d.)

The insertion system is properly aligned with the insertion path using the graduations on the frame and arc. The insertion process is then initiated either via manual control or by activating the motors. The graduations on the insertion handle indicate the depth of insertion and are used to confirm that the target site has been reached, the lead is connected to the implantable pulse generator and the generator is turned on. The surgeon then discusses with the patient concerning the effect of the stimulation to determine if the optimal site has been reached. Proper placement of the lead will result in effective treatment of the disorder without impeding the normal functionality of the brain. The surgeon will often ask the patient to perform simple motor control tasks such as raising an arm, blinking, and speaking to ensure that the treatment is not creating unwanted side effects. If necessary, the lead is repositioned until this has been accomplished. The surgeon then fine-tunes the electrical stimulation to ensure that an optimal level is being delivered. The optimal level is determined by the surgeon but best practices indicate that the minimum amount of stimulation required to treat the disorder should be used. Under-stimulation of the target cells results in ineffective treatment whereas overstimulation can result in stimulation of healthy tissue causing tingling or pain sensations as well as lower device life due to increased battery power consumption. 
The implantable pulse generator is inserted into a void in the body generally under the clavicle, as seen in Figure 6. The hole in the skull is filled with a molded component designed to ensure that the patient's brain is completely protected after the procedure while also providing a port to allow the lead to exit the skull. This plug is a permanent implant, designed to allow for bone tissue ingress to further anchor the plug. All incisions are stitched closed and the procedure is concluded.

After the procedure the patient is required to undergo several monthly checkups to ensure that the lead implant position has not shifted, all electrical connections are intact, that no infection has occurred, and the pulse generator is performing correctly. This is followed by yearly exams to ensure the optimal performance of the device, to ensure that the stimulation lead has not migrated after the procedure via $x$-ray, and to continuously monitor for infections.

\subsubsection{Current Research}

Most research and advancement in stereotactic surgery have been focused in radiosurgery (or stereotactic radiotherapy) for means of destroying lesions or brain cells responsible for the neurological disorder being treated. Radiosurgery implements multiple beams of gamma radiation all focused at the target site. Each beam is not powerful enough to destroy tissue, but the radiation dosage at the intersection of these beams is. This type of surgery can be thought of as "knifeless" surgery, as the tissue itself is destroyed by radiation and reabsorbed into the body. Advancements have been made concerning beam accuracy, treatment algorithms, and multi-beam treatment, as well as the ability to conform radiated areas to the complex geometries of lesions (Szeifert, et al. 2009), (Nangiana, et al. 2009). However radiology, by the nature of the procedure, entails permanent loss of brain tissue This research has shown improvements in limiting damage to healthy tissue, but it is not possible for this type of 
procedure to cure or palliate symptoms without destroying the cells. You can only cut with a knife, and in the same manner radiation is solely destructive. Since brain cells do not undergo mitosis, their loss is irreparable. Although radiology has been shown to be an effective treatment for the ablation of tumors and metastases, this form of treatment for neurological disorders does so at the cost of the brain tissue and associated functionality. The complete destruction of non-regenerative tissue should be done as a last resort. The mechanisms designed and discussed in this thesis are designed to advance stereotactic stimulation procedures, which in turn, could reduce the number of cases in which radiology is required.

Recent research concerning deep brain stimulation has been focused on its efficacy and other potential disorders which may be treatable via deep brain stimulation. The following table describes some of the recent studies concerning aspects of deep brain stimulation. Studies concerning implant technique and lead placement were not found. 
Table 1 - Recent DBS Studies and Articles

\begin{tabular}{|c|c|c|c|}
\hline Title & Synopsis & Authors & Journal \\
\hline $\begin{array}{l}\text { Deep Brain Stimulation } \\
\text { for Treatment-Resistant } \\
\text { Depression }\end{array}$ & $\begin{array}{l}\text { DBS was effectively used to } \\
\text { reverse symptoms of depression } \\
\text { in patients for whom other forms } \\
\text { of treatment were unsuccessful. }\end{array}$ & $\begin{array}{l}\text { Mayberg, } \\
\text { et al. }\end{array}$ & $\begin{array}{l}\text { Neuron, Volume 45, } \\
\text { Issue 5, 651-660, } \\
\text { March } 2005\end{array}$ \\
\hline $\begin{array}{l}\text { Deep brain stimulation } \\
\text { for refractory obsessive- } \\
\text { compulsive disorder }\end{array}$ & $\begin{array}{l}\text { DBS provided promising results } \\
\text { for the research subjects and } \\
\text { holds potential value for OCD } \\
\text { patients. }\end{array}$ & $\begin{array}{l}\text { Abelson, } \\
\text { et al. }\end{array}$ & $\begin{array}{l}\text { Biological } \\
\text { Psychiatry, Volume } \\
\text { 57, Issue 5, 510- } \\
516, \text { March } 2005\end{array}$ \\
\hline $\begin{array}{l}\text { A Randomized Trial of } \\
\text { Deep-Brain Stimulation } \\
\text { for Parkinson's Disease }\end{array}$ & $\begin{array}{l}\text { DBS plus medication proved to be } \\
\text { more beneficial than medication } \\
\text { alone. }\end{array}$ & $\begin{array}{l}\text { Deuschl, } \\
\text { et al. }\end{array}$ & $\begin{array}{l}\text { New England } \\
\text { Journal of Medicine, } \\
355: 896-908, \\
\text { August } 2006\end{array}$ \\
\hline $\begin{array}{l}\text { Mechanism of deep } \\
\text { brain stimulation: } \\
\text { Excitation or inhibition }\end{array}$ & $\begin{array}{l}\text { A discussion concerning the } \\
\text { proposed mechanisms } \\
\text { responsible for the beneficial } \\
\text { effect of deep brain stimulation. }\end{array}$ & Vitek & $\begin{array}{l}\text { Movements } \\
\text { Disorders, Volume } \\
\text { 17, Issue S3, S69- } \\
\text { S72, March } 2002\end{array}$ \\
\hline $\begin{array}{l}\text { Long-term Hardware- } \\
\text { related Complications of } \\
\text { Deep Brain Stimulation }\end{array}$ & $\begin{array}{l}\text { An assessment of the occurrence } \\
\text { rate of complications attributed to } \\
\text { the DBS implant for a single-site, } \\
\text { single surgeon practice. }\end{array}$ & $\begin{array}{l}\text { Oh, } \\
\text { et al. }\end{array}$ & $\begin{array}{l}\text { Neurosurgery, } \\
\text { Volume 50, Issue 6, } \\
1268-1276, \text { June } \\
2002\end{array}$ \\
\hline $\begin{array}{l}\text { Deep brain stimulation of } \\
\text { the subthalamic nucleus: } \\
\text { Clinical Effectiveness } \\
\text { and safety }\end{array}$ & $\begin{array}{l}\text { The effectiveness of DBS for } \\
\text { patients with Parkinson's disease } \\
\text { was confirmed for the sample of } \\
\text { patients included in the study. }\end{array}$ & $\begin{array}{l}\text { Lopiano, } \\
\text { et al. }\end{array}$ & $\begin{array}{l}\text { Neurology, 2001: } \\
56: 552-554\end{array}$ \\
\hline $\begin{array}{l}\text { MR Imaging-Related } \\
\text { Heating of Deep Brain } \\
\text { Stimulation Electrodes: } \\
\text { In Vitro Study }\end{array}$ & $\begin{array}{l}\text { The heating relationship between } \\
\text { DBS lead electrodes and the } \\
\text { specific absorption rate of MR } \\
\text { images was evaluated. }\end{array}$ & $\begin{array}{l}\text { Finelli, } \\
\text { et al. }\end{array}$ & $\begin{array}{l}\text { American Journal of } \\
\text { Neuroradiology, } \\
\text { Volume } 23,1795- \\
1802 \text {, November } \\
2002\end{array}$ \\
\hline
\end{tabular}

The lack of research and development concerning the implant apparatus and the surgical procedures may be due to prohibitive cost associated with requirements for obtaining approval for use and sale from government agencies (e.g. FDA). 


\section{Development of a New Device}

\subsection{Justification}

The effectiveness of neurostimulation therapy is dependent on the accuracy and magnitude of the electric stimulation. The more accurate the implant of the stimulation lead, the less electricity is required for effective treatment. Inaccurate placement of the stimulation lead is currently corrected by increasing the stimulating current or voltage. It can also be addressed by "current steering" which is accomplished by changing the resistance on the electrodes of the stimulation lead and hence causing the electrical stimulation to follow the path of least resistance. These solutions to inaccuracy bring with them unwanted side effects including shorter battery life and a larger affected region of non-target brain tissue stimulation. Lowering electrode resistance generates a larger current field but drains the battery more quickly. Since deep brain stimulation leads are currently implanted in a straight line and utilize axisymmetric electrodes, an axisymmetric current field is generated. Hence only a cylindrical volume of target tissue surrounding the lead is stimulated. As the power of the neurostimulation electrical signal increases, the signal influences a larger portion of the brain. This excessive stimulation can cause imaginary tingling sensations which the brain interprets to be from other parts of the body. It can also cause other negative neurological effects. Thermal and electrical activity maps of brain activity show that the target tissue generally does not have a cylindrical shape. The ability to generate a non-symmetrical, non-cylindrical volume of target tissue would allow the surgeon to provide a more effective and energy efficient treatment for each unique application. By deflecting the tip of the lead, the distance between the contacts changes and electrical stimulation becomes more focused as the contacts get closer together. This effect is demonstrated using FEA in the results section of the thesis. The ability to deflect the tip of the lead also provides the 
additional advantage of being able to guide the lead around sensitive parts of the brain rather than piercing them, as is currently required by a straight linear implant.

The design and control of this system are designed to give surgeons improved accuracy. Improved stimulation lead placement accuracy will theoretically provide longer battery life and minimize healthy tissue stimulation. If this technology is developed into a FDA approved device, the empirical results will greatly improve the understanding of effect of curvilinear lead implant profiles. This empirical data will then help drive the development of new deep brain stimulation leads specifically designed for these types of implants.

\subsection{Mechanical Component Design}

The following design requirements and constraints were used to generate the design concepts described in the design matrix.

1. The system must be digitally controlled.

2. The system must have a maximum step resolution of approximately 1 micron.

3. The system must be compatible with current lead designs.

4. The system must be able to deflect the distal end of the lead.

5. The deflection must be possible in any plane.

6. The system must be able to insert and retract the lead.

7. The system must be compatible with the Leksell stereotactic frame.

8. The lead must be able to be removed from the system without disturbing the distal end of the implanted lead.

9. The system must not damage the lead.

10. The system must allow the lead contacts to be activated during the implant without removal from the system.

11. Only the lead is allowed to have direct contact with brain tissue. 
Several design concepts were considered. The following sections detail each of the hypothesized concepts.

\subsubsection{Roller Design}

The roller design was the simplest idea involving a stepper motor driving a series of gears and ultimately a pair of rollers between which the lead was driven via friction. The active roller is powered via a geared down stepper motor and the passive roller holds the lead in place and provides the required normal force to transfer the torque of the stepper motor through the roller to the lead body. The stepper motor provides accurate advancement and retraction with very little associated cost, gears were implemented to reduce the speed of the stepper motor, increase the resolution of insertion distance per step, and increase the force with which the lead is driven to the target site. The passive roller was placed on a spring axle similar to what is utilized in mechanisms employed by printers to propel paper. This unusual axle choice allows the system to maintain a constant normal force on the lead even if the lead diameter varies (see Figure 16 Spring Axle Deflection Schematic). This simple, cost effective design was ultimately chosen to develop.

\subsubsection{Coil Drive}

A coil drive is effectively a spring coiled around the shaft to be driven and then rotated about its own axis. 


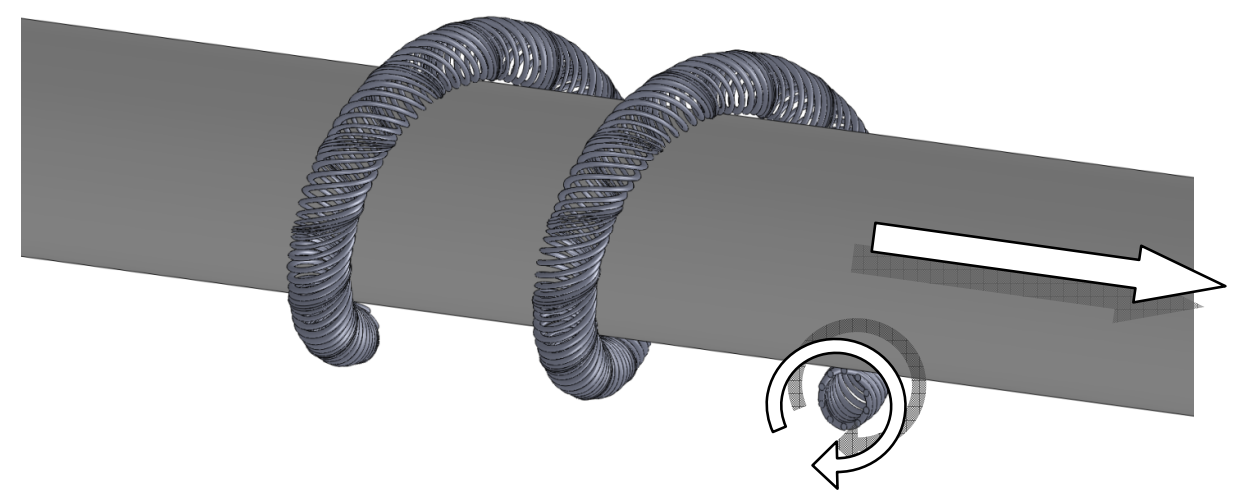

Figure 11 - Coil Drive Concept

As the spring rotates, the lengths of the spring coil in contact with the shaft are all moving in the same direction. Static friction, the normal force the spring applies to the shaft, and the torque causing the spring to rotate all combine to produce a net force along the axis of the shaft. Changing the direction of the torque on the spring will change the direction in which the shaft moves. The weakness of this design is that the spring's winding direction impairs its ability to apply a normal force to the shaft when the torque is applied in the same direction as the winding. There is also a risk of the coils coming into contact with each other and binding.

\subsubsection{Dual Rollers / Conveyor Concepts}

These two concepts were both derived from the common conveyor belt. The dual/multi roller design simply had the belt removed. The main advantage of the conveyor design is the transmission of friction along the length of the belt in contact with the lead. This increase in area decreases the necessary normal pressure to generate the same normal force and hence tangential force on the lead. The dual/multi-roller concept provide the same benefit, however the load is applied at multiple points rather than over a given length. The advantage of these systems is also their weakness; the lead body is composed of a soft silicone or polyurethane. In the event that the rollers/belt is not providing a constant load, the lead could buckle inside the system, damaging the lead. 


\subsubsection{Collet Concepts / Pencil Mechanism}

Several different versions of a collet based design were investigated. The basis for this design is derived from the mechanism in mechanical pencil which advances the graphite. The advancement mechanism in a mechanical pencil and lathe both employ the same basic tool, the inclined plane to fixate the work piece. As the collet is pulled into the lathe, the collet concentrically grips the work piece. In the same way, the mechanical pencil grips the graphite and the whole mechanism slides forward. The graphite is released, the mechanism slides back to its original location and static friction holds the graphite in its new location. This type of mechanism provides the following advantages for the lead insertion system: a highly repeatable step-based motion, high driving force without concern of slippage. The main drawback associated with this type of mechanism is that the motion is only in one direction and reversing the motion requires a similar mechanism oriented in the opposite direction. Duplicating the mechanism increases the complexity of the system and software required to control it. Also the ability to advance/retract the lead on micron scale would be very difficult.

\subsubsection{Four Bar Linkage}

The four bar linkage concept was developed based on a solution to the inability of the collet concepts to be easily reversed. The four bar linkage utilizes a linkage with lengths that form a parallelogram. The longer lengths are parallel to the axis of the lead and one of the shorter legs is attached to a motor. As the motor spins, the longer bar comes into contact with the lead and drives it forward. As the motor continues to turn, the bar releases the lead, rotates back to its original position and the cycle repeats. Reversing the motion of the lead is easily accomplished by reversing the driving motor. However, the linkage travels in a circle and hence the amount of load the linkage puts on the lead varies through the entire cycle. This can be accounted for, but again at a cost of 
increasing the complexity of the system. As with the pencil mechanism, this concept would be very difficult to generate accuracy on a micron level.

\subsubsection{Design Matrix}

The following design matrix details the breakdown of the pros and cons of each of the different design concepts considered. The concept which provided the maximum benefit across all weighted design considerations was chosen and developed. These values were generated based on feedback from surgeons and industry professionals.

Table 2 - Mechanical Design Matrix

\begin{tabular}{|c|c|c|c|c|c|c|c|c|c|c|c|}
\hline 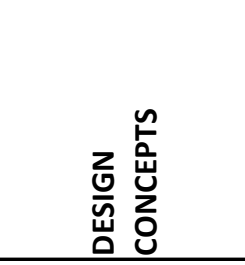 & 苑 & 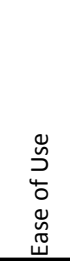 & 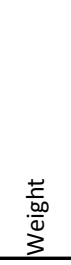 & 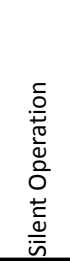 & 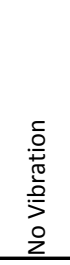 & 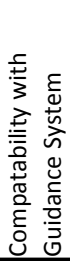 & 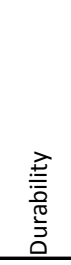 & 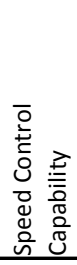 & 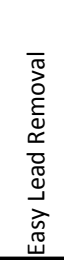 & 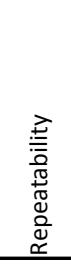 & 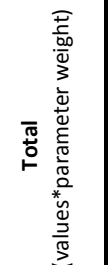 \\
\hline Parameter Weight $\rightarrow$ & 0.15 & 0.10 & 0.10 & 0.05 & 0.05 & 0.10 & 0.10 & 0.10 & 0.15 & 0.10 & \\
\hline Roller & 0.95 & 1 & 0.75 & 0.75 & 0.5 & 1 & 1 & 1 & 1 & 0.75 & 0.91 \\
\hline Coil Drive & 1 & 1 & 0.75 & 0.7 & 0.8 & 1 & 0.9 & 1 & 0.85 & 0.85 & 0.90 \\
\hline Dual Rollers & 0.85 & 1 & 0.65 & 0.7 & 0.5 & 1 & 1 & 1 & 1 & 0.85 & 0.89 \\
\hline Conveyor & 0.8 & 1 & 0.65 & 0.65 & 0.65 & 1 & 0.75 & 1 & 1 & 0.85 & 0.86 \\
\hline Dual Split Collet & 0.75 & 1 & 0.75 & 0.75 & 0.85 & 1 & 1 & 0.65 & 0.9 & 0.7 & 0.84 \\
\hline Wrap-around Roller & 0.95 & 0.8 & 0.75 & 0.75 & 0.6 & 0.25 & 1 & 1 & 0.15 & 0.85 & 0.70 \\
\hline Pencil Mechanism & 0.25 & 1 & 0.85 & 0.8 & 0.8 & 0.65 & 0.7 & 0.65 & 0.85 & 0.6 & 0.69 \\
\hline \begin{tabular}{|l|} 
Dual 4-Bar Linkage \\
\end{tabular} & 0.4 & 0.8 & 0.5 & 0.8 & 0.85 & 1 & 0.65 & 0.65 & 0.15 & 0.65 & 0.59 \\
\hline Collet and Brake & 0.25 & 0.8 & 0.4 & 0.75 & 0.85 & 1 & 1 & 0.65 & 0.15 & 0.65 & 0.59 \\
\hline \begin{tabular}{|l} 
Dual Collet \\
\end{tabular} & 0.25 & 0.8 & 0.4 & 0.75 & 0.85 & 1 & 1 & 0.65 & 0.15 & 0.65 & 0.59 \\
\hline
\end{tabular}

A design matrix (Table 2) was used to determine a composite score of each concept based on multiple, value-weighted criteria (cost, ease of use, etc). This allows for easy identification of the most viable design concept.

\subsubsection{Guidance System Concept}

Once the insertion mechanism concept was selected, an appropriate mechanism for guidance was required. Due to design constraint \#11, which states, "Only the lead is allowed to have direct contact with brain tissue", and since there is no guidance mechanism built into a current deep brain stimulation lead, the ability to deflect the distal section of the lead is confined to the central lumen of the lead. The implantation of 
transvenous leads requires guidance under similar constraints. Guiding the lead through the tortuous venous structure of the heart to its target implant site is accomplished by utilizing a system composed of a pre-curved stylet and a rigid straight sheath. The surgeon can advance or retract the rigid sheath thereby exposing the pre-curved section of the stylet. The stylet deflects the lead and effectively guides the lead through the venous structure. This effective and FDA-approved method of guiding a lead was used as the basis of the guidance system for the deep brain stimulation lead. In order to improve on this system and combine its utility with that of the insertion system, the manual manipulation of the stylet and the sheath was replaced with a stepper motor and a linear stepper motor respectively. The actuation and control of this subsystem are discussed in detail in section 3.2.12.

\subsubsection{Overview of Combined System Functionality}

Given the conceptual overview of the roller insertion system and the stylet/sheath guidance system, an overview of the combined functionality of the system is required.

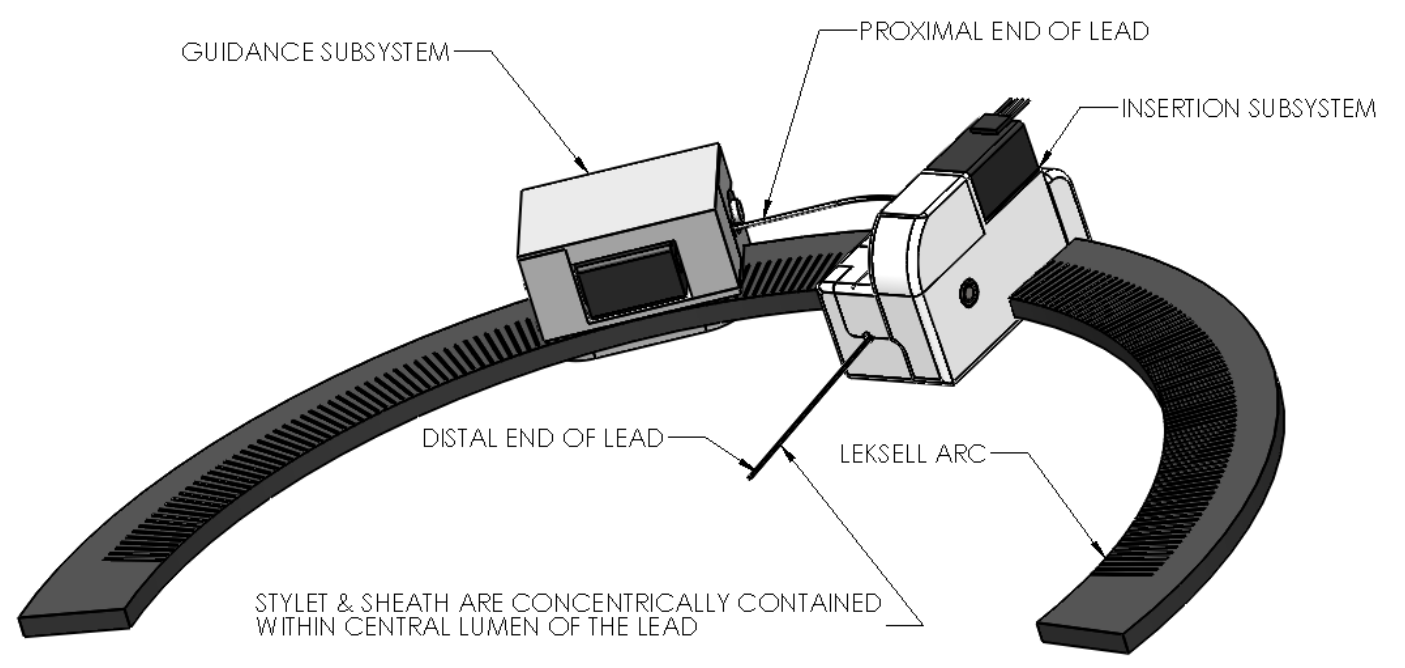

Figure 12 - Complete guidance/implant system mounted on Leksell Arc 
The insertion mechanism is composed of two subsystems mounted on the Leksell arc.

The arc is mounted onto the Leksell frame, shown previously in Figure 9 - Leksell

Frame. This frame allows the arc to be positioned in any desired plane. Once the plane is chosen, the Leksell frame and Leksell arc are locked together providing a rigid platform which is referenced to the patient's anatomy. The following table details the function of each of the subsystems.

Table 3 - Subsystem Function

\begin{tabular}{|l|l|l|}
\hline \multicolumn{2}{|c}{ Function } & \multicolumn{1}{c|}{$\begin{array}{c}\text { Responsible } \\
\text { Subsystem }\end{array}$} \\
\hline $\begin{array}{l}\text { Drives lead forward into the patient / } \\
\text { extracts lead out of patient }\end{array}$ & Insertion Subsystem & $\begin{array}{l}\text { stepper motor, worm and } \\
\text { worm gear, rollers and } \\
\text { associated axles }\end{array}$ \\
\hline $\begin{array}{l}\text { Holds the lead in place until } \\
\text { insertion/extraction is initiated by the } \\
\text { surgeon }\end{array}$ & Insertion Subsystem & worm and worm gear \\
\hline $\begin{array}{l}\text { Applies a radial compressive load to } \\
\text { the lead to generate friction to transfer } \\
\text { the motor torsion to the lead }\end{array}$ & Insertion Subsystem & rollers and axles \\
\hline $\begin{array}{l}\text { Creates a 1 micron/step resolution for } \\
\text { the insertion/extraction motion }\end{array}$ & Insertion Subsystem & $\begin{array}{l}\text { Stepper motor, worm and } \\
\text { worm gear, and rollers }\end{array}$ \\
\hline Deflects the tip of the lead & Guidance Subsystem & $\begin{array}{l}\text { sheath, stylet, and linear } \\
\text { stepper motor }\end{array}$ \\
\hline Rotates the plane of tip deflection & Guidance Subsystem & $\begin{array}{l}\text { stylet, stepper motor, spur } \\
\text { gear and sprocket }\end{array}$ \\
\hline Allows for activation of lead electrodes & Guidance Subsystem & circuitry \\
\hline
\end{tabular}

The proximal (referring to the end closest to the surgeon and farthest from the patient) end of the lead, sheath, and stylet are all fixated into the guidance subsystem. The distal (referring to the end closest to the patient and farthest from the surgeon) end of the lead with the sheath and stylet housed inside enters the insertion system from the back, exits through the front, and is driven forward and into the patient. This two part system greatly simplifies the mechanism required to handle leads that are different in overall length. It 
also allows for the lead to be easily removed from the subsystems at the conclusion of the implant procedure.

The functionality of the combined system is best described through the movement of the lead. The combined system will move the lead axially, deflect the distal end up to $15^{\circ}$, and rotate the tip deflection $360^{\circ}$. Mathematically, the lead can be considered to be along the r-axis of a system with spherical coordinates with the tip deflection occurring in the $\theta$ direction, and the rotation of the deflection in the $\varphi$ direction.

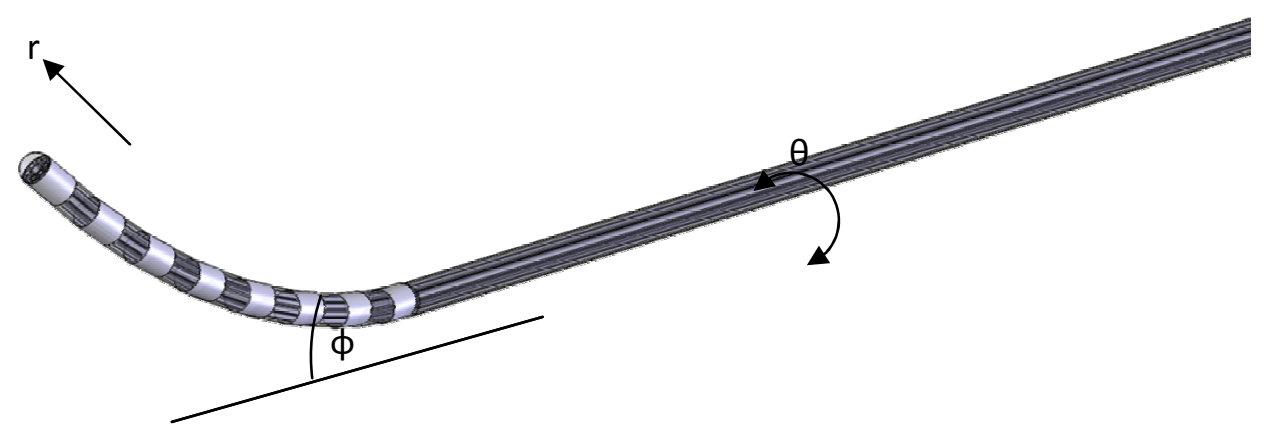

Figure 13 - Implant Coordinates

The three different stepper motors control the three different axes of the motion. The stepper motor driving the insertion subsystem controls the motion along the r-axis, the stepper motor in the guidance subsystem controls the $\varphi$-axis, and the linear stepper motor in the guidance subsystem controls the $\theta$-axis. Since each of the axes is controlled by a unique motor, motion can be constrained to any single axis or combined. This gives the surgeon complete control over the motion of the lead: insertion/retraction, tip deflection, and rotation. While active, stepper motors retain their position, preventing the lead from migrating during the implant procedure. The discrete motion of the stepper motors combined with appropriate gearing transforms the motion into accurate, repeatable, and reversible steps. Digital control of the system can be implemented simply as advancing, retracting, or rotating the desired number of steps. The accuracy and motion of the lead is relative to the location of the driving mechanism, but by 
attaching the mechanism to the Leksell frame, this location can be correlated directly to the patient's anatomy. This gives the surgeon the ability to know the precise location and orientation of the lead inside the brain.

\subsubsection{Insertion Drive Subsystem}

The insertion subsystem controls the advancement of the lead into the brain. This is accomplished by using two contoured rollers to apply pressure to the outer diameter of the stimulation lead and advance the lead at the tangential velocity of the rollers.

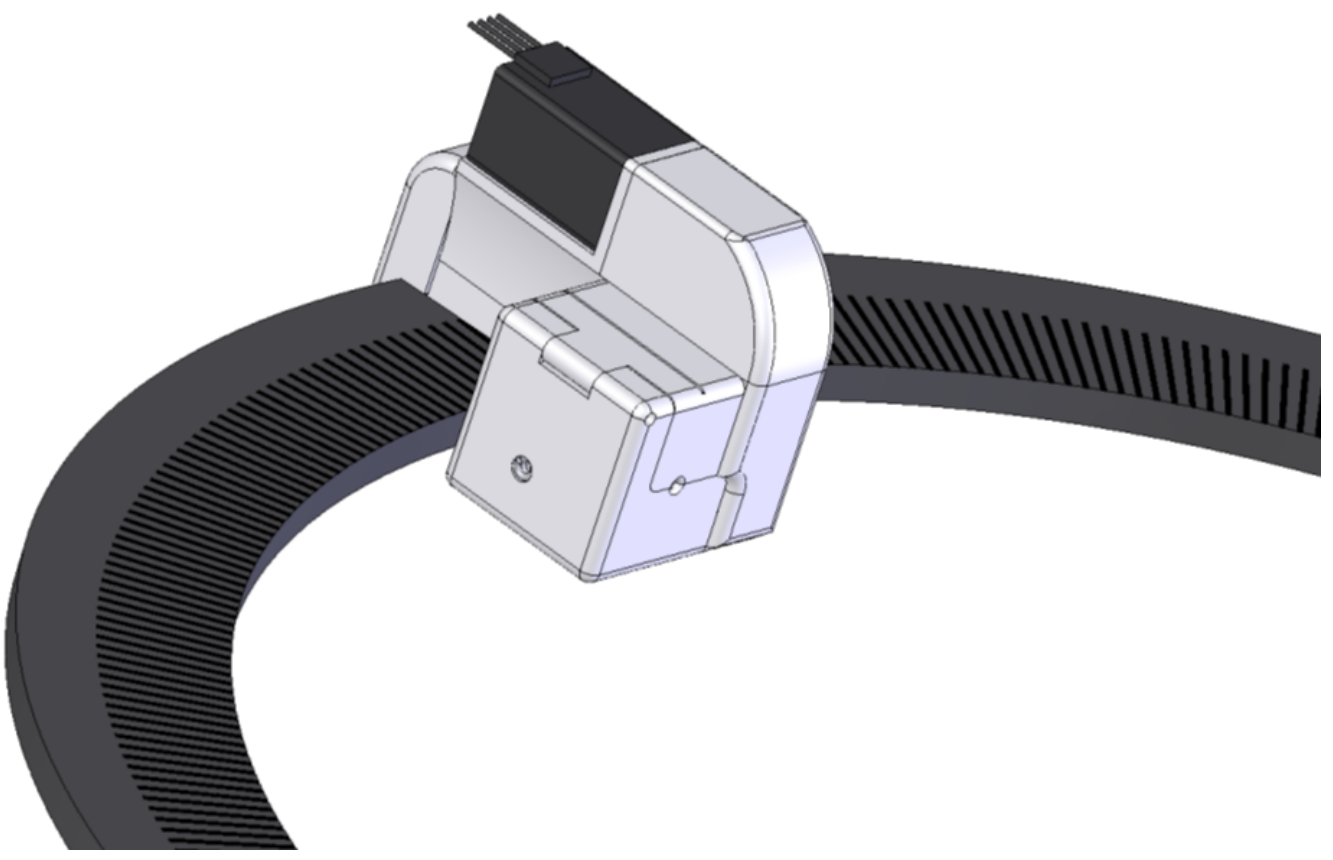

Figure 14 - Complete Insertion Subsystem Mounted on Leksell Arc 


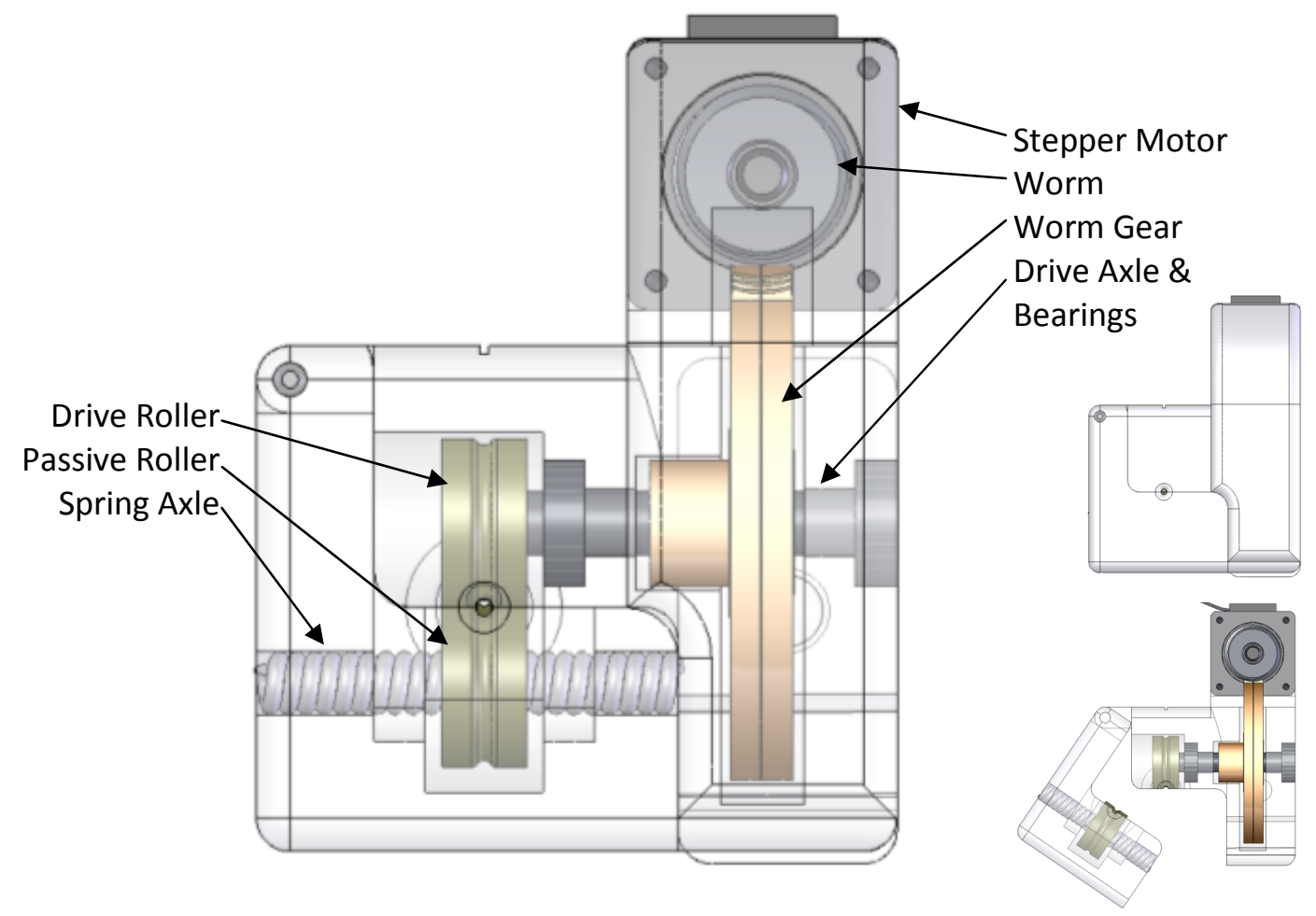

Figure 15 - Transparent View of Insertion Subsystem System

See Figure 15 - Transparent View of Insertion Subsystem System for an illustration of the associated drive components. A 200 step/rev stepper motor drives a worm and worm gear. The worm gear drives a shaft supported by two bearings which in turn drives the upper roller. The lead is inserted into the groove on the two rollers from the back and driven out the front. The lead is held against the upper roller by the lower roller's spring shaft. Once the lead has been driven to the correct location, the drive system is opened and the lead is removed. This hinged action ensures that the lead can easily be removed from the system without altering the implant location.

The high reduction ratio of the worm and worm gear (100:1) provides several features. The first is that this reduction increases the accuracy with which the lead can be placed. Secondly, the high reduction ratio inhibits the worm gear from driving the worm and hence the lead does not move unless driven by the stepper motor. Hence the worm and worm gear provide a lock-out capability if the stepper motor is not energized, to ensure 
the lead does not slip out of place. Finally, it also greatly increases the torque and hence linear driving force that can be applied to the lead because the worm gear drives the upper roller and provides the friction required to linear drive the lead to the desired implant location. This frictional drive system is discussed in further detail below.

The following section details the calculations made to ensure the system is accurate on a micron level and to ensure that enough torque can be applied to the rollers to generate the force necessary to advance the lead into the brain tissue.

\subsubsection{Advance \& Retract Lead Inputs}

The motor and gears were chosen to ensure that for every step of the motor, the lead would advance only 1 micron and to ensure that the pressure on the distal end of the lead is enough to pass through the brain tissue.

Table 4 - Motor Properties

\begin{tabular}{|l|r|r|}
\hline Degrees / Step & 1.8 & \\
\hline Max Torque (N-m) & 0.02 & $\mathrm{~T}_{\operatorname{MAX}}$ \\
\hline Max Speed (rpm) & 50 & $\omega_{\operatorname{MAX}}$ \\
\hline Controller Steps / Full Step & 2 & \\
\hline
\end{tabular}

National Electrical Manufacturers Association (NEMA) Size 8 stepper motor

Table 5 - Worm and Gear Properties

\begin{tabular}{|l|r|r|}
\hline Worm Ratio (teeth / rev) & $1 / 1$ & \\
\hline Gear Ratio (teeth / rev) & $100 / 1$ & \\
\hline Worm Pressure Angle & $14.5^{\circ}$ & $\alpha$ \\
\hline Worm Lead Angle & $1^{\circ} 47^{\prime}$ & $\mathrm{V}$ \\
\hline Worm Pitch Diameter (in) & 0.500 & $\mathrm{~d}_{\mathrm{w}}$ \\
\hline Gear Pitch Diameter (in) & 1.5625 & $\mathrm{~d}_{\mathrm{G}}$ \\
\hline Friction Coefficient & 0.044 & $\mu$ \\
\hline
\end{tabular}

Worm Gear: Stock Drive ProductSterling Instrument P/N: S1B84AC064B100S

Worm: Stock Drive Product-Sterling Instrument P/N: 64DP/1 Lead $/ 1.783^{\circ} \mathrm{RH} / .50 \mathrm{PD}$

Table 6 - Roller Properties

\begin{tabular}{|l|r|r|}
\hline Contact Diameter $(\mathrm{mm})$ & 13 & $\mathrm{~d}_{\mathrm{R}}$ \\
\hline Coefficient of Static Friction & $0.9-1.1$ & $\mu_{\mathrm{s}}$ \\
\hline
\end{tabular}




\subsubsection{Advance \& Retract Equations}

$$
\begin{gathered}
\text { Reduction Ratio }=\left(\frac{\text { output teeth } / \text { rev }}{\text { input teeth } / \text { rev }}\right)=\frac{\frac{100 \text { teeth }}{1 \text { rev }}}{\frac{1 \text { tooth }}{1 \text { rev }}}=100 \\
\text { Efficiency }=\eta=\frac{\cos (\alpha)-\mu * \tan (\gamma)}{\cos (\alpha)+\mu * \operatorname{cotan}(\gamma)}=\frac{\cos \left(14.5^{\circ}\right)-.044 * \tan \left(1^{\circ} 47\right)}{\cos \left(14.5^{\circ}\right)+.044 * \operatorname{cotan}\left(1^{\circ} 47\right)}=.41=41 \%
\end{gathered}
$$

Note: Due to the slow speed of the system, any losses associated with the ball bearings are considered negligible and were not included in the efficiency calculations. Ball bearings were chosen because they do not require lubricant and generate minimal dust. Also the stepper motor controller is capable of half-stepping, thereby doubling the resolution.

$$
\begin{gathered}
\frac{\text { Linear Motion }(m)}{\text { Step }}=\frac{\text { Degrees }}{\text { Step }} * \frac{1 \text { rev }}{360^{\circ}} * \frac{1}{\text { Reduction Ratio }} * \frac{\text { Full Step }}{\text { Controller Steps }} * d_{R} \pi * \frac{1 m}{1000 \mathrm{~mm}} \\
=\frac{1.8^{\circ}}{\text { step }} * \frac{1 \text { rev }}{360^{\circ}} * \frac{1}{100} * \frac{1}{2} * 13 m m * \pi * \frac{1 m}{1000 \mathrm{~mm}}=\frac{1.0 * 10^{-6} \mathrm{~m}}{\text { controller step }}=1.0 \frac{\text { micron }}{\text { controller step }} \\
\text { Max Linear Speed }\left(\frac{\mathrm{mm}}{\mathrm{s}}\right)=\omega_{\text {MAX }} * \frac{1}{\text { Reduction Ratio }} * d_{R} * \pi \\
=50 \mathrm{rpm} * \frac{1}{100} * 13 \mathrm{~mm} * \pi=20.42 \frac{\mathrm{mm}}{\mathrm{s}} \\
\text { Max Linear Force }(\mathrm{N})=T_{M A X} * \frac{d_{G}}{d_{W}} * \frac{\cos (\alpha)-\mu * \tan (\gamma)}{\cos (\alpha) * \tan (\gamma)+\mu} * \frac{1}{\frac{d_{R}}{2}} \\
=0.02 \mathrm{~N} \cdot \mathrm{m} * \frac{1.5625 \mathrm{in}}{0.500 \mathrm{in}} * 13.04 * \frac{1}{\frac{13 \mathrm{~mm}}{2}} * 1000 \frac{\mathrm{mm}}{1 \mathrm{~m}}=125.4 \mathrm{~N}
\end{gathered}
$$


Since the coefficient of friction between polyurethane and itself can vary between .9 and 1.2 , a value of 1 was chosen and the actual force transferred via friction from the rollers to the lead can be assumed to be close to this calculated value.

$$
\begin{gathered}
\text { Max Insertion Pressure }=\frac{\text { Max Linear Force }}{\text { Cross }- \text { sectional Area of Lead }}=\frac{125.4 \mathrm{~N}}{1.31 \mathrm{~mm}^{2}} \\
=95,725 \mathrm{kPa}(13.9 \mathrm{ksi})
\end{gathered}
$$

The pressure required to penetrate brain tissue $3.183^{\star} 10^{6} \mathrm{~Pa}$ (Henry, et al. 1998), and hence the system is capable of driving the lead into the brain. It is also important to note that the lead could be considered a thin column, however since only a short length of the lead is not housed within the insertion system or supported by brain tissue, buckling is not considered a major concern. Hence the limiting factor in the insertion system is the amount of normal force generated by the rollers. This is discussed and calculated below.

Concerning the transfer of torque from roller to the lead, the following has been incorporated into the design. The lower roller is passive and provides radial pressure on the lower half of the lead. A solid axis would either crush the lead if the diameter became too large or lose contact with the lead if the diameter became too small. In either case, the result would be a procedural failure. This design issue was overcome by using a spring axle to hold the lower roller in contact with the lead and upper roller as shown in Figure 15. A bearing separates the roller from the spring itself to reduce frictional loses. This spring axle is fixed such that it is always deflected in the middle and maintains a continuous normal force between the two rollers and hence generates the frictional force on the outer diameter of the lead required to generate the static frictional force used to propel the lead forward during insertion. This spring axle provides a stable and continuous frictional force despite variations in the outer diameter of the lead. The following calculations derive the force applied to the lead by the rollers in both the 
nominal and max conditions. When the rollers are in contact, the tensile spring axle has to deflect.

Spring Length $=\mathrm{L}$

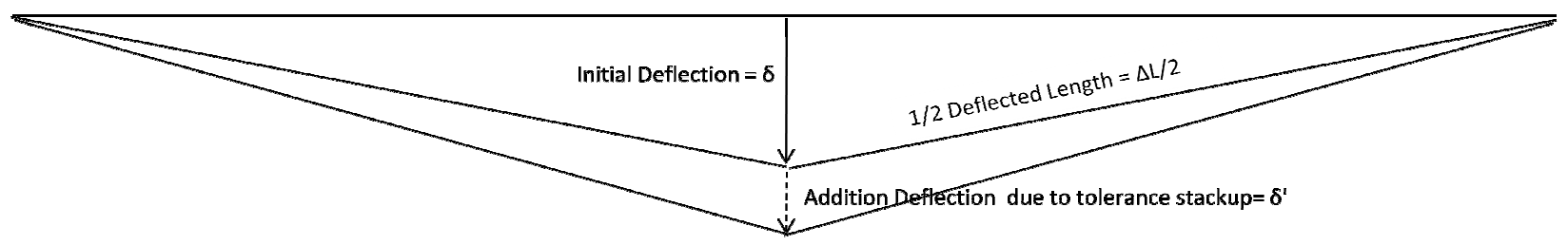

Figure 16 - Spring Axle Deflection Schematic

The following system parameters are known:

Spring Length = .375", Spring Rate $=2.5 \mathrm{lbs} / \mathrm{in}$, nominal deflection is $0.1 "$,

Half of the total deflected length of the spring is: $\Delta L / 2=\sqrt{\left(\frac{L}{2}\right)^{2}+(\delta)^{2}}$

This deflection generates an axial force in the spring based on the spring rate of the spring. The rollers are only subjected to the component of axial force normal to the rollers axis.

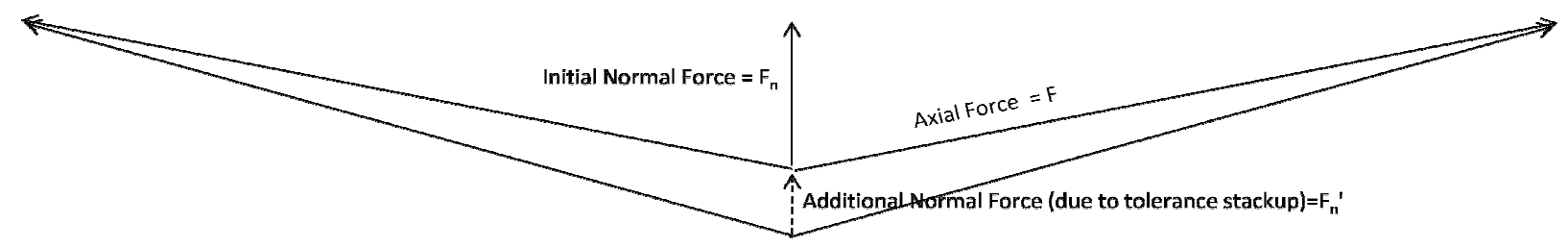

Figure 17 - Spring Axle Free Body Diagram

The axial force $(F)$ is simply the change in length $(\Delta L-L)$ times the spring rate. The normal component of the force acting upon the roller is:

Given that the tolerance of the lead diameter and the roller diameter is $\pm .003 "$, the nominal/maximum load on the rollers is $1.00 \mathrm{lbs}_{f} / 1.06 \mathrm{lbs}_{f}$. Hence the maximum amount of variation results in only a $6 \%$ change in the amount of normal load applied to the lead. Given that the coefficient for polyurethane on polyurethane is generally above 1.0 , the 
entire normal load is translated into driving force. It should be noted that the rollers are contoured to apply the force evenly to the circumference of the lead with minimal deformation of the lead, ensuring that the guidance system is not crushed. Hence the maximum insertion pressure when recalculated using the $1 \mathrm{lb}_{\mathrm{f}}$ load is 500 psi. The theoretical pressure to penetrate human tissue is $3.183^{*} 10^{6} \mathrm{~Pa}$ (Henry, et al. 1998) or 461 psi. Hence, the system exerts enough pressure to insert the system into brain tissue. In the event that a greater force is required, the spring constant for the axle can be increased, which in turn would increase the normal force and the driving force.

\subsubsection{Guidance Subsystem}

The guidance subsystem controls the angle and orientation of deflection of the distal tip of the lead. Figure 18 shows the overall composition of the guidance subsystem, the components are described in detail in Figure 21 and Figure 22.

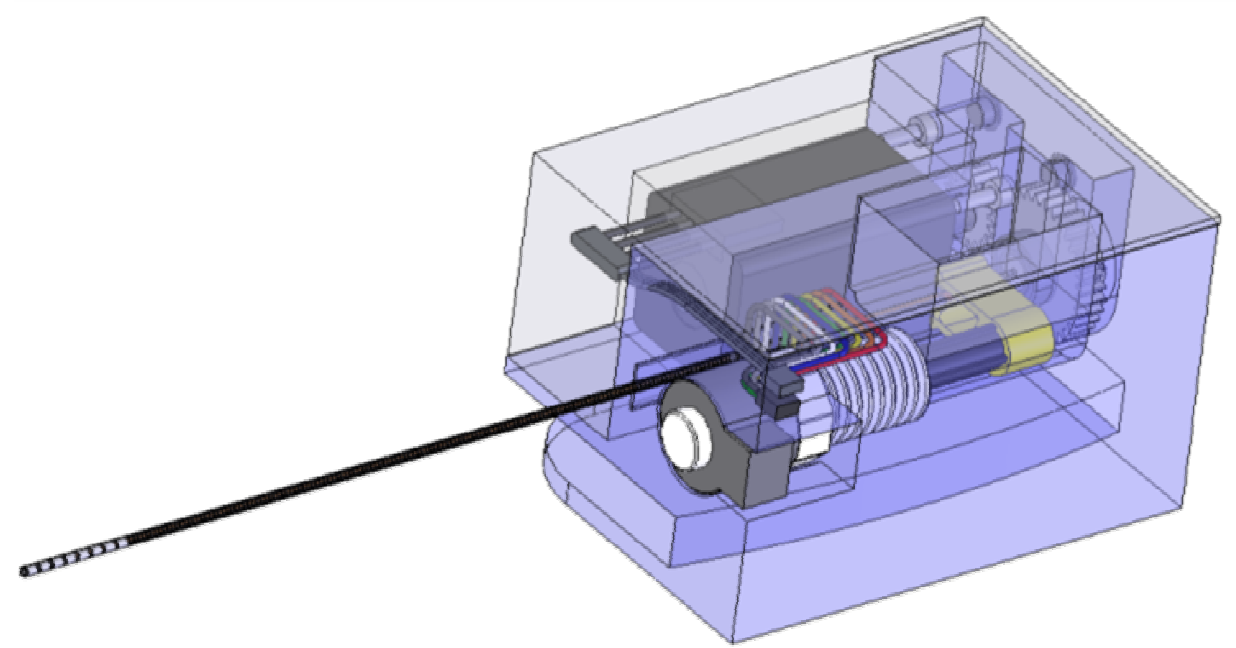

Figure 18 - Transparent View of Complete Guidance Mechanism

The center lumen of the deep brain stimulation lead is open on the proximal end to allow for guide wire or stylet access. This lumen allows for a simple two-component mechanism to control the deflection. A stylet which has been formed to a desired curved orientation is housed inside a stiff outer sheath. The sheath is inserted into the center 
lumen of the lead down to the distal end. The pre-curved stylet is then fully inserted into the sheath (see Figure 21 - Sheath Drive and Electrode Wiring Illustration). The distal end of the lead is straight when the sheath completely covers the stylet. As the outer sheath is retracted, the lead is exposed to the pre-curved stylet which starts to deflect the tip of the lead. See Figure 19 - Formed Stylet and Rigid Sheath. The angle of deflection increases as more of the pre-curved stylet is exposed. This combination of curved stylet and sheath has been shown to be a very effective tool for navigating through the complex curvature of the veins and arteries during pacemaker lead implants (St Jude Medical CRMD 2010). Hence this mechanism is already utilized and trusted by the surgeons and the adaptation of this technology for deep brain stimulation leads implants should be well received.
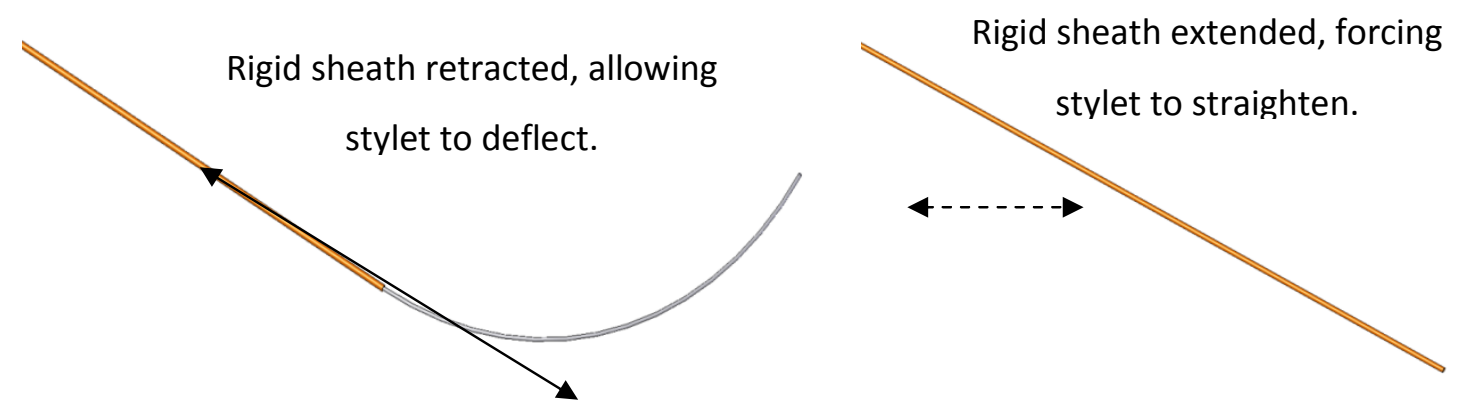

Figure 19 - Formed Stylet and Rigid Sheath

This simple two-component system translates linear motion of the outer sheath into angular deflection. By placing this deflection system inside of the center lumen of the lead, the polyurethane lead can be deflected. The amount of deflection of the lead is based on the geometry and material properties of the lead and the formed stylet and sheath.

The linear stepper motor advances its shaft with each step rather than rotating it. The number of steps the linear motor takes determines the length of the curved stylet that is allowed to deflect the lead. At full extension, the stepper motor retracts $13.87 \mathrm{~mm}$ of the 
sheath exposing the equivalent length of the curved stylet. The radius of curvature which produces a $15^{\circ}$ deflection with a $13.87 \mathrm{~mm}$ cord was determined using Solidworks to be $53 \mathrm{~mm}$. See figure below.

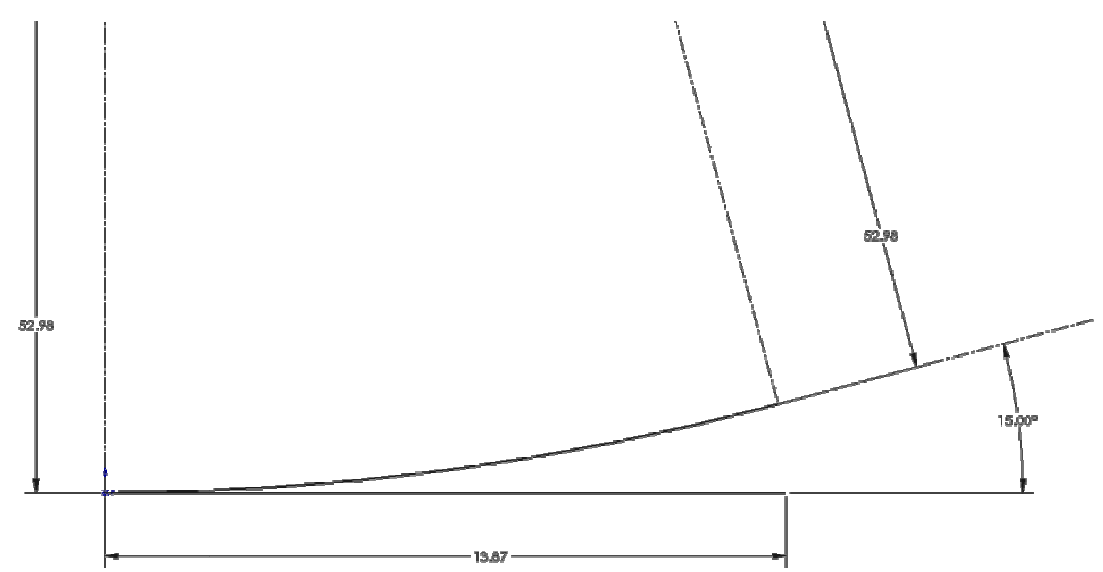

Figure 20 - 15 Degree Tip Deflection

A tighter radius of curvature must be used to form the stylet so that the stylet can deflect the lead to this desired radius. The distal end of the lead is composed of a complex multi-lumen polymer extrusion with eight of the nine lumens housing stainless steel cables. See Figure 8 - Cross-sectional view of lead extrusion for a scaled image of the extrusion profile. This profile is then clad with eight evenly spaced cylindrical platinum iridium contacts which provide the contact area for the electrical stimulation. This results in a discontinuous deflection pattern due to abrupt changes in cross-section profile. The ability to determine the exact deflection profile of the lead with the inserted stylet is not feasible without either an advanced FEA software analysis tool or empirical data. The following calculations are provided as an estimate for the requirements of the formed stylet.

Assuming that the stylet acts as a constant force spring, the lead will follow a constant radius of curvature independent of the exposed length of stylet. This assumption is valid 
because the stylet is formed with a constant radius of curvature, the ratio between its diameter and radius of curvature is of similar magnitude to commercial constant force springs (roll springs, e.g. tape measure), and it undergoes the same type of deformation. Each infinitesimal length of the stylet applies the same force to the corresponding length of the lead. Hence, the stylet assembly can be assessed as a simple cantilever beam with a distributed load.

Since the combined deflection of the lead and the stylet and the initial orientation of the lead are straight, this provides enough information to determine the required form radius of the stylet. The system can be considered as two fixed cantilevered beams. The lead can be modeled as a fixed cantilevered beam with a distributed load (generated by stylet). Since the desired slope is known, the following equation for beam deflection can be used to determine the required deflection load. The angle at the tip of the lead is desired to be 15 degrees, or a slope of $-\tan \left(15^{\circ}\right)$.

The equation for the slope at the end of a fixed beam with a distributed load is: slope = $-\frac{w L^{3}}{6 E I}$

Rearranging to solve for the distributed load: $w=-\frac{6 \tan \left(15^{\circ}\right) E I}{L^{3}}$

Once the required distributed load is determined, the stylet can then be similarly modeled as a beam with the above load applied. The resulting deflection of the stylet will be the required form the stylet must be set to in order to generate the necessary load to deflect the lead.

The calculations associated with this deflection are in Appendix A1, provide for a deflection of $15^{\circ}$ in any direction. Figure 21 shows the mechanism which actuates the tip deflection. 


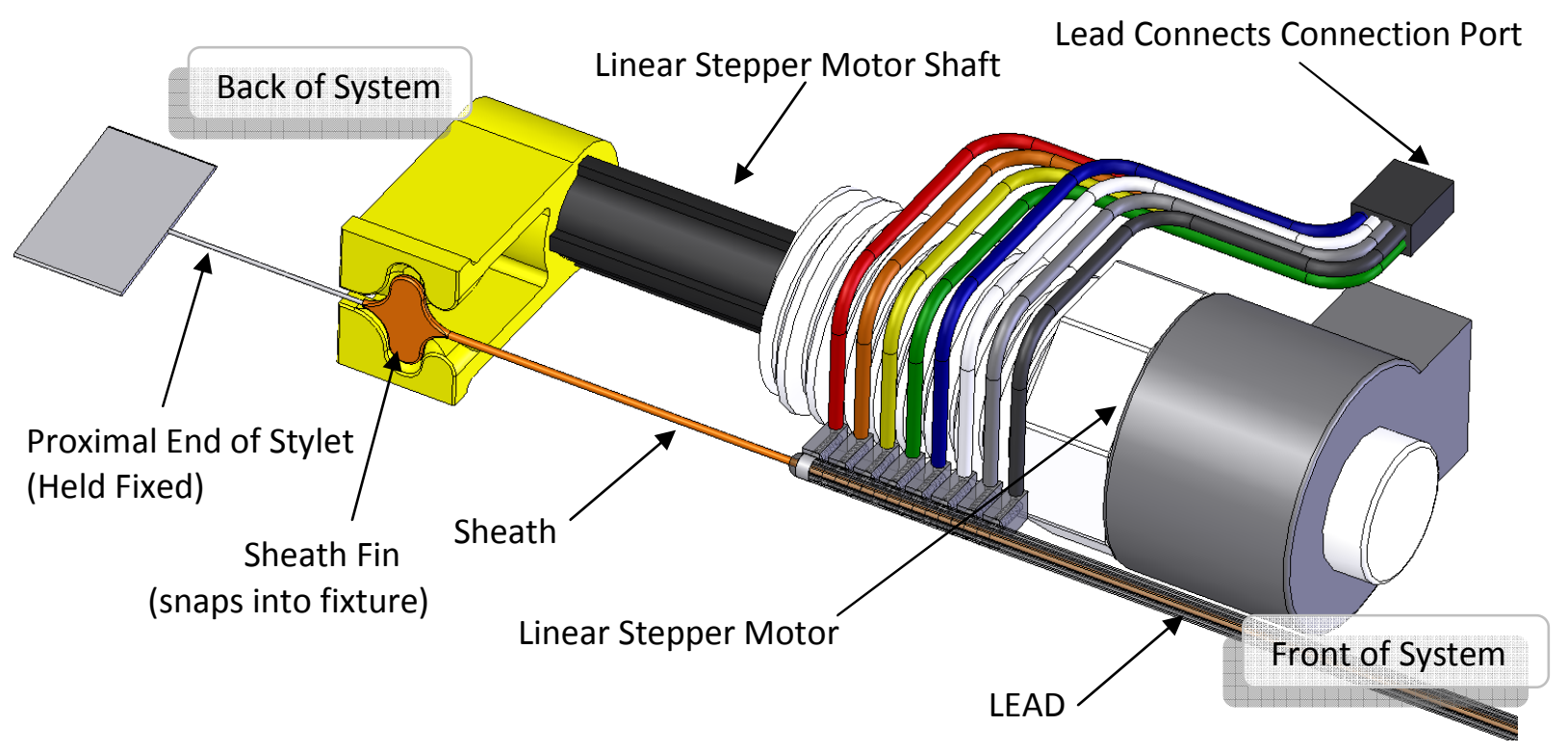

Figure 21 - Sheath Drive and Electrode Wiring Illustration

The faring has been removed in Figure 21 to show the details of sheath drive system.

The sheath (orange component) snaps into the yellow guide and is driven in and out of the lead by the linear stepper motor. Since the stylet and sheath may come into blood contact during use, they must be designed as single-use only. Hence the driving mechanism must be able to be refitted with a new stylet and sheath for each procedure. First the sheath is inserted from the front of the system, and snapped into place. Next, the lead is slid onto the sheath, and inserted into the system. Finally, the stylet is inserted from the back of the system into the sheath. Thus the ability of the components to snap into place provides a positive lock as well as a convenient way of insertion and removal.

Since the stylet is only curved in a single direction, the stylet and sheath assembly provides angular deflection in only a single plane. In order for this deflection to be useful the plane and direction of deflection must be user controlled rather than fixed. This is accomplished by attaching a fin to the proximal end of the formed stylet. This fin fits into a slot in a gear connected to a stepper motor. This allows the stepper motor inside the 
guidance subsystem to rotate the plane of curvature of the stylet to any desired orientation (phi coordinate). See Figure 22 - Stylet Fin and Gear Drive.

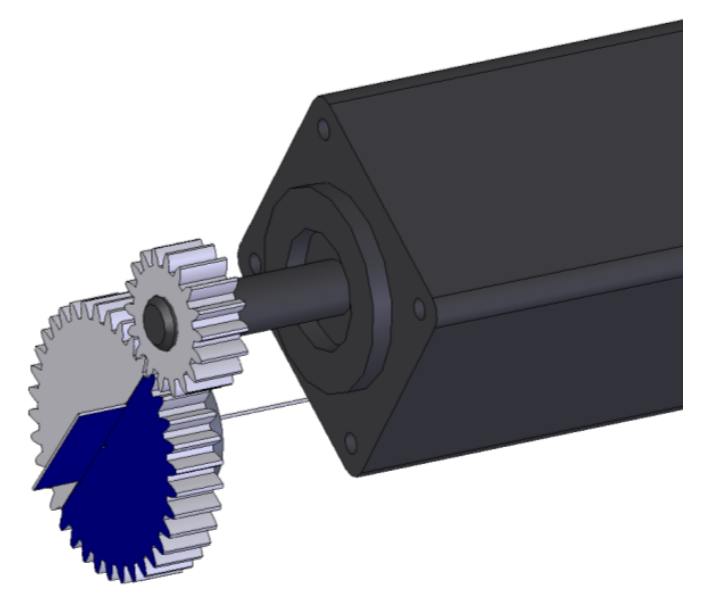

Figure 22 - Stylet Fin and Gear Drive

In order to ensure that the fin is inserted into the gear slot correctly, the gear and fin are color coded. The $200 \mathrm{step} /$ revolution stepper motor is reduced by a ratio of $2: 1$ and hence the resolution of orienting the deflection plane is 400 step/revolution or 0.9 degrees per step.

Combining the tip deflection and the rotation of the plane of deflection gives a conical volume through which the system is able to navigate. See Figure 23 - Volume of Potential Implant Locations. This conical volume was derived by the maximum angle of deflection and 360 degree rotation of that vector and provides a graphical representation of all of the possible target implant locations. Compared with the single vector provided by the currently available systems, this design provides significant versatility. 


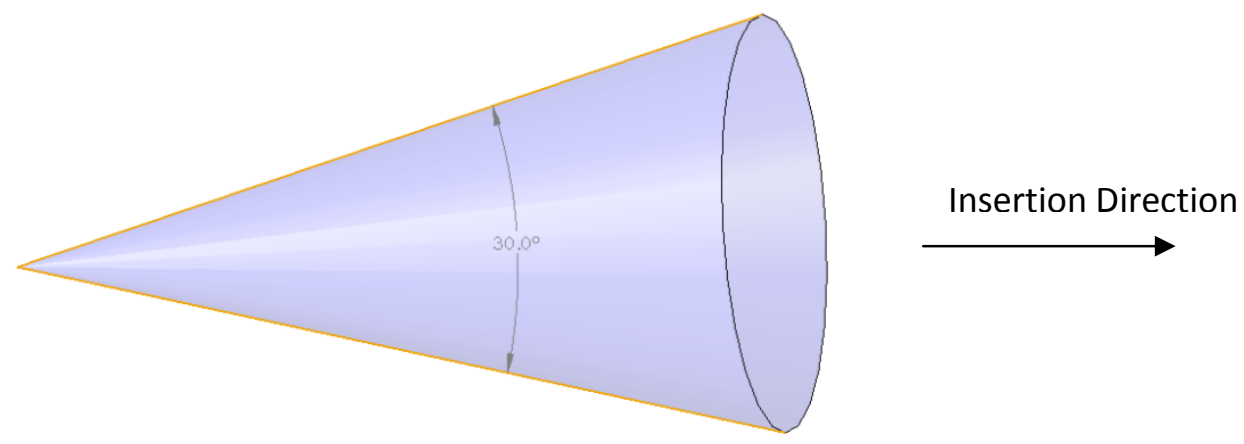

Figure 23 - Volume of Potential Implant Locations

This cone is centered on the axis of the insertion mechanism. The deeper the implant target site, the larger the cross-section of potential implant sites. Due to the anatomical structure of human head, the most desirable access locations are on the back of the skull. This is due to both ease of access to the majority of desired targets and also the ability to hide scars. The off-axis navigational ability of this system allows the surgeon to reach areas deep inside of the brain and implement contoured implant positions.

Since only the center lumen is being implemented for the guidance system, the external contacts can still be employed during the procedure. In Figure 24 - Close-up of Electrical Connections, the mechanism used to ensure electrical contact with the lead is shown.

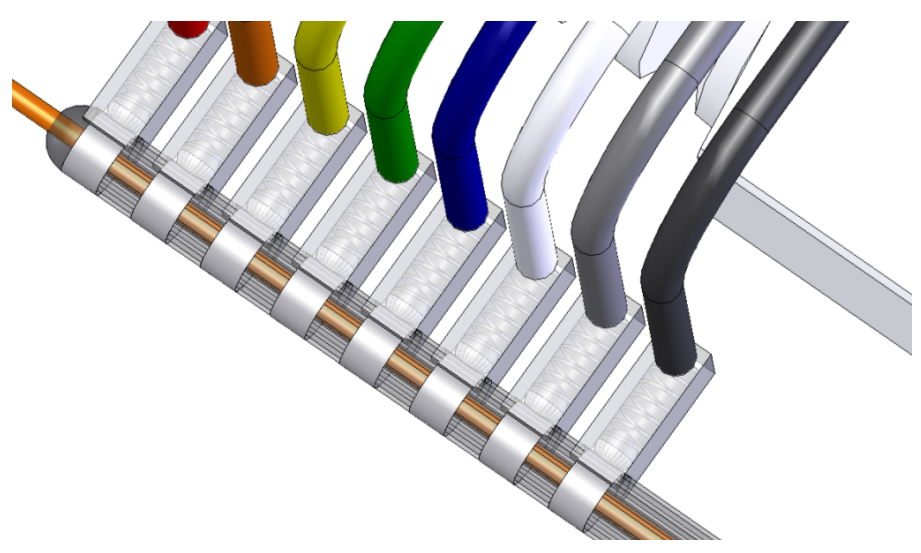

Figure 24 - Close-up of Electrical Connections 
A small spring is spot welded on one end creating a ball. The other end of the spring is soldered to wires that are tethered to a connector on the outside of the mechanism. The ball-spring is housed inside a small insulator to ensure that shorting between contacts does not occur. The spring ensures that slight variations in the diameter of the lead contacts do not result in the loss of electrical conduction. This design mechanism is identical to the header on the implantable pulse generator in which this proximal end of the lead will be housed after the completion of the implant procedure. This ability allows the surgeon to energize the device during the procedure to test an implant location and contour. Immediate feedback from the patient can help the surgeon determine if the current implant location is optimal or if relocation is required. 


\section{Software}

The software can be broken down into two main divisions: user interface design and functional programming. The user interface was designed to provide the surgeon with all necessary information in a clean organized manner, and the programming was designed to ensure full functionality. All code was written in LabView 8.2® (National Instruments 2010). The LabView design environment provides a continuously compiling platform with modules of prewritten/tested code as well as the ability to integrate custom software. The ease with which motion control, graphical interfacing, timing, and feedback can all be generated and tested simultaneously made LabView an ideal choice for this application. It also allows for step by step simulation and testing to ensure software performance and stability. The following block diagram details the software's layout. Each of the sections of code is discussed below.

Initialize: Inputs, User

Interface, Stepper Motor

Parameters, Databases

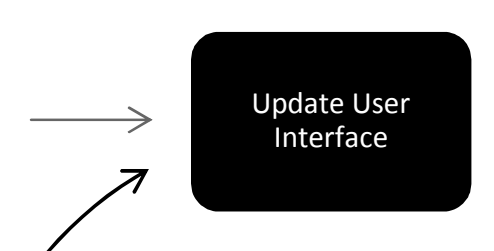

Update Lead

Current Location

and Orrientation

Variables
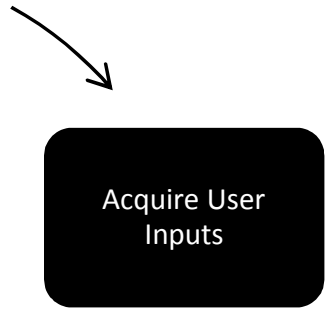

2

Send Motor

Commands to

Drivers

Figure 25 - Software Block Diagram

It should be noted that the current beta version software MUST NOT BE USED for any procedure involving live subjects. Its intended use is to prove feasibility of digital control 
of the mechanical system prototype. All software utilized as part of a surgical procedure must meet all FDA standards and receive approval before utilization.

\subsection{Software Inputs and Controls}

The user interface is an interactive front panel displayed on the computer monitor controlled simultaneously by mouse, keyboard, or joystick. The interactive front panel is shown in Figure 26 - Quadrants of User Interface Front.

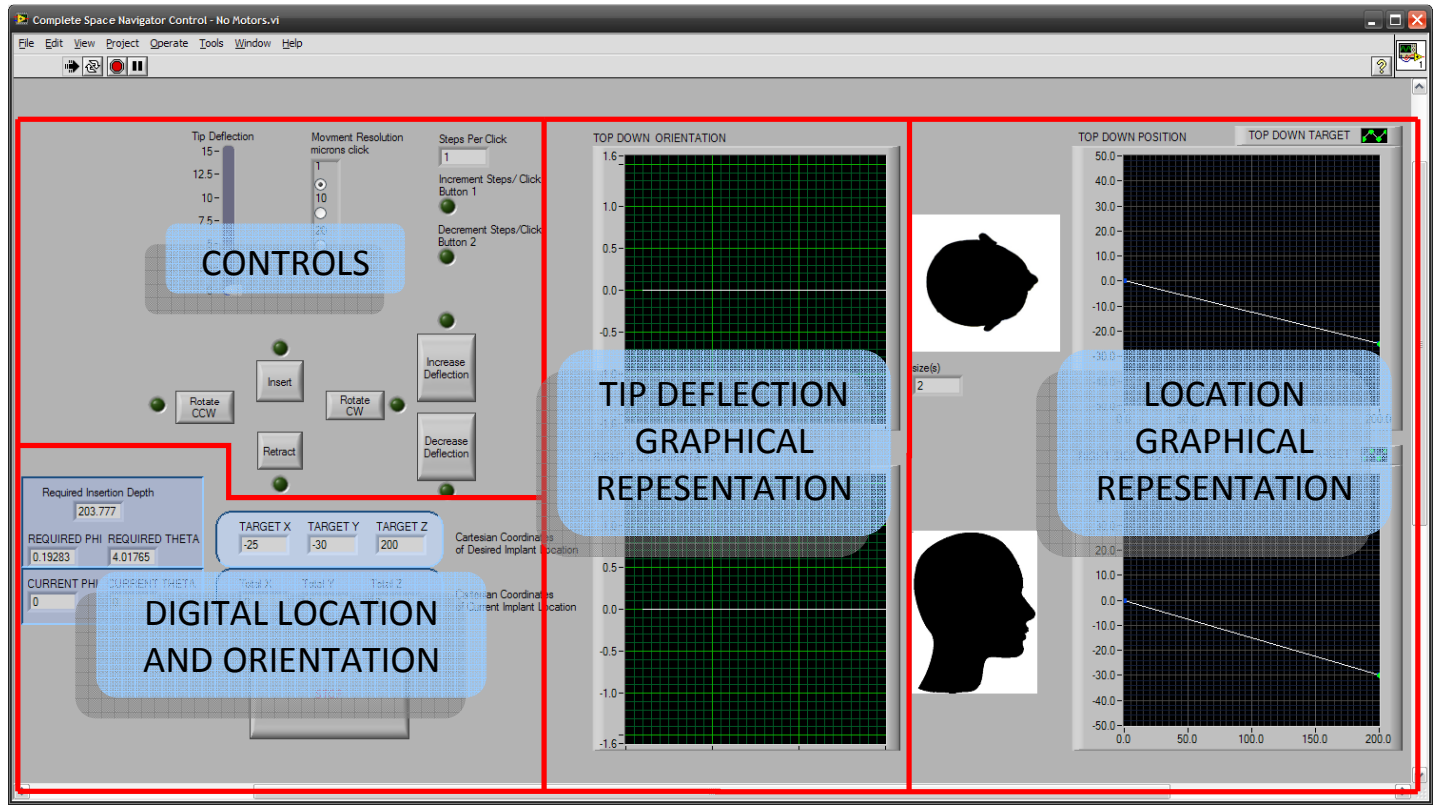

Figure 26 - Quadrants of User Interface Front Panel

This interactive front panel provides feedback concerning placement, orientation, and speed. This solely tracks intent, and should be verified via x-ray or other imaging techniques. The screen provides buttons to allow for "mouse" control of the device simply by clicking on the desired action. Each of these on-screen buttons is also programmed to respond to keyboard inputs. The third component of the user interface is the use of a "joystick". The SpaceNavigator ${ }^{\mathrm{TM}}$ was chosen for this system due to its small size, portability, and the ability to maintain sterility without inhibiting use. A disposable sterile sleeve can be slid over the controller and tied to the wire to ensure that 
SpaceNavigator ${ }^{\mathrm{TM}}$ can be used repeatedly without autoclaving or other techniques which will damage the electronics.
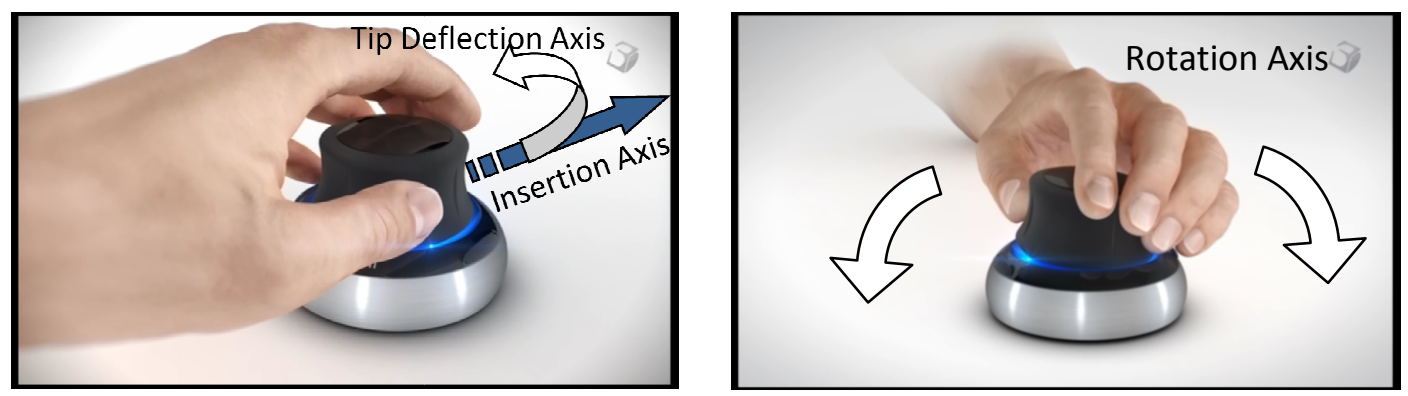

Figure 27 - SpaceNavigator ${ }^{\mathrm{TM}}$ (3D Connexion (A Logitech Company) 2008)

However, the software has been developed in such a way as to allow for the use of any joystick or directional control device. The SpaceNavigator ${ }^{\mathrm{TM}}$ is a contoured grip which can be pushed or rotated about all three Cartesian axes. This allows for three dimensional manipulation with a single hand. This device allows for intuitive controls during implant: push forward / pull back on the grip to advance or retract the lead, rock back / rock forward to deflect or straighten the distal tip of the lead, and rock left / right to rotate the tip deflection direction. This provides the surgeon with the ability to use a single hand to control the implantation process. The SpaceNavigator ${ }^{\mathrm{TM}}$ is controlled simply by pushing, pulling, or rotating in any direction. The navigator driver outputs the current position of the SpaceNavigator ${ }^{\mathrm{TM}}$ as absolute values along the three Cartesian axes and the associated three rotations about those axes. The software scales the speed of the raw output of the SpaceNavigator ${ }^{\mathrm{TM}}$ to speeds appropriate for insertion. This scaling also provides additional resolution to the system. The six Cartesian inputs are translated in the software into cylindrical coordinates. The stepper motors drive the system axially and by providing a deflection and rotation and hence cylindrical coordinates allow for simpler algorithms to determine motor steps to obtain the desired location. The software outputs both Cartesian and cylindrical coordinates to the user to assist with the implant. 


\subsection{User Interface Layout}

The user interface was developed to provide a simple, easy to use interface that displays all of the required feedback in an organized manner. It is divided into four quadrants: controls, digital location and orientation, tip deflection graphical representation, and location graphical representation. See Figure 26 - Quadrants of User Interface Front. Each quadrant is discussed in detail below.

The "Controls" quadrant contains all of the user controls. These controls determine the speed, orientation, and resolution with which the system will perform the DBS lead insertion. The following figure and table details the function of each of these controls.

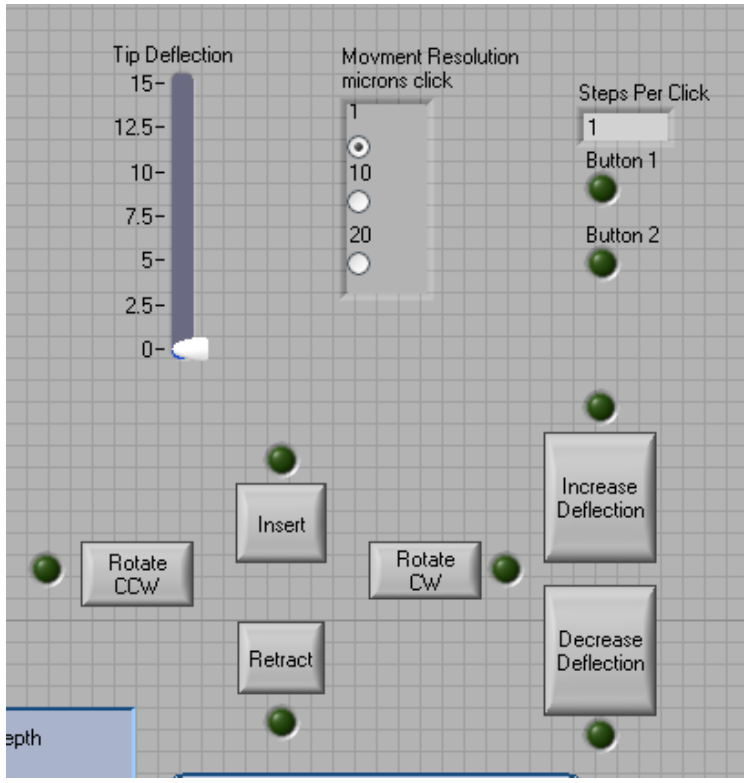

Figure 28 - Controls Quadrant of User Interface 


\begin{tabular}{|c|c|}
\hline CONTROL NAME & DESCRIPTION \\
\hline Tip Deflection & $\begin{array}{l}\text { This control determines the amount of deflection of the tip of } \\
\text { the lead. An algorithm in the software translates the } \\
\text { displayed values (in degrees) into steps to be delivered to the } \\
\text { motor controlling this motion. It is set by clicking and dragging } \\
\text { the mouse, or by rotating the joystick about the Y-axis. }\end{array}$ \\
\hline $\begin{array}{l}\text { Movement } \\
\text { Resolution }\end{array}$ & $\begin{array}{l}\text { If the mouse or keyboard is used for insertion, a single } \\
\text { mouse click or keyboard press must be linked to a definite } \\
\text { amount of motion. Radio buttons are used to ensure that a } \\
\text { controllable speed of implant is maintained during the } \\
\text { procedure. These radio buttons are controlled by mouse } \\
\text { selection. Movement Resolution can also be controlled by the } \\
\text { joystick buttons (see below). }\end{array}$ \\
\hline Steps Per Click & $\begin{array}{l}\text { Use of a joystick allows for more refined control of Movement } \\
\text { Resolution and this indicator shows the current value. Each } \\
\text { step is equivalent to } 1 \text { micron. }\end{array}$ \\
\hline Button 1 & $\begin{array}{l}\text { Indicator showing that button } 1 \text { on the joystick was pressed. } \\
\text { This button can be linked to any desired function. Default } \\
\text { function is to increase the microns per click by } 1 \text {. LED } \\
\text { illuminates if the button is pressed. }\end{array}$ \\
\hline Button 2 & $\begin{array}{l}\text { Indicator showing that button } 2 \text { on the joystick was pressed. } \\
\text { This button can be linked to any desired function. Default } \\
\text { function is to decrease the microns per click by } 1 . \text { LED } \\
\text { illuminates if the button is pressed. }\end{array}$ \\
\hline Insert & $\begin{array}{l}\text { This button drives the lead forward the amount stated in } \\
\text { "Steps Per Click". LED illuminates if the button is pressed. }\end{array}$ \\
\hline Retract & $\begin{array}{l}\text { This button draws back the lead the amount stated in "Steps } \\
\text { Per Click". LED illuminates if the button is pressed. }\end{array}$ \\
\hline $\begin{array}{l}\text { Rotate CW } \\
\text { (Increase Phi) }\end{array}$ & $\begin{array}{l}\text { This button rotates the orientation of the tip deflection } 1 \\
\text { degree clockwise as viewed along the axis of insertion. LED } \\
\text { illuminates if the button is pressed. }\end{array}$ \\
\hline $\begin{array}{l}\text { Rotate CCW } \\
\text { (Decrease Phi) }\end{array}$ & $\begin{array}{l}\text { This button rotates the orientation of the tip deflection } 1 \\
\text { degree counterclockwise as viewed along the axis of } \\
\text { insertion. LED illuminates if the button is pressed. }\end{array}$ \\
\hline $\begin{array}{l}\text { Increase Deflection } \\
\text { (Increase Theta) }\end{array}$ & $\begin{array}{l}\text { This button increases the angle of deflection by } 1 \text { degree. } \\
\text { LED illuminates if the button is pressed. (Deflection is defined } \\
\text { as the angular deviation away from the initial axis of } \\
\text { insertion.) }\end{array}$ \\
\hline $\begin{array}{l}\text { Decrease Deflection } \\
\text { (Decrease Theta) }\end{array}$ & $\begin{array}{l}\text { This button decreases the angle of deflection by } 1 \text { degree. } \\
\text { LED illuminates if the button is pressed. }\end{array}$ \\
\hline
\end{tabular}




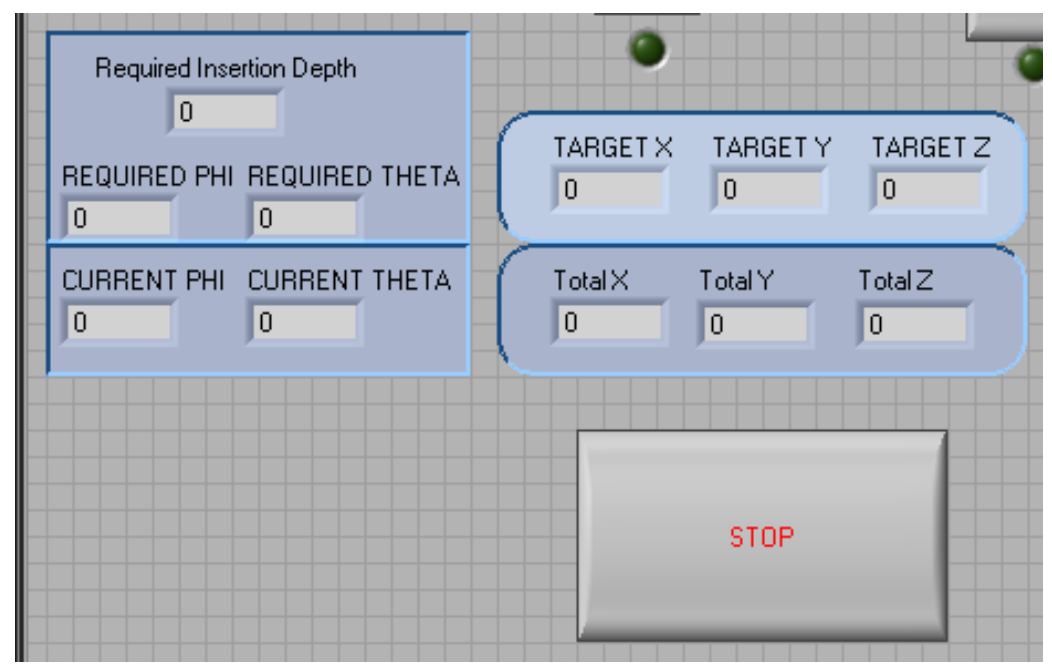

Figure 29 - Digital Display and Calculated Vectors

The Digital Location and Orientation quadrant of the code is used to provide the surgeon with accurate and current information throughout the operation, while also providing an aid in gauging distance to the desired target site. Based on the Cartesian coordinates of the desired implant site and the current location of the distal end of the lead, referenced to the insertion mechanism, the software automatically calculates the direct linear path required for a line-of-site implant. This vector, defining this linear path from the distal tip of the lead to the desired implant site, is displayed in spherical and Cartesian coordinates as (Required Insertion Depth, Required Phi, and Required Theta) and as (Target $\mathrm{X}$, Target $\mathrm{Y}$, Target $\mathrm{Z}$ ). Alongside these parameters, the system also shows the current orientation of the distal end of the lead (Current Phi, Current Theta) and (Total X, Total Y, Total Z). Since the insertion mechanism drives the lead along its current arc determined by the amount of tip deflection, the variance between the desired target and the current orientation is crucial to ensuring that the surgeon is able to guide the lead to the desired location. In the case of an emergency there is also a stop button which can be selected to lock all motors in their current orientation. This ensures no further motion if the operation must be aborted, and then the lead may then be manually extracted. 
Blue Square Icon represents current

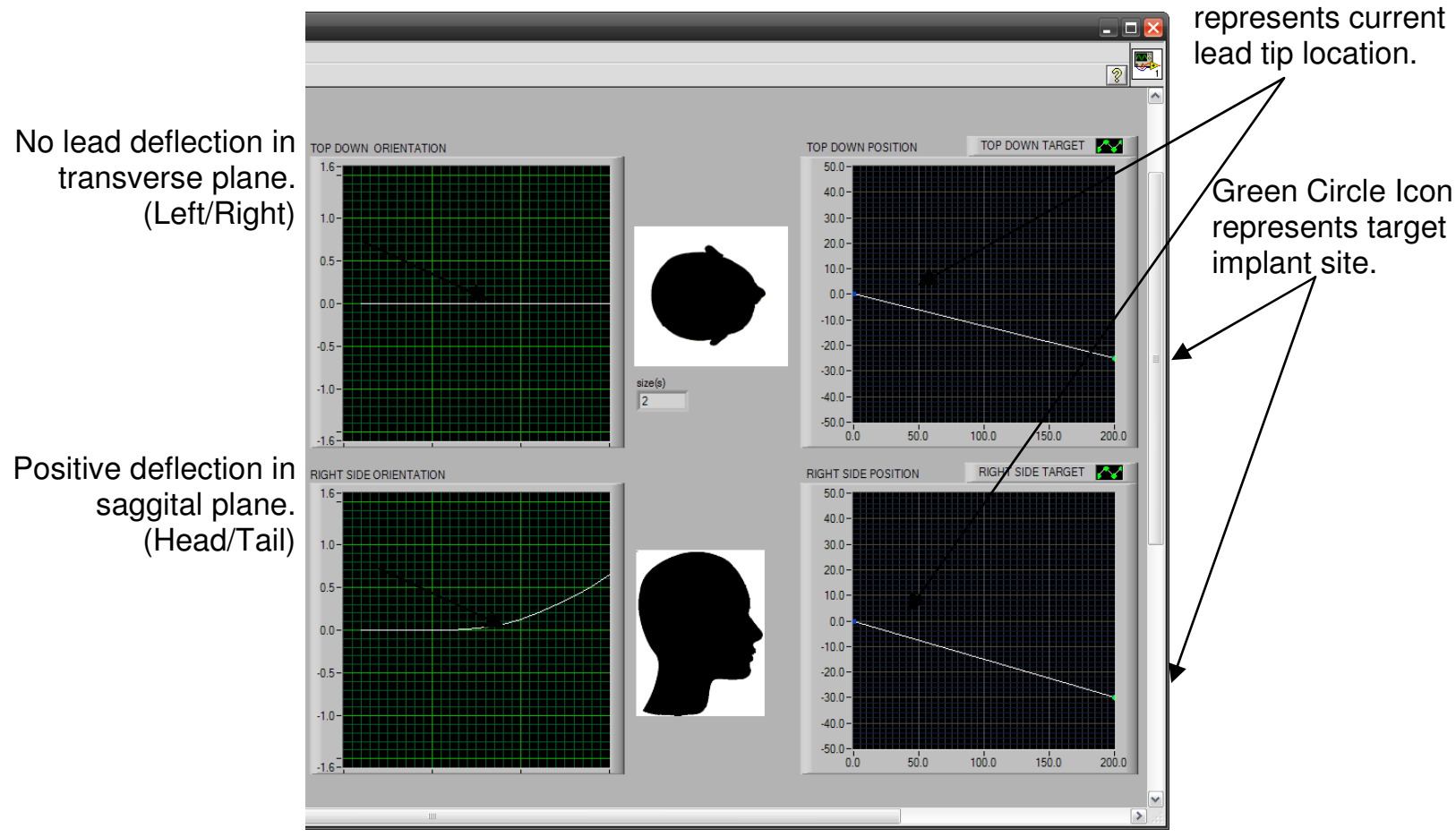

Figure 30 - Graphical Display of Lead Orientation and Proximity to Target Site

The Tip Deflection Graphical Representation quadrant and the Location Graphical

Representation quadrant are visualization tools to assist the surgeon with understanding lead location and orientation. Since the system can be rotated 360 degrees and deflected up to 15 degrees at any given rotation, either a 3D graph or orthogonal views are required. Orthogonal views were used due to their simplicity. A top down view and a right side view are provided for both the orientation and position graphs. Simple bitmaps were also included to remind the surgeon which graph corresponds to which 2D plane. This simple display is similar to orthogonal engineering drawings as it provides three dimensional information to the surgeon using only two dimensional displays. In the above graphic, the lead is deflecting straight up towards the top of the patient's head, whereas the target implant is located in the lower right side of the patient's brain. The following image show the lead in the correct orientation to approach the target site. This is also confirmed by the digital panel output. 


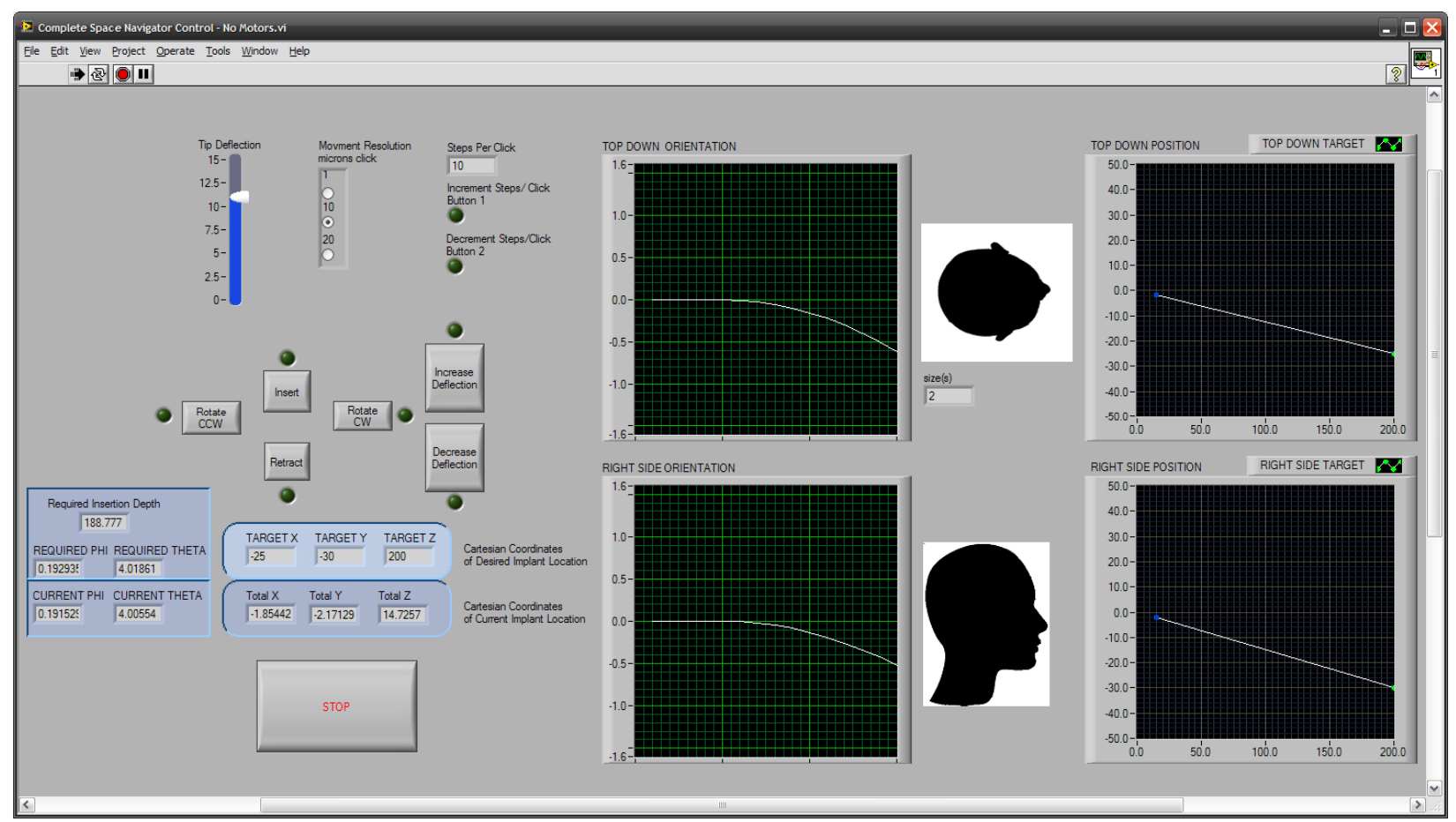

Figure 31 - Graphical User Interface Displaying Correct Target Approach

It is important to note that these displays are only dependent on the driving outputs of the system. There is no positional feedback from the lead to determine actual orientation and position. This must be confirmed by fluoroscopy or other imaging techniques. The user interface could be dramatically improved by developing software which can transform fluoroscopy into a three dimensional image providing accurate visual feedback for the surgeon, thus negating the need for the above orthogonal views.

\subsection{Functional Programming}

The functional section of the code is designed to be a simple 'while' loop that reads user inputs, generates required motion and updates the display for a given time duration. This type of construct was chosen to ensure that the software provides a stable tool which would be a very responsive control over the mechanical system. The following schematics and graphical coding illustrate the chronological execution of the software. 
An overview of the entire functional software is shown in Appendix A2 - National Instruments LabView Code.

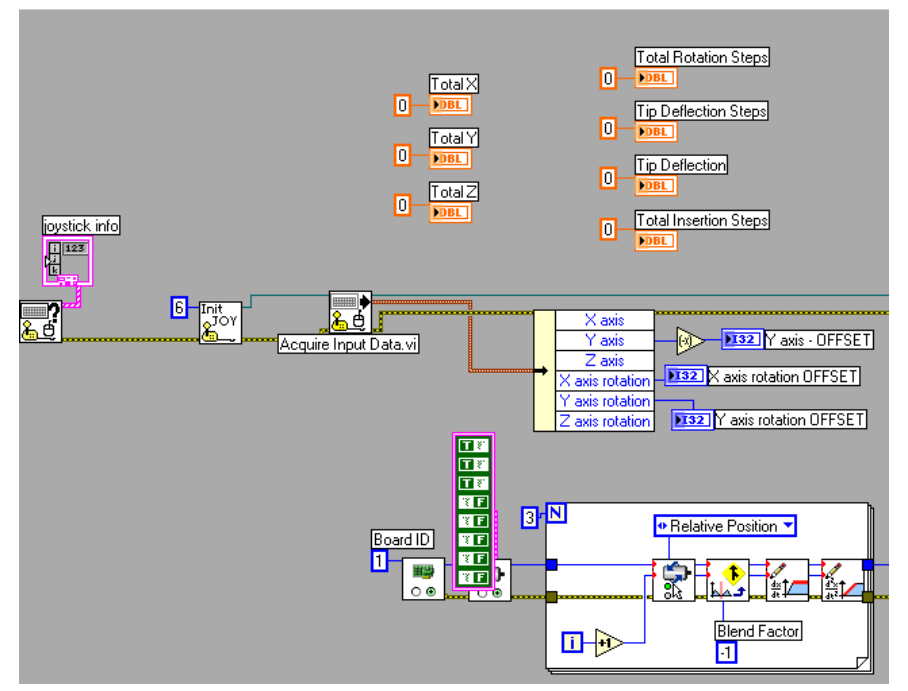

Figure 32 - Functional Code for Initialization

1. The software execution begins with an initialization of the graphical user interface and digital displays with a null (blank) value.

2. The Space Navigator is initiated and its current position is set as neutral.

2.1. The Y-Axis vector is utilized as the insertion depth input.

2.2. The X-Axis rotation vector is utilized as the tip deflection input.

2.3. The $\mathrm{Y}$-Axis rotation vector is utilized as the tip rotation input.

2.4. All other Space Navigator outputs are ignored.

3. The keyboard is initiated.

4. The motor driver software is initiated and all motion parameters are set.

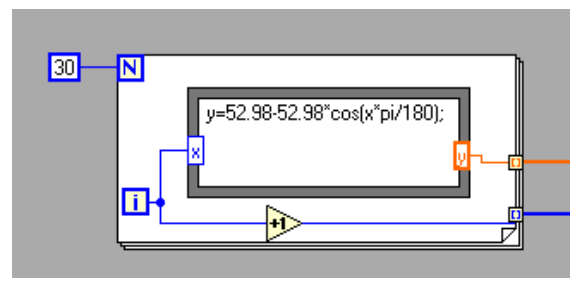

Figure 33 - Functional Code for Graphical Display Database 
5. A database for all of the points required to graphically simulate the deflection curves is generated as shown in the above figure. It contains the deflection of the lead based on the amount of exposed pre-curved stylet. This database dramatically decreases the processing load required for simulating implant orientation and location. The orientation and location can be displayed simply by accessing a different set of data from this database eliminating the need to recalculate every time the tip deflection is changed. This finishes the initialization.

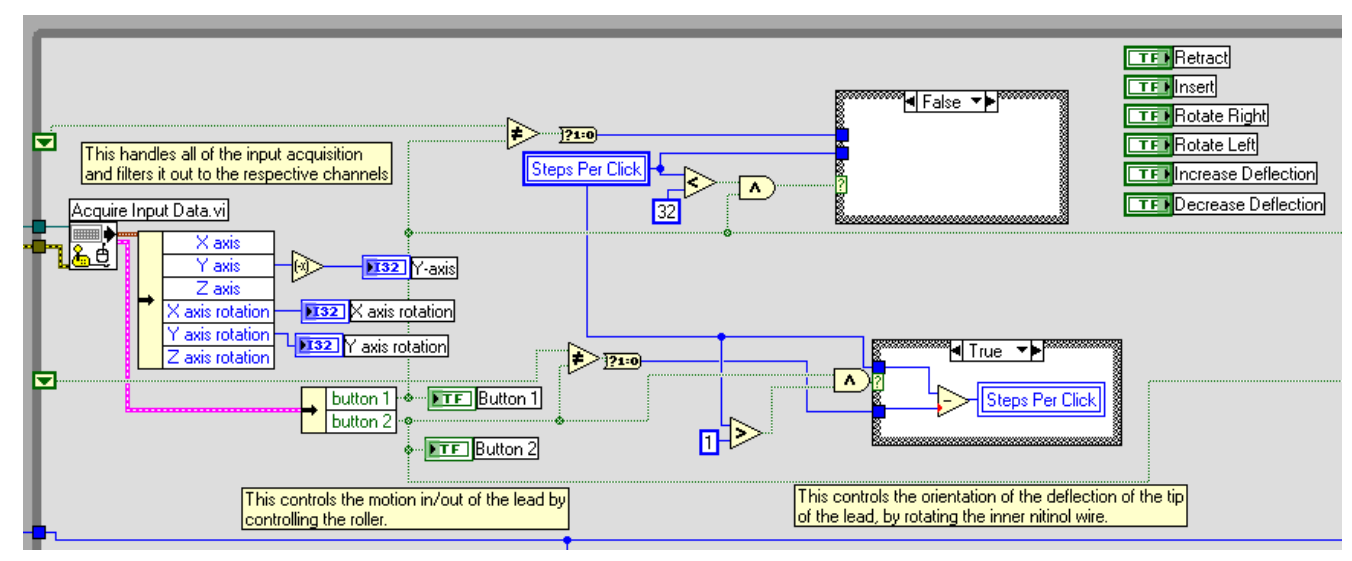

Figure 34 - Functional Code for Space Navigator Input Acquisition

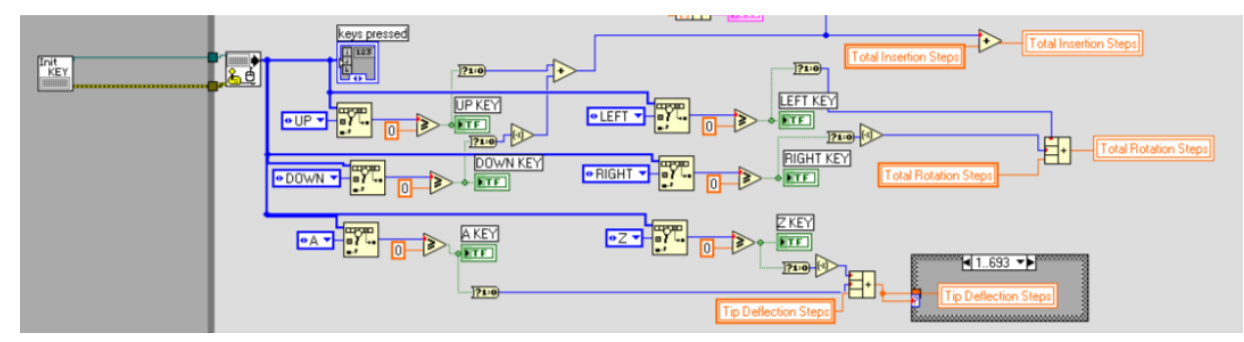

Figure 35 - Functional Code for Keyboard Input Acquisition

6. The while loop is initiated which contains the main section of the software.

7. The inputs from the Space Navigator, keyboard and GUI (via mouse) are acquired.

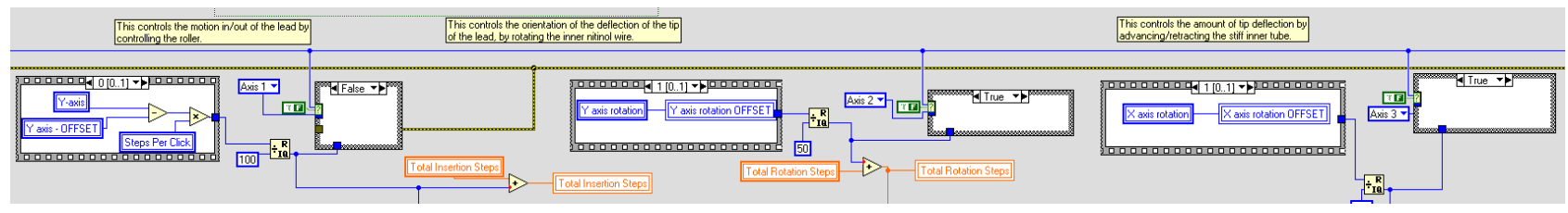

Figure 36 - Functional Code for Stepper Motor Control 
8. The software computes the required motion for each of the three stepper motors and drives the stepper motors to the appropriate position. The software is timed so that it initiates motion of the three stepper motors in the following order: insertion, rotation, deflection. This ensures the driving motion of the lead facilitates the rotation and deflection of the lead. Since the lead is contained within tissue, deflecting the lead must be combined with forward motion since its only "cutting" surface is the front tip.

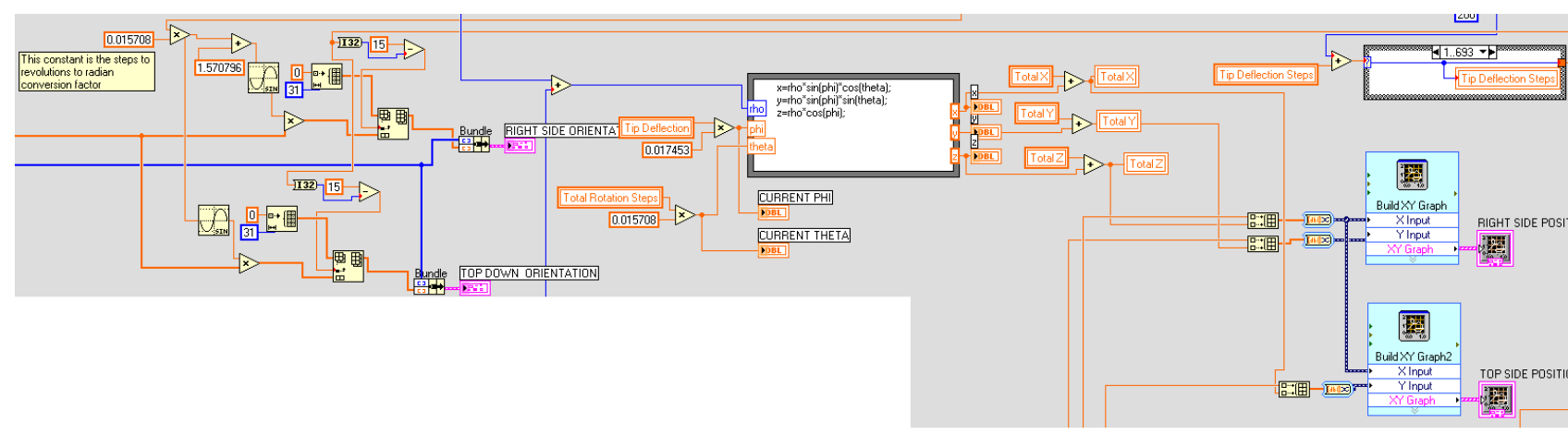

Figure 37 - Functional Code for Position and Orientation Computation

9. The new location and orientation of the lead are computed in Cartesian and Cylindrical coordinates and the digital displays and graphical displays are updated. 10. The while loop is completed and restarted unless the stop button has been pressed. All algorithms used for graphical display, coordinate transformation, three dimension to two dimension projection, and motion output can be viewed un-compiled in the Guidance Software VI which is included as a digital appendix to this thesis. The following is a short discussion concerning the algorithms used within the software.

Once the inputs have been acquired several conversions must be applied in order to correctly display the orientation and the position of the lead. This is done via the following:

1. Convert inputs from steps into rotational degrees, tip deflection degrees, and linear insertion distance (microns). This is done simply by taking the motor rotations, dividing 
by the steps/revolution for each specific motor, accounting for gearing ratios, and converting to radians for the two rotational motors and distance for the linear motor.

2. Since the lead orientation display is split into two normal views (top down and ride side), the system must determine the projected deflection in each plane. First, the tip deflection database is queried based on the total tip deflection. This provides an array with data points representing the deflection in a normal view. Second, the projection onto each of the planes is determined by taking the sine of the rotation angle referenced to the respective plane and multiplying the queried tip deflection database by this value.

3. Since the position display is also split into two normal views, the same projection must be applied. However in this case, the total history of motion of the lead must be determined. This is done by incrementally determining the 3D Cartesian vector associated each cycle of the software, and adding its components to the appropriate Total $X$, Total $Y$, Total $Z$ variables. Given that these parameters are already normal, projection is simple. The $Z$ and $X$ axis are displayed in the Top Down View and the $Z$ and $Y$ axis are displayed in the Right Side View.

4. Finally, the displays are updated. Note: At this point in the development there is no safeguard against the loss of electrical power. The lead would have to be manually removed and the procedure restarted.

\section{Testing}

Two types of finite element analysis were performed on the system. The first was vibration analysis to determine if the driving frequency of the stepper motors would excite any of the natural frequencies of the Leksell arc. The second was an electro- 
thermal analogy utilizing heat flux as an analog to electrical current. This was performed to assess the differences in stimulation volume and location for two lead orientations.

\subsection{Vibration Testing}

Vibration analysis was performed to ensure that the high degree of accuracy of the insertion system is not defeated by resonance of the Leksell arc stimulated by the vibrations generated by the rotation of the stepper motors and drive mechanisms. The first fifteen natural frequencies of the Leksell arc were determined using an ABAQUS wire model utilizing beam elements with both ends of the arc fully restrained (encased boundary condition) since the arc is secured to the frame with bolts. A convergence study was performed to ensure that enough elements were implemented in order to ensure that the results had converged sufficiently for application to this investigation.

Table 8 summarizes the convergence study performed by implementing consecutively higher mesh densities on the arc. The ABAQUS output for the first 15 modes of the Leksell arc without the insertion device mounted was implemented for this convergence study. Since the maximum driving frequency is below the first mode, the convergence study was concluded after the five lowest modes converged to within $\pm 1.5 \mathrm{~Hz}$.

Table 8 - Leksell Arc Natural Modes of Vibration Convergence Study

\begin{tabular}{|r|r|r|r|}
\cline { 2 - 4 } \multicolumn{1}{r|}{ Mode Number } & 32 elements & \multicolumn{6}{c|}{$\mathbf{6 6}$ elements } & 330 elements \\
\hline 1 & 290.7 & 290.6 & 290.6 \\
\hline 2 & 831.7 & 831.3 & 831.1 \\
\hline 3 & 1721.5 & 1720.0 & 1719.5 \\
\hline 4 & 2177.6 & 2175.5 & 2174.8 \\
\hline 5 & 2909.5 & 2906.0 & 2904.9 \\
\hline 6 & 2958.8 & 2955.3 & 2954.2 \\
\hline 7 & 3613.9 & 3612.3 & 3611.8 \\
\hline 8 & 4373.7 & 4367.5 & 4365.6 \\
\hline 9 & 5022.6 & 5017.2 & 5015.6 \\
\hline 10 & 5188.2 & 5192.8 & 5194.1 \\
\hline
\end{tabular}




\begin{tabular}{|r|r|r|r|}
\hline 11 & 6088.5 & 6080.4 & 6077.8 \\
\hline 12 & 6804.3 & 6822.8 & 6828.4 \\
\hline 13 & 8006.2 & 8005.2 & 8004.0 \\
\hline 14 & 8339.7 & 8338.0 & 8337.5 \\
\hline 15 & 8454.8 & 8492.7 & 8504.4 \\
\hline
\end{tabular}

*NOTE: Convergence Study performed with a different material, and hence the values are different than those stated for the analysis below.

Two concentrated point masses representing the guidance system and the insertion mechanism were added to the Leksell arc model. Figure 38 and Table 9 below detail the properties of the model.

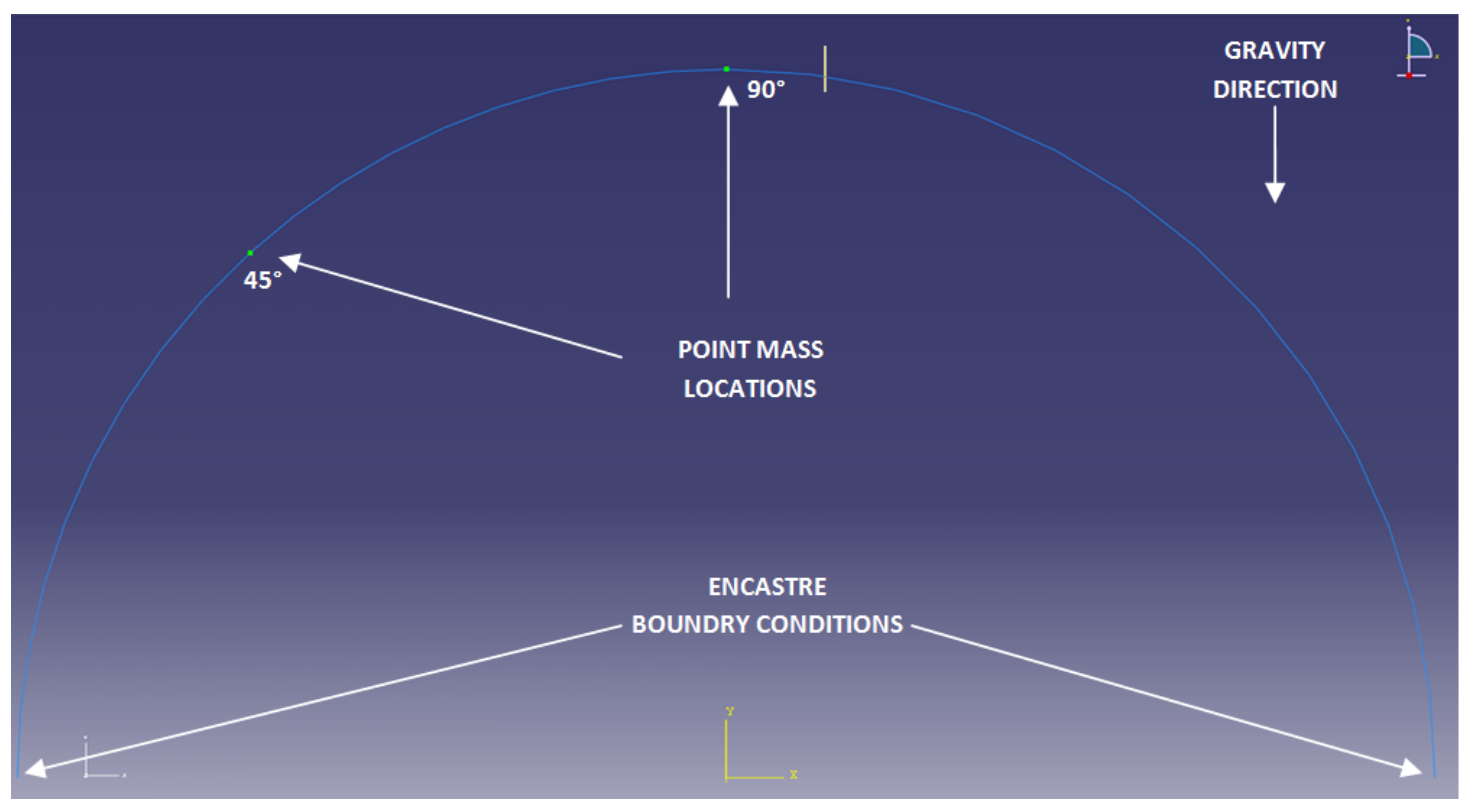

Figure 38 - FEA Vibration Model

Table 9 - FEA Vibration Model Properties

\begin{tabular}{|l|l|c|c|}
\hline Model Component & Property & Value & Units \\
\hline Part & Type & WD Deformable & \\
\hline Part & Feature-Type & \\
\hline Part & $\begin{array}{l}\text { Section-Sketch-Arc } \\
\text { Radius }\end{array}$ & 0.11 & $\mathrm{~m}$ \\
\hline Materials & Density & 4500 & $\mathrm{~kg} / \mathrm{m}^{3}$ \\
\hline Materials & $\begin{array}{l}\text { Elastic - Young's } \\
\text { Modulus }\end{array}$ & $1.16 \mathrm{E}+11$ & $\mathrm{~Pa}$ \\
\hline Materials & $\begin{array}{l}\text { Elastic - Poisson's } \\
\text { Ratio }\end{array}$ & 0.3 & \\
\hline
\end{tabular}




\begin{tabular}{|l|l|cc|}
\hline Model Component & Property & Value & Units \\
\hline Section & Shape & 0.0075 & $\mathrm{~m}$ \\
\hline Profile & A (thickness) & 0.04 & $\mathrm{~m}$ \\
\hline Profile & B (width) & Point Mass & \\
\hline Inertia & Type & .225 & $\mathrm{~kg}$ \\
\hline Inertia & Inertia1 - Mass & Point Mass & \\
\hline Inertia & Type & .225 & $\mathrm{~kg}$ \\
\hline Inertia & Inertia1 - Mass & Gravity & \\
\hline Load & Type & $(0,-9.81,0)$ & $\mathrm{m} / \mathrm{s}^{2}$ \\
\hline Load & Gravity Magnitude & Encastre & \\
\hline Boundary Condition & BC1 - Type & Encastre & \\
\hline Boundary Condition & BC2 - Type & \\
\hline
\end{tabular}

Table 10 presented below compares the ABAQUS results for three different trials.

Similar to a concentrated mass on a pendulum, the lowest natural frequency is associated with all of the mass being concentrated as far away from the encased point as possible.

Table 10 - Leksell Arc with Additional Point Mass and Moments of Inertia

\begin{tabular}{|c|c|c|c|}
\hline $\begin{array}{c}\text { Mode } \\
\text { Number }\end{array}$ & $\begin{array}{l}\text { Arc } \\
\text { Mass } \\
\text { Only }\end{array}$ & $\begin{array}{l}\text { Frequency (Hz } \\
\text { Arc Mass and } \\
\text { Combined Point } \\
\text { Mass at } 90^{\circ}\end{array}$ & $\begin{array}{c}\text { Arc Mass and } \\
\text { Point Mass at } \\
45^{\circ} \text { and } 90^{\circ}\end{array}$ \\
\hline 1 & 61.0 & 57.4 & 58.3 \\
\hline 2 & 207.7 & 203.8 & 199.7 \\
\hline 3 & 663.7 & 640.3 & 637.3 \\
\hline 4 & 971.0 & 902.4 & 927.5 \\
\hline 5 & 1091.0 & 1089.1 & 1089.6 \\
\hline 6 & 1647.5 & 1609.4 & 1583.0 \\
\hline 7 & 2170.4 & 2170.4 & 2170.4 \\
\hline 8 & 2764.8 & 2693.0 & 2656.7 \\
\hline 9 & 2887.5 & 2887.5 & 2887.4 \\
\hline 10 & 3529.3 & 3528.3 & 3528.4 \\
\hline 11 & 3627.4 & 3626.3 & 3626.7 \\
\hline 12 & 4942.9 & 4941.6 & 4940.1 \\
\hline 13 & 5203.7 & 5203.6 & 5203.6 \\
\hline 14 & 6675.7 & 6673.6 & 6674.2 \\
\hline 15 & 6856.2 & 6855.9 & 6856.0 \\
\hline
\end{tabular}

The following calculations take the maximum possible speed of the stepper motor before gear reduction and calculate the first 13 harmonics. The ratios of these frequencies over 
the lowest natural frequency of the Leksell arc with all of the system mass focused at the $90^{\circ}$ location.

$$
50 \mathrm{rpm} * \frac{1 \mathrm{~min}}{60 \mathrm{~s}}=.83 \mathrm{~Hz}
$$

Table 11 - Harmonics of Maximum Driving Frequency

\begin{tabular}{|c|c|c|}
\hline $\begin{array}{c}\text { Driving Frequency and } \\
\text { Harmonics }\end{array}$ & & $\begin{array}{c}\text { Frequency } \\
\text { Ratio } \\
\left(\mathbf{f}_{\text {driving }} / f_{n}\right)\end{array}$ \\
\hline Maximum Driving Frequency & $0.83 \mathrm{~Hz}$ & 0.014 \\
\hline 2nd Harmonic & $1.66 \mathrm{~Hz}$ & 0.028 \\
\hline 3rd Harmonic & $2.49 \mathrm{~Hz}$ & 0.043 \\
\hline 4th Harmonic & $3.32 \mathrm{~Hz}$ & 0.057 \\
\hline 5th Harmonic & $4.15 \mathrm{~Hz}$ & 0.071 \\
\hline 6th Harmonic & $4.98 \mathrm{~Hz}$ & 0.085 \\
\hline 7th Harmonic & $5.81 \mathrm{~Hz}$ & 0.100 \\
\hline 8th Harmonic & $6.64 \mathrm{~Hz}$ & 0.114 \\
\hline 9th Harmonic & $7.47 \mathrm{~Hz}$ & 0.128 \\
\hline 10th Harmonic & $8.30 \mathrm{~Hz}$ & 0.142 \\
\hline 11th Harmonic & $9.13 \mathrm{~Hz}$ & 0.157 \\
\hline 12th Harmonic & $9.96 \mathrm{~Hz}$ & 0.171 \\
\hline 13th Harmonic & $10.79 \mathrm{~Hz}$ & 0.185 \\
\hline
\end{tabular}

Given that the largest possible ratio is 0.185 and this ratio applies to the thirteenth harmonic, these calculations show that the entire operating range of the system is not high enough to resonate with the natural frequencies of the Leksell arc and guidance system whose combined natural frequency is approximately $57 \mathrm{~Hz}$.

\subsection{Electro-Thermal Analogy FEA Analysis}

\subsubsection{Analogy Design and Inputs}

In order to assess the effectiveness of the implementation of curved implant contours, the following finite element analysis was performed. Since ABAQUS does not perform electrical current path simulation, an electro-thermal analogy was implemented. This 
analogy uses the similarities between heat flux and electrical current to correlate the thermal output from ABAQUS to an equivalent electrical analysis (Redler, et al. 1995). The equations which define heat flux and electrical conductivity follow the same general formulation.

$$
\begin{gathered}
V=I R \quad(\text { Electrical Equation) } \\
\Delta T=\frac{Q}{K}=Q \cdot \frac{1}{K} \text { (Thermal Equation) }
\end{gathered}
$$

Although the units are different, a unit-less analysis such as ABAQUS finite element analysis can be used. In order to solve an electrical analysis problem with a thermal analysis software such as ABAQUS, the electrical system must first be prepared for the analysis by "converting" the electrical units into thermal units. This is done by using the above equations to create property and unit correlations or analogs. The electrical and thermal variables are defined in Table 12.

\begin{tabular}{|c|c|c|c|}
\hline \multicolumn{3}{|c|}{ Electrical } & \multirow[b]{7}{*}{$\mathrm{R}=\Sigma \mathrm{rL} / \mathrm{A}$} \\
\hline 1 & Current & Amp & \\
\hline $\mathrm{V}$ & Voltage & Volt & \\
\hline$r$ & Resistivity & $\Omega-m$ & \\
\hline$L$ & Length & $\mathrm{M}$ & \\
\hline A & Area & $\mathrm{m}^{2}$ & \\
\hline $\mathrm{R}$ & Resistance & $\Omega$ & \\
\hline \multicolumn{3}{|c|}{ Thermal } & \multirow{5}{*}{$1 / \mathrm{K}=\Sigma(1 / \mathrm{k}) \mathrm{L} / \mathrm{A}$} \\
\hline Q & Heat Transfer Rate & Watt & \\
\hline$T$ & Temperature & ${ }^{\circ} \mathrm{C}$ & \\
\hline $\mathrm{K}$ & Overall Conduction Coefficient & $\mathrm{W} /{ }^{\circ} \mathrm{C}$ & \\
\hline$k$ & Thermal Conductivity & $\mathrm{W} /\left(\mathrm{m}-{ }^{\circ} \mathrm{C}\right)$ & \\
\hline
\end{tabular}

Table 12 - Electro-Thermal Component Definitions

These properties and their corresponding units are then transformed using the electro thermal analogy. Each electrical property and its corresponding thermal property are correlated via an independent analog. This analog allows for the electrical inputs to be 
transformed into thermal inputs, and for the thermal solution to be translated back to an electrical solution. Table 13 contains the analogs used to perform the correlation. The units stated below must be maintained to ensure that the translated results are of the appropriate scale.

Table 13 - Electro-Thermal Analogs

\begin{tabular}{|rl|}
\hline $\mathrm{T}\left[{ }^{\circ} \mathrm{C}\right]$ & $=\mathrm{V}[$ Volts $]$ \\
\hline $\mathrm{Q}[$ Watts $]$ & $=\mathrm{I}[$ Amps $]$ \\
\hline $1 / \mathrm{K}\left[{ }^{\circ} \mathrm{C} /\right.$ Watts $]$ & $=\mathrm{R}[$ Ohms $]$ \\
\hline $1 / \mathrm{k}$ [Meter- ${ }^{\circ} \mathrm{C} /$ Watts $]$ & $=\mathrm{r}[$ Ohm-Meters $]$ \\
\hline
\end{tabular}

Note: all analogs are scaled 1:1 in magnitude however some properties are inversely proportional.

In order to simplify the analysis, the lead body is considered to be an ideal insulator and the contacts are considered to be ideal source/sink. Considering the high impedance of polyurethane (lead body) and the high conductivity of platinum (contacts), this assumption is acceptable. Since the internal leakage between contacts is negligible and affects only the magnitude not the profile of the electrical stimulation, it is excluded from this analysis. By excluding internal leak paths, the lead can be modeled as boundary surfaces. The source electrode is modeled as a heat flux load evenly distributed over the electrode surface area as dictated by the current/heat transfer analog and the ideal source assumption. The sink (electrical ground) electrode is modeled as a $0^{\circ} \mathrm{C}$ temperature boundary condition over the surface of the electrode as dictated by the voltage/temperature analog and the ideal sink assumption. This greatly reduces the amount of elements required by the analysis and allows for only the brain tissue to be modeled. Although the brain is known to a heterogeneous organ, since a lead targets a small amount of tissue, the brain tissue can be modeled as homogenous. Table 14 details the electrical properties of brain tissue used in this analysis.

Table 14 - Brain Tissue Properties 


\begin{tabular}{|l|c|c|l|}
\hline Property & \multicolumn{1}{c}{ Value } & Units & Reference \\
\hline Impedance & $500-1500$ & Ohms-cm & (Butson, et al. 2006) \\
\hline Volume & 1400 & $\mathrm{ml}$ & (Glezer and Blinkov 1968) \\
\hline Weight & 1400 & $\mathrm{~g}$ & $\begin{array}{l}\text { (Rengachary and Ellenbogen } \\
2005)\end{array}$ \\
\hline Density & 1000 & $\mathrm{~kg} / \mathrm{m}^{\wedge} 3$ & - \\
\hline Youngs Modulus & 1000 & $\mathrm{~Pa}$ & (Bilston, et al. 1997) \\
\hline
\end{tabular}

From the above brain tissue properties, the FEA model was created with the following inputs (Table 15).

Table 15 - FEA Electro-thermal Analogy Model Properties

\begin{tabular}{|l|l|c|c|}
\hline Model Component & Property & Value & Units \\
\hline Part & Type & 0.75 & - \\
\hline Materials & Conductivity & 1000 & $\mathrm{~kg} / \mathrm{m}^{\wedge} 3$ \\
\hline Materials & Density & & \\
\hline Materials & $\begin{array}{l}\text { Elastic - Young's } \\
\text { Modulus }\end{array}$ & 1000 & $\mathrm{~Pa}$ \\
\hline Materials & $\begin{array}{l}\text { Elastic - Poisson's } \\
\text { Ratio }\end{array}$ & 0.3 & - \\
\hline Materials & Specific Heat & 0.001 & - \\
\hline Section & Type & $\begin{array}{c}\text { Solid, } \\
\text { Homogeneous }\end{array}$ & - \\
\hline Load (Source) & Type & $\begin{array}{c}\text { Surface Heat } \\
\text { Flux }\end{array}$ & - \\
\hline Load (Source) & Distribution & Uniform & - \\
\hline Load (Source) & Magnitude & 0.05 & $\mathrm{~W} / \mathrm{mm}^{2}$ \\
\hline Load (Source) & Amplitude & Instantaneous & - \\
\hline Boundary Condition (Sink) & Type & Temperature & - \\
\hline Boundary Condition (Sink) & Distribution & Uniform & - \\
\hline Boundary Condition (Sink) & Magnitude & 1 & ${ }^{\circ} \mathrm{C}$ \\
\hline Boundary Condition (Sink) & Amplitude & Instantaneous & - \\
\hline
\end{tabular}

This FEA analysis was performed on two different orientations of the lead. The first is to determine the generic shape of the electrical stimulation field for a standard stereotactic implant. This provides a baseline to determine the effect a curvilinear implant orientation would have on the stimulation field. It also provides a comparison to previous work shown below (Figure 39). 


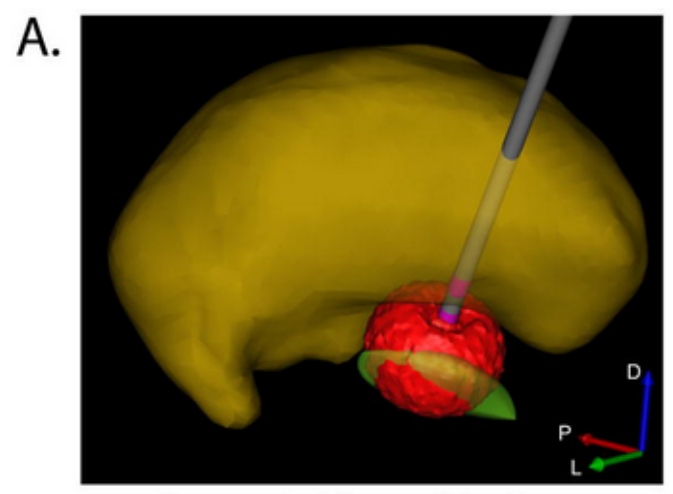

Isotropic Tissue Medium w/ Electrode Encapsulation
B.

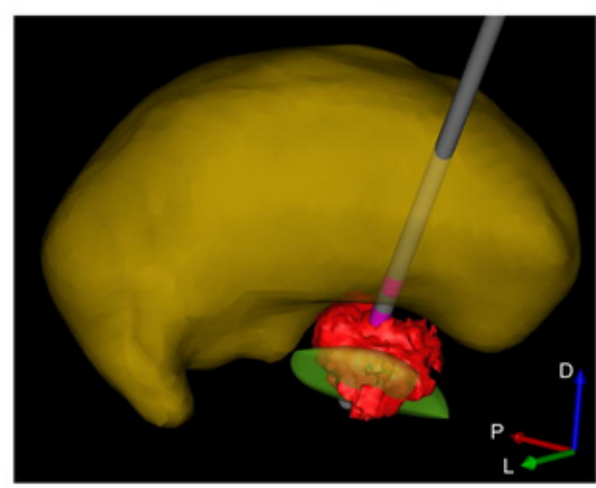

DTI-Based Tissue Medium w/ Electrode Encapsulation

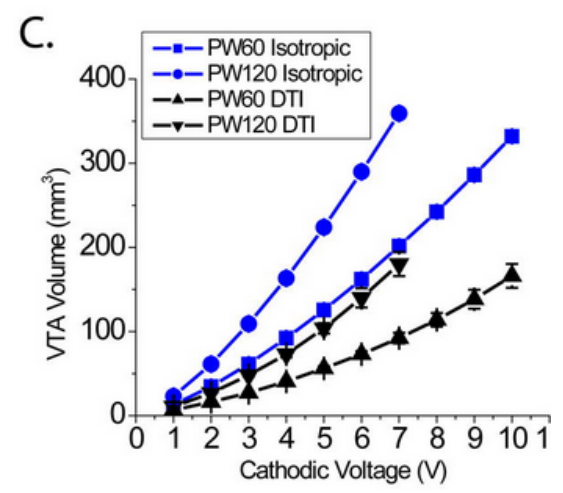

Figure 39 - Volume of Tissue Activated by Deep Brain Stimulation (Butson, et al. 2007) Dr. Butson, et al. generated the figures shown in Figure 39 using MRI and DTI images. These figures show the volume of activated tissue for a given voltage. The graph details the relationship between the stimulation voltage amplitude and the volume of activated tissue. The results suggest that the volume of activated tissue takes on the general shape of an ellipsoid that is pierced by the DBS lead. This is expected given an axisymmetric lead implant profile. Since this analysis was derived from images of a DBS patient, it serves as an excellent basis for comparison to the electro-thermal analogy used in this thesis.

The second analysis was designed to determine the effect a curved implant contour has on the shape of the volume of affected tissue. The curved implant contours should generate a non-axisymmetric current distribution with the majority of the current travelling through the tissue on the concave side of the lead. It should also generate a 
more constant current density through the target tissue since the contacts are no longer axisymmetric and distance between the lengths of the lead contacts has been reduced on the concave side of the deflected lead.

The analysis for a curved implant contour cannot be correctly modeled using planar analysis since there is no axis of symmetry. However, a plane of symmetry does exist since the lead can only be curved in a single direction. The plane in which the lead is deflected provides the plane of symmetry. Hence the analysis must be performed using 3D analysis; however the plane of symmetry can be utilized to halve the volume necessary for analysis. This results in a decrease in the element size in the analysis and increase in the analysis resolution.

\subsubsection{FEA Results}

The first analysis performed was a linear and axi-symmetric lead implant as shown in the following figure. A graphic representing the lead contacts has been over-laid on top of the analysis to show how the analysis corresponds to the lead contacts (gray) and the insulating spacers (light blue). The lead contact on the right is the current source for this analysis and the lead contact on the left is the ground. Although a deep brain stimulation lead generally has more than 2 contacts, the following analysis uses only two electrodes to determine the general shape of the volume of affected tissue. The magnitude of the volume of affected tissue has already been shown to be dependent on the voltage potential as shown by Butson in Figure 39. The analysis is not concerned with the magnitude of affected volume but rather its contour and relationship to the DBS lead body. 


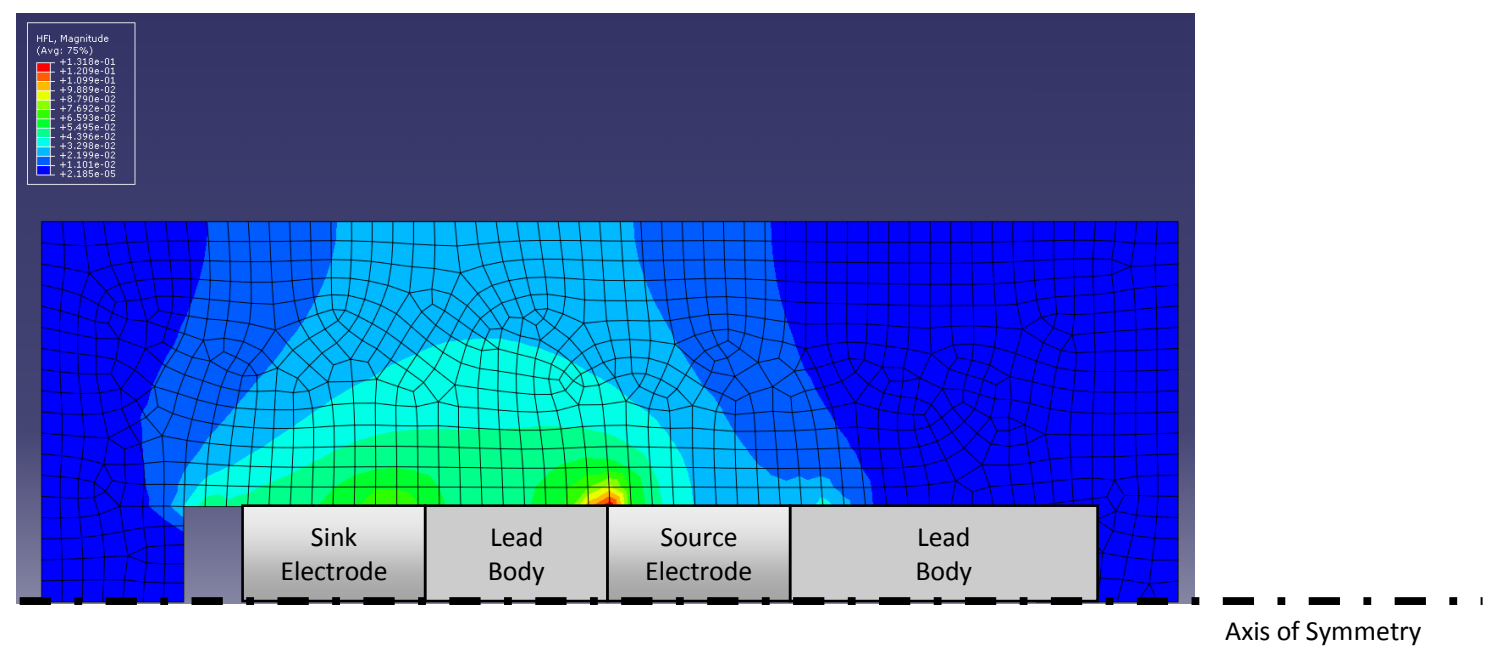

Figure 40 - Current Density Distribution for Axisymmetric Lead Implant

A convergence study showed that the results had converged within $5 \%$ of iterative values for a $3 \mathrm{X}$ increase in nodes/elements. A singularity (highlighted in red in the above graphic) is noted in the analysis due to the zero degree boundary condition utilized to simulate the sink electrode. The analysis provides an estimate of the contour and current density gradient of the region of stimulation for an average level of stimulation. Since only the outer surface of the lead contacts are exposed to the tissue, the shortest path between the two contacts is the cylinder of tissue connecting the two edges of the contacts. The current density of the electrical stimulation is inversely proportional to the radial distance of tissue from the lead. The current density also decreases in the axial direction from the midpoint between the two contacts. This analysis shows that an axisymmetric lead implant generates an axisymmetric field of electrical stimulation as expected and that the current density forms a decreasing gradient proportional the axial distance of the tissue from the lead. The resulting geometric shape is an ellipsoid pierced by the DBS lead. This is confirmed by the MRI analysis shown in Figure 39.

The above analysis has shown that the electro-thermal analogy has generated a similar shape of the volume of affected tissue as compared to Butson, et al. This confirms that the FEA model is a viable tool to assess the effect of curvilinear implant orientations. 
The FEA model was then applied to a lead that has been deflected. As described above, a 3D model was used due to the non-axisymmetric nature of a deflected lead. A convergence study was performed to ensure that the analysis had sufficiently converged. The average heat flux for a specific node was determined for each iterative run. The plot below compares the average heat flux at a given node vs. the total number of nodes. The plot shows that the analysis has converged to within $10 \%$. The analysis was performed at node 48 , which represents the rightmost corner node of the sink electrode in Figure 43 - 3D ABAQUS Heat Flux .

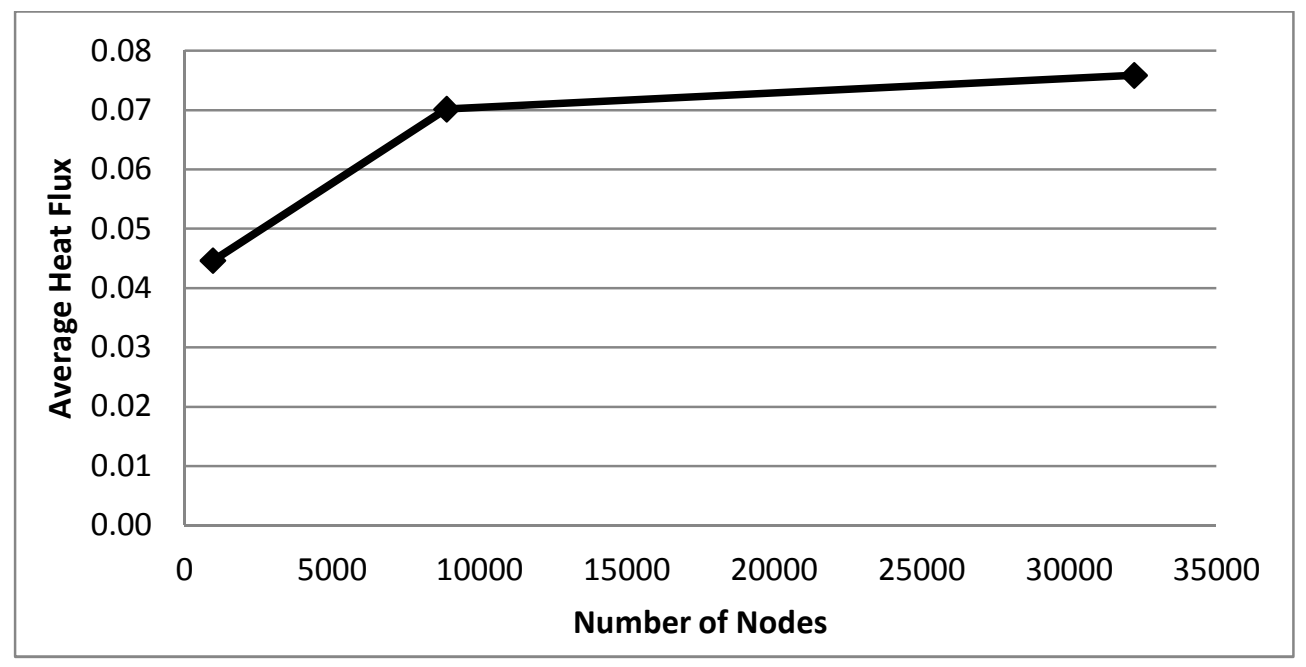

Figure 41 - Electro-Thermal 3D Analysis Convergence Study

The analysis below shows the heat flux distribution for a curved lead implant. Heat flux is equivalent to electrical current based on the electro-thermal analogy. 


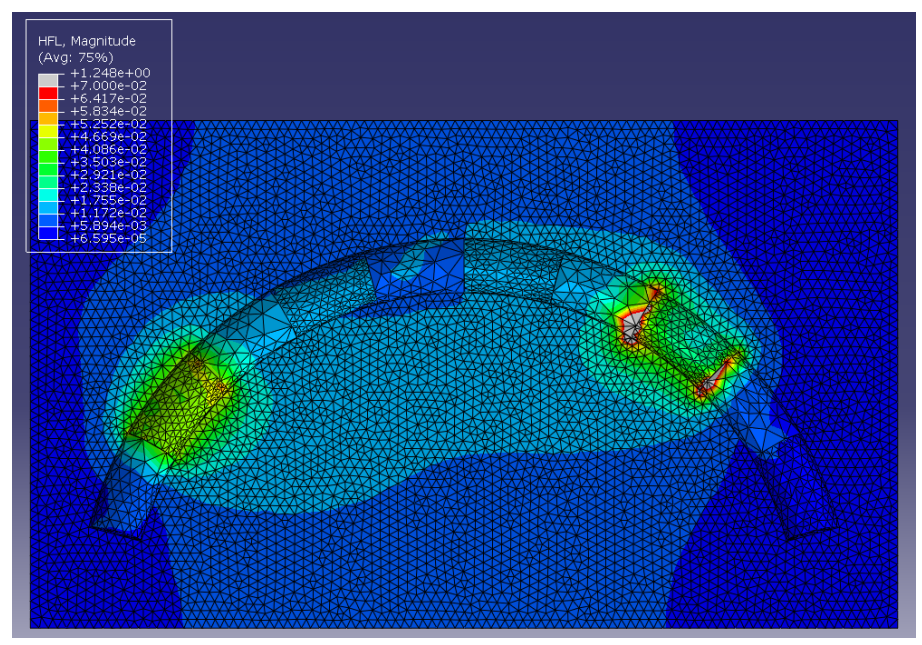

Figure 42 - 3D ABAQUS Heat Flux in Brain Tissue

The above graphic is repeated below with the addition of a DBS lead graphic to detail the electrical stimulation source and sink. It should be noted that the two darkest shades in the gradient are orders of magnitude less than the rest of the gradient.

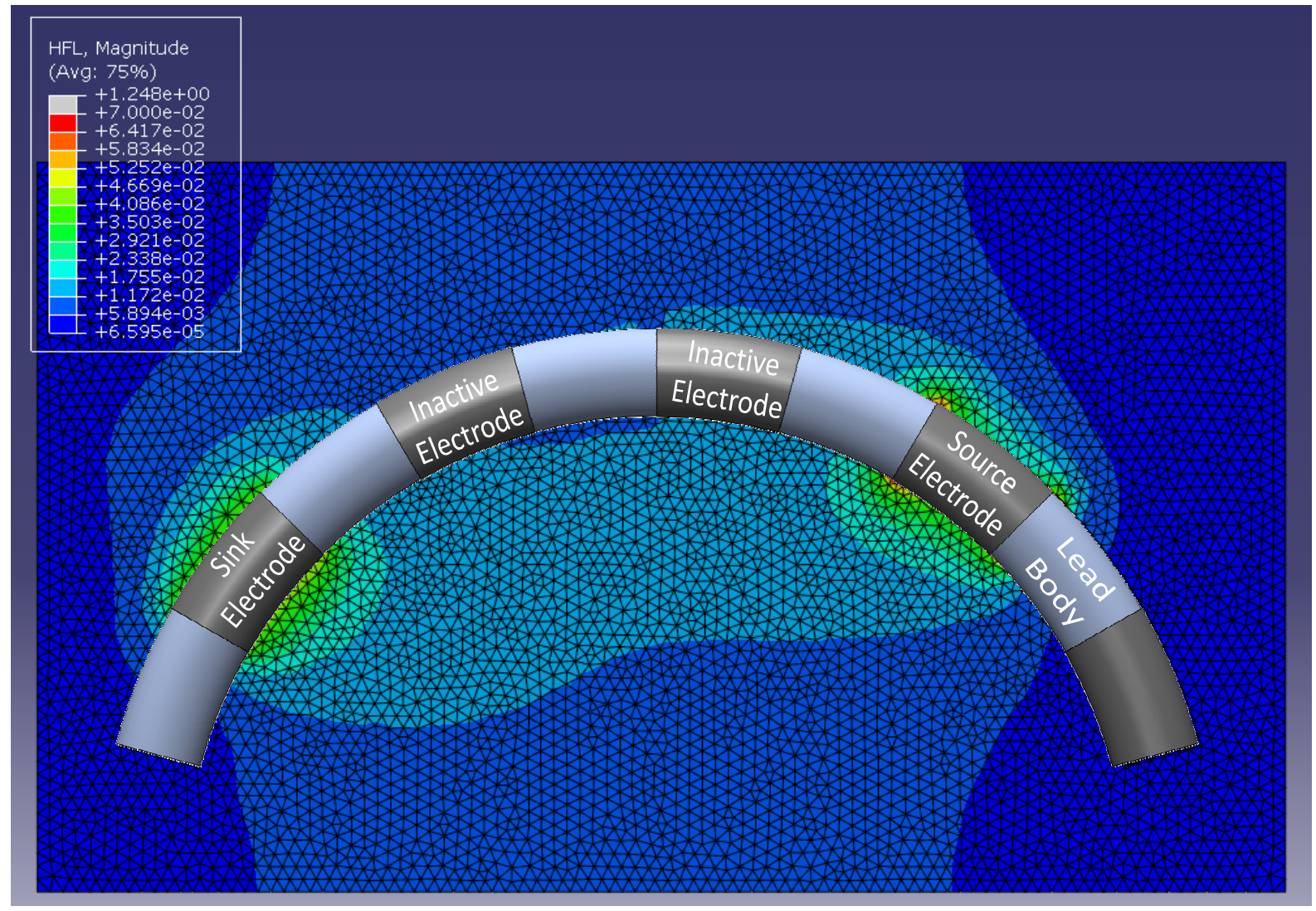

Figure 43 - 3D ABAQUS Heat Flux in Brain Tissue with DBS Lead Graphic 
The result is a dramatically different current distribution when compared with the linear implant orientation in Figure 40. The curvature of the lead changes the relative orientation between the source and sink electrodes. This provides two distinct differences between the different implant orientations. The first is that the electrical current is almost completely contained within the tissue on the concave side of the lead. The second is that the current density is also much more uniform. These differences are discussed in the discussion section below.

\section{Discussion}

The research, design, and analysis presented herein are intended to improve the therapy of deep brain stimulation by increasing lead implant accuracy, focusing electrical stimulation, and providing digital guidance of the implant procedure. The efficacy with which the proposed design accomplishes these tasks is discussed. The following discussion also provides recommendations concerning empirical testing to verify the stated theoretical calculations, and suggests avenues for further research and development.

\subsection{System Development}

The system was developed with the goal of providing neurosurgeons with the ability to produce asymmetric lead implant orientations in order to focus the DBS electrical stimulation within a desired volume of brain tissue by deflecting the lead's distal tip. However, the deflection must be controllable and precise to be of value. The number of mathematical calculations associated with the curvilinear implantation is too difficult and time consuming to be manually feasible. Hence, computer control of the system was required. Given these overarching guidelines, a set of design inputs was created, and the system was designed in accordance. As detailed in Section 3.2.9, the insertion 
subsystem was designed to provide advancement/retraction accuracy on a micron level. Section 3.2.12 describes the development of the guidance subsystem capable of up to $15^{\circ}$ of deflection in any direction. When controlled simultaneously by the software, described in Section 4, the two subsystems are theoretically capable of generating an accurate, curvilinear lead implant profile.

\subsection{Computational Analysis}

The calculations in Section 3.2, Section 5, and Appendix A1, support the claim that the system is capable of withstanding the loads applied during the implant procedure. These loads include the static friction and normal force required to translate the motor torque into the driving force on the lead body, as well as the ability to deflect/straighten the lead. The testing also indicates that the vibrations of the motors will not excite the natural frequencies of the Leksell frame, thereby confirming compatibility.

However the capability to deflect the lead is only useful if the corresponding field of electrical stimulation can be shown to be dramatically different than that of a straight lead. Section 5.2 uses an electro-thermal finite element analogy to theoretically predict the fields of stimulation for both cases. The results of the finite element analysis show that the deflection of the lead dramatically changed the contour of the stimulation volume. Almost the entirety of the current was contained within the concavity of the lead. Hence increasing the amount of curvature of the lead can be used to progressively focus the current in the tissue on the concave side of the lead. This has the two-fold effect of increasing the stimulation of the target tissue and decreasing the stimulation of the healthy tissue. Since less of the net stimulation applied to the tissue is wasted, lower levels of stimulation can be used to obtain equivalent therapy, thereby helping to maximize device performance and increasing battery life. It is also important to note that this analysis only utilizes a single source and sink electrode. Given that current 
technology allows for each electrode to be set to a unique voltage potential with reference to the others, the possible contours of the stimulation volume are almost limitless.

The current density is also much more uniform for the deflected lead analysis. This is driven primarily by the orientation of the active electrodes with reference to each other. The contacts are no longer in-line with each other, which increases the projected area shared by the two electrodes. This increase in projected area assists with creating a more uniform current distribution. This allows the surgeon to increase the level of stimulation while decreasing the risk of overstimulation of the tissue. It should be noted that this increase in current density uniformity could also be accomplished by the implant of two leads parallel to each other. However, there is an added cost and risk associated with implanting multiple leads, and this analysis has shown that equivalent stimulation is possible with a single lead.

\subsection{Validation and Future Analysis}

All of the testing and analysis done so far has only been theoretical. The system must be prototyped and tested in vitro using synthetic human tissue, cadavers, and animal models to determine if the design specifications chosen are viable. Empirical data from these tests will provide the basis for assessing the risk/benefit of implementing the implant guidance system as currently envisioned. If the results indicate that the advantages outweigh the risks, the mechanical system and software must be refined through the design verification / validation process. Design verification is composed of an exhaustive series of tests to confirm that the design meets all requirements with an acceptable confidence and reliability. The design validation process confirms that all requirements have been correctly chosen by assessing the system performance during a clinical trial. 


\section{Conclusions}

The proposed mechanical system design, LabView software, and the associated finite element analysis and theoretical calculations support the proposed hypothesis: Digital control of the lead implant process will allow for asymmetric implant orientations and corresponding asymmetric electrical stimulation fields.

Given the stated parameters of brain tissue, the design of the system was shown to be theoretically capable of generating the forces and torque necessary to deflect the distal lead tip and simultaneously drive/retract the lead. The driving software provides multiple input methods and converts the inputs into step commands for the three stepper motors driving the system. Although a complete system has not been fabricated, the software was shown to correctly control free-standing stepper motors. Finally, a finite element analysis based thermo-electric analogy was used to predict the electrical stimulation field generated by an implanted lead. The analysis was shown to closely represent previous work, and when applied to a deflected lead, shows that the volume of stimulation can be manipulated based on lead orientation.

The deep brain lead guidance and insertion system detailed above was developed in response to the ever increasing need for precision and accuracy in the medical field; specifically, finding ways of coupling the surgeon's skills with advanced technology resulting in faster, safer surgeries and improved patient care. This two part system would potentially give surgeons very precise placement control while providing a new innovative ability - off axis navigation/tip deflection which will allow for focused electrical stimulation of the target tissue. Although the focus of this thesis was not to determine optimal implantation paths or generate new forms of treatment, as these fields are beyond the abilities of the author, hopefully the development of this tool will generate further research and be a stepping stone for improved patient care. 


\section{Future Development}

The next step in off-axis guidance and curvilinear lead implant contours is to fabricate a system and rigorously test it in a medium which simulates the material and mechanical properties of brain matter. The results will provide much needed empirical data to either support moving forward with a system as designed or indicate if modifications or complete reassessment of the implant technique is required. Once a viable and proven system has been fabricated, empirical data concerning the electrical stimulation can be acquired to confirm the validity of the FEA electro thermal analogy.

The combination of surgical guidance software and three dimensional imaging software has the potential to provide numerous improvements over current practice including: optimized mapping of the implant before the surgery based on MRI/CAT scans, precise implant guidance controlled by the computer based on those calculations, simulated implant scenarios, and virtual training simulators. 


\section{Appendices}

\section{A1. Tip Deflection}

The input parameters yield the required load that must be applied by the stylet in order to accomplish the desired deflection based on the stiffness of the lead.

$\mathrm{E}_{\text {polyurethane }}=1.25 \mathrm{GPa} \quad \mathrm{L}=13.87 \mathrm{~mm} \quad I=\frac{1}{4} \pi\left(1.27^{4}-0.51^{4}\right)=1.99 \mathrm{~mm}^{4}$

$$
\text { required load per } m m=w=-\frac{6 \tan \left(15^{\circ}\right) \cdot 1.25 \mathrm{GPa} \cdot 1.99 \mathrm{~mm}^{4}}{(13.87 \mathrm{~mm})^{3}}=-4.79 \frac{\mathrm{N}}{\mathrm{mm}}
$$

This is the required load to deflect the lead to angle of 15 degrees. The radius with which the stylet must be formed to generate this load can now be calculated.

$\mathrm{E}_{\text {Nitinol }}=75 \mathrm{GPa}$ (annealed nitinol) $\quad \mathrm{L}=13.87 \mathrm{~mm} \quad I=\frac{1}{4} \pi 0.23^{4}=0.0022 \mathrm{~mm}^{4}$

$$
\text { Required slope }=\tan ^{-1}\left(\frac{(4.79 \mathrm{~N} / \mathrm{mm})(13.87 \mathrm{~mm})^{3}}{6(28 G P a)\left(0.0022 \mathrm{~mm}^{4}\right)}\right)=88^{\circ}
$$

This slope determines the formed radius of the stylet.

$$
\text { Required radius }=10 \mathrm{~mm}
$$

When inserted into the lead, the stylet with this radius of curvature will deflect the lead 15 degrees. 
A2. National Instruments LabView Code

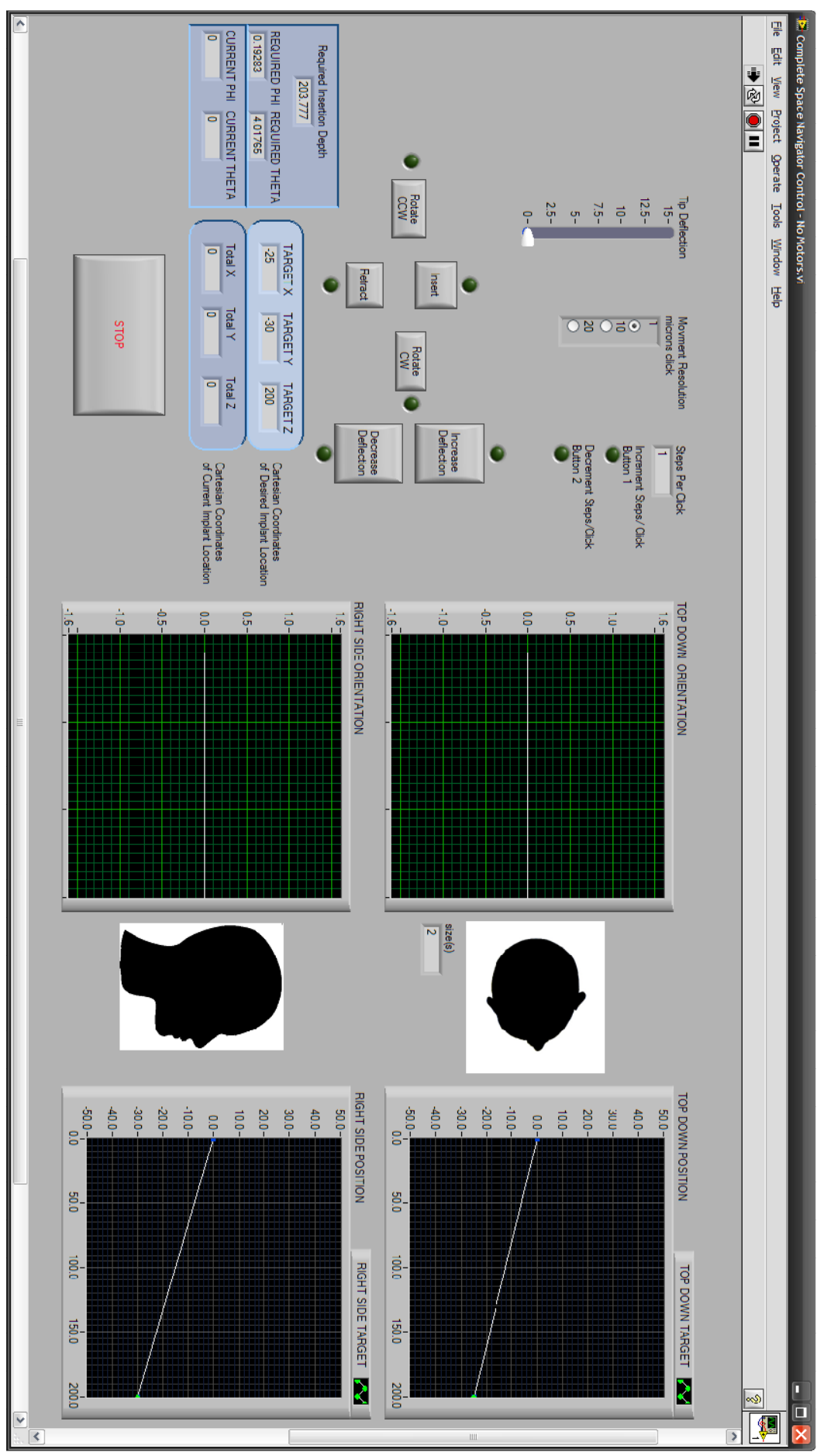

Figure 44 - Front Panel 


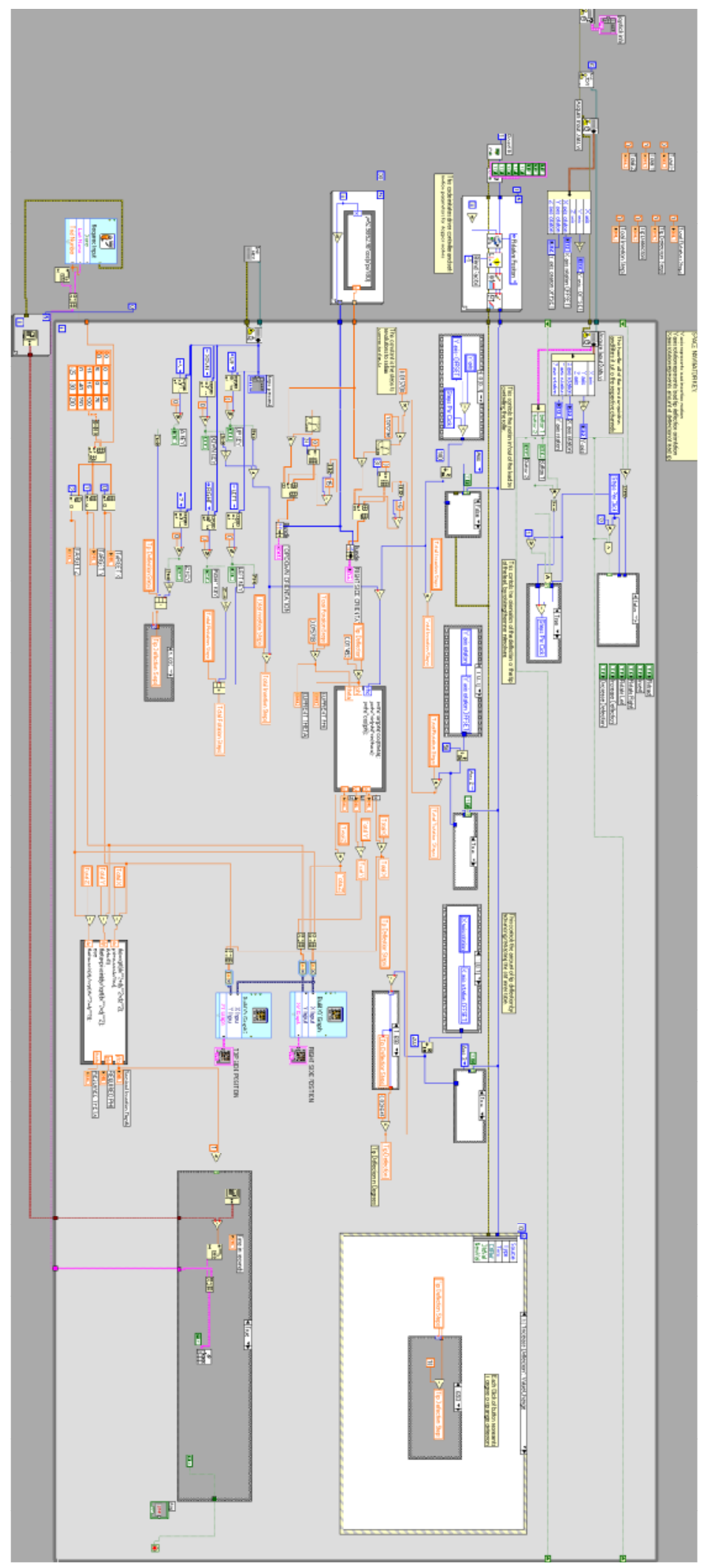

Figure 45 - Code Overview 
It should be noted that LabView layers the code for different instances of case structures. In the above overview, only one case of Boolean event handling (true/false) structures is shown. For example, one of the case structures handles the question, did the user click on the stop button? The code acts differently depending on the answer. All potential instances have been programmed, however the graphical manner in which LabView displays code, does not allow for both situations to be viewed at the same time. These instances are still contained within the actual LabView code.

\section{A3. Proposed Usage Instructions}

NOTE: The following instructions for use have not been approved by the FDA or any other agency. These instructions for use are solely for theoretical research. Clinical evaluation and FDA approval is required before the application of these instructions in any surgical setting.

These instructions dictate the proper preparation, use, and disposal of the deep brain implant guidance system.

Section 1: Preparation

1. The sealed system tray is to be removed from its sterilized pouch. Ensure that the sterilization seal has not been compromised by examining the condition of the sterilization seal and lid.

2. Pass the sealed system tray into the sterile operating environment and open the system tray.

3. Remove the contents of the system tray. Ensure the following are included:

3.1. Insertion mechanism

3.2. Guidance mechanism

3.3. Insertion connection wire

3.4. Guidance connection cable 
4. Connect the insertion mechanism to the control station. Ensure that the insertion mechanism responds to input.

4.1. In the event that failure or intermittent response is observed, check connections and repeat. If failure or intermittent response continues, do not use system for implant.

5. Connect the guidance mechanism to the control station. Ensure that the guidance mechanism responds to input.

5.1. In the event that failure or intermittent response is observed, check connections and repeat. If failure or intermittent response continues, do not use system for implant.

6. Mount the insertion mechanism onto the Leksell arc.

7. Align the desired axis of implant with the highlighted groove on the insertion drive.

8. Mount the guidance system onto the Leksell arc on the right lateral side of the arc. Ensure that the lead port is facing towards the guidance system.

9. Insert the proximal end of the stylet sheath into the groove on the lead port of the guidance system. Ensure that the sheath snaps into location.

10. Insert the distal end of the formed stylet into the slot on the guidance system and ensure that the colors on the tab line up with the corresponding colors on the drive gear. This is required to ensure that the system correctly orients the curvature of the stylet.

11. Backload the lead onto the stylet sheath until the lead bottoms out inside of the guidance system. Ensure that all of the proximal lead contacts are contained inside the guidance system. Otherwise remove and reinsert lead into guidance system. In the event of continued difficulty, use different lead.

12. Insert the distal end of lead into drive system until resistance is met. 
13. Using the control screen, advance the lead and check to ensure that the lead responds correctly to all commands: insertion, extraction, deflection, and rotation.

14. After the systems responsiveness has been confirmed, the preparation is complete.

Section 2: Lead Insertion

1. Adjust the Leksell frame, so that it aligns with the desired insertion trajectory. This trajectory must have been predetermined using computed tomography or magnetic resonance imaging. This trajectory is at the discretion of the surgeon.

2. Advance the lead into the breach in the patient's skull.

3. Using the Graphical User Interface, patient feedback, and fluoroscopy, drive the system to the desired implant site. Use the software to determine track distance from desired implant site as well as current lead orientation.

4. As the target implant site is approached use the deflection and rotational ability of the system to curve the lead around the site, thus increasing the electrical current through the target brain matter.

5. Once target implant site has been reached and acceptable lead configuration is confirmed, set levels of stimulation to minimum therapeutic levels. Program implantable stimulator to same levels.

6. Release lead from drive system.

7. Follow routine practice for connecting lead to implantable pulse generator and incision closure. 


\section{A4. Failure Mode and Effects Analysis (FMEA)}

Failure modes and effects analysis is a tool utilized by engineers to assess potential problems, design issues/limitations, user error, etc as well as the possible harm that may be caused by these unintended events. This is required by the FDA as part of the design verification activities for all medical devices. (FDA 1997)

The following FMEA table is laid out in the following manner:

1. The correct step in the procedure/device use is stated. (Description of Use Step)

2. The desired outcome / rational for this step is stated. (Function of Outcome of Use Step)

3. All possible failures/complications associated with this step are stated. (Hazard)

4. The potential harm which may be caused by this failure/complication is stated. (Failure Effect)

5. The potential sources of this failure mode is stated (Potential Root Cause of Failure Mode)

6. The class of the potential source is determined. (Use or Design)

7. The occurrence rate of this failure mode is either stated (if known) or estimated (if unknown) based on the Expected Rate of Incidence Table (1-5 ranking determined by decades). (Rate)

8. The potential for detection of the failure mode AND such detection preventing the associated harm. (Difficulty of Detection)

9. The severity of the potential harm is stated (if known) or estimated (if unknown). ( Severity)

10. Finally, the risk index is calculated by multiplying all three factors: Rate, Detection, and Severity together. (Risk Index)

11. This combined risk index is used to determine if the design is safe enough for use, or if redesign is required. The combination allows all the different aspects of all the different failure modes to be assessed against a single scale. If ANY of the risk indexes are above a certain threshold, the design cannot move forward. In this case the risk index was set to 30 , anything above this value would indicate that the design "as is" not viable. Risk indexes close to or equal to 30 should be evaluated again to determine if design improvements or training can decrease the associated risks. 
Table 16 - FMEA Definitions

\begin{tabular}{|c|c|c|}
\hline Category & Scale & Definition \\
\hline \multirow{5}{*}{$\begin{array}{l}\text { Severity of } \\
\text { Issue }\end{array}$} & 1 & Negligible \\
\hline & 2 & Minor \\
\hline & 3 & Moderate \\
\hline & 4 & Critical \\
\hline & 5 & Catastrophic \\
\hline \multirow{5}{*}{$\begin{array}{l}\text { Expected } \\
\text { Rate of } \\
\text { Incidence }\end{array}$} & 1 & Remote $(<1: 10,000)$ \\
\hline & 2 & Low $(>1: 10,000)$ \\
\hline & 3 & Moderate $(>1: 1000)$ \\
\hline & 4 & High $(>1: 100)$ \\
\hline & 5 & Very High ( > 1:10) \\
\hline \multirow{5}{*}{$\begin{array}{l}\text { Difficulty of } \\
\text { Detection }\end{array}$} & 1 & Easy (>90\%) \\
\hline & 2 & Fair $(>70 \%)$ \\
\hline & 3 & Moderate $(>50 \%)$ \\
\hline & 4 & Hard $(>30 \%)$ \\
\hline & 5 & Very Hard $(<30 \%)$ \\
\hline
\end{tabular}

Table 17 - FMEA

\begin{tabular}{|c|c|c|c|c|c|c|c|c|c|c|}
\hline ฮ્ & 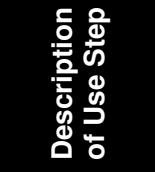 & 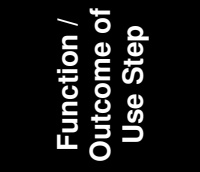 & 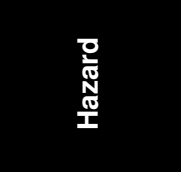 & 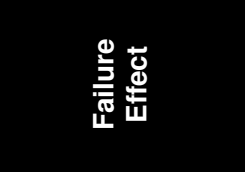 & 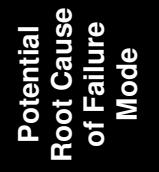 & 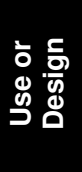 & 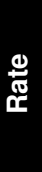 & 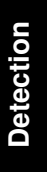 & ஓ & 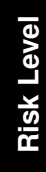 \\
\hline 1 & $\begin{array}{l}\text { Patient } \\
\text { Selection }\end{array}$ & $\begin{array}{l}\text { Determine if } \\
\text { DBS is } \\
\text { appropriate } \\
\text { treatment }\end{array}$ & $\begin{array}{l}\text { Inappropriate } \\
\text { patient } \\
\text { selection }\end{array}$ & $\begin{array}{l}\text { Allergic reaction, } \\
\text { bleeding, failure of } \\
\text { treatment, stroke, } \\
\text { death }\end{array}$ & User error & U & 1 & 5 & 5 & 25 \\
\hline 2 & $\begin{array}{l}\text { Guide lead } \\
\text { to target } \\
\text { location }\end{array}$ & $\begin{array}{l}\text { Lead is placed } \\
\text { to provide } \\
\text { optimal } \\
\text { treatment }\end{array}$ & Motor fails & $\begin{array}{l}\text { Motion inhibited / } \\
\text { prolonged } \\
\text { procedure }\end{array}$ & $\begin{array}{l}\text { System life } \\
\text { expectancy } \\
\text { surpassed }\end{array}$ & D & 1 & 1 & 4 & 4 \\
\hline
\end{tabular}




\begin{tabular}{|c|c|c|c|c|c|c|c|c|c|c|}
\hline 3 & $\begin{array}{l}\text { Guide lead } \\
\text { to target } \\
\text { location }\end{array}$ & $\begin{array}{l}\text { Lead is placed } \\
\text { to provide } \\
\text { optimal } \\
\text { treatment }\end{array}$ & $\begin{array}{l}\text { Encoder } \\
\text { misses step }\end{array}$ & $\begin{array}{l}\text { Lead position no } \\
\text { longer accurately } \\
\text { depicted on } \\
\text { screen }\end{array}$ & $\begin{array}{l}\text { System life } \\
\text { expectancy } \\
\text { surpassed }\end{array}$ & D & 1 & 5 & 4 & 20 \\
\hline 4 & $\begin{array}{l}\text { Guide lead } \\
\text { to target } \\
\text { location }\end{array}$ & $\begin{array}{l}\text { Lead is placed } \\
\text { to provide } \\
\text { optimal } \\
\text { treatment }\end{array}$ & $\begin{array}{c}\text { Motor } \\
\text { overheats }\end{array}$ & $\begin{array}{l}\text { Motion inhibited / } \\
\text { prolonged } \\
\text { procedure }\end{array}$ & $\begin{array}{c}\text { System life } \\
\text { expectancy } \\
\text { surpassed, voltage } \\
\text { surge, environment } \\
\text { out of use range }\end{array}$ & U & 1 & 1 & 4 & 4 \\
\hline 5 & $\begin{array}{l}\text { Guide lead } \\
\text { to target } \\
\text { location }\end{array}$ & $\begin{array}{l}\text { Lead is placed } \\
\text { to provide } \\
\text { optimal } \\
\text { treatment }\end{array}$ & Gears jam & $\begin{array}{l}\text { Motion inhibited / } \\
\text { prolonged } \\
\text { procedure }\end{array}$ & $\begin{array}{c}\text { System life } \\
\text { expectancy } \\
\text { surpassed, foreign } \\
\text { matter }\end{array}$ & $U$ & 1 & 1 & 4 & 4 \\
\hline 6 & $\begin{array}{l}\text { Guide lead } \\
\text { to target } \\
\text { location }\end{array}$ & $\begin{array}{l}\text { Lead is placed } \\
\text { to provide } \\
\text { optimal } \\
\text { treatment }\end{array}$ & Rollers slip & $\begin{array}{l}\text { Lead position no } \\
\text { longer accurately } \\
\text { depicted on } \\
\text { screen }\end{array}$ & $\begin{array}{c}\text { System life } \\
\text { expectancy } \\
\text { surpassed, foreign } \\
\text { matter, axial } \\
\text { required force too } \\
\text { high }\end{array}$ & $U$ & 1 & 5 & 4 & 20 \\
\hline 7 & $\begin{array}{l}\text { Load lead } \\
\text { into } \\
\text { insertion } \\
\text { mechanism } \\
\end{array}$ & $\begin{array}{l}\text { Prepare lead } \\
\text { for insertion }\end{array}$ & $\begin{array}{l}\text { Spring Axle } \\
\text { fatigues }\end{array}$ & $\begin{array}{l}\text { Motion inhibited / } \\
\text { prolonged } \\
\text { procedure }\end{array}$ & $\begin{array}{l}\text { System life } \\
\text { expectancy } \\
\text { surpassed }\end{array}$ & $U$ & 1 & 5 & 5 & 25 \\
\hline 8 & $\begin{array}{l}\text { Guide lead } \\
\text { to target } \\
\text { location }\end{array}$ & $\begin{array}{l}\text { Lead is placed } \\
\text { to provide } \\
\text { optimal } \\
\text { treatment }\end{array}$ & Lead jams & $\begin{array}{l}\text { Motion inhibited / } \\
\text { prolonged } \\
\text { procedure }\end{array}$ & $\begin{array}{l}\text { User error, foreign } \\
\text { matter }\end{array}$ & $U$ & 2 & 1 & 5 & 10 \\
\hline 9 & $\begin{array}{l}\text { Guide lead } \\
\text { to target } \\
\text { location }\end{array}$ & $\begin{array}{l}\text { Lead is placed } \\
\text { to provide } \\
\text { optimal } \\
\text { treatment }\end{array}$ & $\begin{array}{l}\text { Wire / tube } \\
\text { jams }\end{array}$ & $\begin{array}{l}\text { Motion inhibited / } \\
\text { prolonged } \\
\text { procedure }\end{array}$ & $\begin{array}{c}\text { System life } \\
\text { expectancy } \\
\text { surpassed, } \\
\text { navigation radius } \\
\text { too small or } \\
\text { tortuous }\end{array}$ & $\mathrm{D}$ & 2 & 3 & 3 & 18 \\
\hline 10 & $\begin{array}{l}\text { Insert wire } \\
\text { into } \\
\text { guidance } \\
\text { mechanism } \\
\end{array}$ & $\begin{array}{c}\text { Guidance } \\
\text { system prep }\end{array}$ & Wire kink & $\begin{array}{l}\text { Guidance system } \\
\text { malfunction }\end{array}$ & User error & $U$ & 2 & 2 & 5 & 20 \\
\hline 11 & $\begin{array}{l}\text { Insert tube } \\
\text { into } \\
\text { guidance } \\
\text { mechanism }\end{array}$ & $\begin{array}{c}\text { Guidance } \\
\text { system prep }\end{array}$ & Tube kink & $\begin{array}{l}\text { Guidance system } \\
\text { malfunction }\end{array}$ & User error & $U$ & 2 & 2 & 5 & 20 \\
\hline 12 & $\begin{array}{l}\text { Stimulation } \\
\text { during } \\
\text { placement }\end{array}$ & $\begin{array}{l}\text { Lead is placed } \\
\text { to provide } \\
\text { optimal } \\
\text { treatment }\end{array}$ & $\begin{array}{l}\text { Connection } \\
\text { failure }\end{array}$ & $\begin{array}{l}\text { No electrical } \\
\text { stimulation during } \\
\text { implant process }\end{array}$ & $\begin{array}{c}\text { System life } \\
\text { expectancy } \\
\text { surpassed, user } \\
\text { error, foreign } \\
\text { matter } \\
\end{array}$ & $U$ & 2 & 3 & 5 & 30 \\
\hline 13 & $\begin{array}{l}\text { Insertion of } \\
\text { lead into } \\
\text { guidance } \\
\text { mechanism }\end{array}$ & $\begin{array}{l}\text { Guidance } \\
\text { system prep }\end{array}$ & $\begin{array}{l}\text { Contact } \\
\text { mismatch/ not } \\
\text { connected }\end{array}$ & $\begin{array}{l}\text { No electrical } \\
\text { stimulation during } \\
\text { implant process, } \\
\text { wrong contacts } \\
\text { being used }\end{array}$ & User error & $U$ & 3 & 2 & 5 & 30 \\
\hline 14 & $\begin{array}{l}\text { Stimulation } \\
\text { during } \\
\text { placement }\end{array}$ & $\begin{array}{l}\text { Location / } \\
\text { treatment } \\
\text { assessment }\end{array}$ & $\begin{array}{l}\text { Stimulation } \\
\text { voltage spike }\end{array}$ & $\begin{array}{c}\text { Brain tissue } \\
\text { damage, stroke, } \\
\text { death }\end{array}$ & $\begin{array}{c}\text { System life } \\
\text { expectancy } \\
\text { surpassed, faulty } \\
\text { circuitry }\end{array}$ & $\mathrm{D}$ & 1 & 1 & 5 & 5 \\
\hline 15 & $\begin{array}{l}\text { Guidance } \\
\text { via Space } \\
\text { Navigator, } \\
\text { on-screen } \\
\text { controls, } \\
\text { keyboard } \\
\end{array}$ & $\begin{array}{l}\text { Lead is placed } \\
\text { to provide } \\
\text { optimal } \\
\text { treatment }\end{array}$ & $\begin{array}{l}\text { Software } \\
\text { Crash }\end{array}$ & $\begin{array}{l}\text { Motion inhibited / } \\
\text { prolonged } \\
\text { procedure }\end{array}$ & $\begin{array}{c}\text { System life } \\
\text { expectancy } \\
\text { surpassed, faulty } \\
\text { circuitry }\end{array}$ & D & 1 & 1 & 4 & 4 \\
\hline
\end{tabular}




\begin{tabular}{|c|c|c|c|c|c|c|c|c|c|c|}
\hline 16 & $\begin{array}{c}\text { Guidance } \\
\text { via Space } \\
\text { Navigator, } \\
\text { on-screen } \\
\text { controls, } \\
\text { keyboard }\end{array}$ & $\begin{array}{l}\text { Lead is placed } \\
\text { to provide } \\
\text { optimal } \\
\text { treatment }\end{array}$ & $\begin{array}{l}\text { Software } \\
\text { Reset }\end{array}$ & $\begin{array}{l}\text { Lose of location, } \\
\text { erratic motion, } \\
\text { stoke, death }\end{array}$ & $\begin{array}{c}\text { Power outage, } \\
\text { misuse }\end{array}$ & $U$ & 1 & 1 & 5 & 5 \\
\hline 17 & $\begin{array}{l}\text { Guidance } \\
\text { via Space } \\
\text { Navigator, } \\
\text { on-screen } \\
\text { controls, } \\
\text { keyboard } \\
\end{array}$ & $\begin{array}{l}\text { Lead is placed } \\
\text { to provide } \\
\text { optimal } \\
\text { treatment }\end{array}$ & $\begin{array}{l}\text { Software } \\
\text { Crash }\end{array}$ & $\begin{array}{l}\text { Motion inhibited / } \\
\text { prolonged } \\
\text { procedure }\end{array}$ & $\begin{array}{c}\text { System life } \\
\text { expectancy } \\
\text { surpassed, faulty } \\
\text { circuitry }\end{array}$ & D & 1 & 4 & 4 & 16 \\
\hline 18 & $\begin{array}{c}\text { Guidance } \\
\text { via Space } \\
\text { Navigator, } \\
\text { on-screen } \\
\text { controls, } \\
\text { keyboard }\end{array}$ & $\begin{array}{l}\text { Lead is placed } \\
\text { to provide } \\
\text { optimal } \\
\text { treatment }\end{array}$ & $\begin{array}{l}\text { Input device } \\
\text { fails }\end{array}$ & $\begin{array}{l}\text { Motion inhibited / } \\
\text { prolonged } \\
\text { procedure }\end{array}$ & $\begin{array}{l}\text { Misuse, foreign } \\
\text { matter }\end{array}$ & $U$ & 2 & 3 & 3 & 18 \\
\hline 19 & $\begin{array}{l}\text { Guidance } \\
\text { via Space } \\
\text { Navigator }\end{array}$ & $\begin{array}{l}\text { Lead is placed } \\
\text { to provide } \\
\text { optimal } \\
\text { treatment }\end{array}$ & $\begin{array}{c}\text { Space } \\
\text { Navigator } \\
\text { doesn't return } \\
\text { to neutral }\end{array}$ & $\begin{array}{c}\text { Lead } \\
\text { misplacement, } \\
\text { undesired motion, } \\
\text { brain trauma, } \\
\text { stroke, death }\end{array}$ & $\begin{array}{l}\text { Misuse, system life } \\
\text { expectancy } \\
\text { surpassed, }\end{array}$ & $U$ & 2 & 2 & 5 & 20 \\
\hline 20 & $\begin{array}{l}\text { Guidance } \\
\text { via Space } \\
\text { Navigator }\end{array}$ & $\begin{array}{l}\text { Lead is placed } \\
\text { to provide } \\
\text { optimal } \\
\text { treatment }\end{array}$ & $\begin{array}{c}\text { Space } \\
\text { Navigator } \\
\text { button gets } \\
\text { stuck } \\
\end{array}$ & $\begin{array}{l}\text { Unable to use } \\
\text { button }\end{array}$ & $\begin{array}{l}\text { Misuse, foreign } \\
\text { matter }\end{array}$ & $U$ & 1 & 1 & 4 & 4 \\
\hline 21 & $\begin{array}{l}\text { Insert wire } \\
\text { into } \\
\text { guidance } \\
\text { mechanism }\end{array}$ & $\begin{array}{c}\text { Guidance } \\
\text { system prep }\end{array}$ & $\begin{array}{l}\text { Wire inserted } \\
\text { wrong } \\
\text { direction }\end{array}$ & $\begin{array}{l}\text { Guidance system } \\
\text { responds } \\
\text { backwards }\end{array}$ & User error & $U$ & 2 & 1 & 5 & 10 \\
\hline 22 & $\begin{array}{l}\text { Insert tube } \\
\text { into } \\
\text { guidance } \\
\text { mechanism } \\
\end{array}$ & $\begin{array}{c}\text { Guidance } \\
\text { system prep }\end{array}$ & $\begin{array}{l}\text { Lead inserted } \\
\text { wrong } \\
\text { direction }\end{array}$ & $\begin{array}{l}\text { Contacts do not } \\
\text { line up, wire } \\
\text { cannot be } \\
\text { inserted }\end{array}$ & User error & $U$ & 1 & 3 & 2 & 6 \\
\hline 23 & $\begin{array}{l}\text { Stimulation } \\
\text { during } \\
\text { placement }\end{array}$ & $\begin{array}{l}\text { Location / } \\
\text { treatment } \\
\text { assessment }\end{array}$ & $\begin{array}{c}\text { Over- } \\
\text { stimulation }\end{array}$ & $\begin{array}{c}\text { Pain, brain tissue } \\
\text { damage, stroke, } \\
\text { death }\end{array}$ & User Error & $U$ & 1 & 3 & 5 & 15 \\
\hline 24 & $\begin{array}{l}\text { Stimulation } \\
\text { during } \\
\text { placement }\end{array}$ & $\begin{array}{l}\text { Location / } \\
\text { treatment } \\
\text { assessment }\end{array}$ & $\begin{array}{l}\text { Under- } \\
\text { stimulation }\end{array}$ & $\begin{array}{c}\text { Faulty treatment, } \\
\text { prolonged } \\
\text { procedure, } \\
\text { ineffective } \\
\text { treatment }\end{array}$ & User Error & $U$ & 1 & 3 & 1 & 3 \\
\hline 25 & $\begin{array}{l}\text { Stimulation } \\
\text { during } \\
\text { placement }\end{array}$ & $\begin{array}{l}\text { Location / } \\
\text { treatment } \\
\text { assessment }\end{array}$ & Short & $\begin{array}{c}\text { Stimulation } \\
\text { transferred to } \\
\text { wrong contacts } \\
\end{array}$ & $\begin{array}{c}\text { Conductive foreign } \\
\text { matter in } \\
\text { connection area }\end{array}$ & $U$ & 1 & 4 & 3 & 12 \\
\hline 26 & $\begin{array}{c}\text { Guidance } \\
\text { via Space } \\
\text { Navigator, } \\
\text { on-screen } \\
\text { controls, } \\
\text { keyboard }\end{array}$ & $\begin{array}{l}\text { Lead is placed } \\
\text { to provide } \\
\text { optimal } \\
\text { treatment }\end{array}$ & $\begin{array}{l}\text { Guidance too } \\
\text { fast }\end{array}$ & $\begin{array}{c}\text { Pain, brain tissue } \\
\text { damage, stroke, } \\
\text { death }\end{array}$ & User Error & $U$ & 1 & 1 & 5 & 5 \\
\hline
\end{tabular}




\section{A5. Assembly and Detail Drawings}

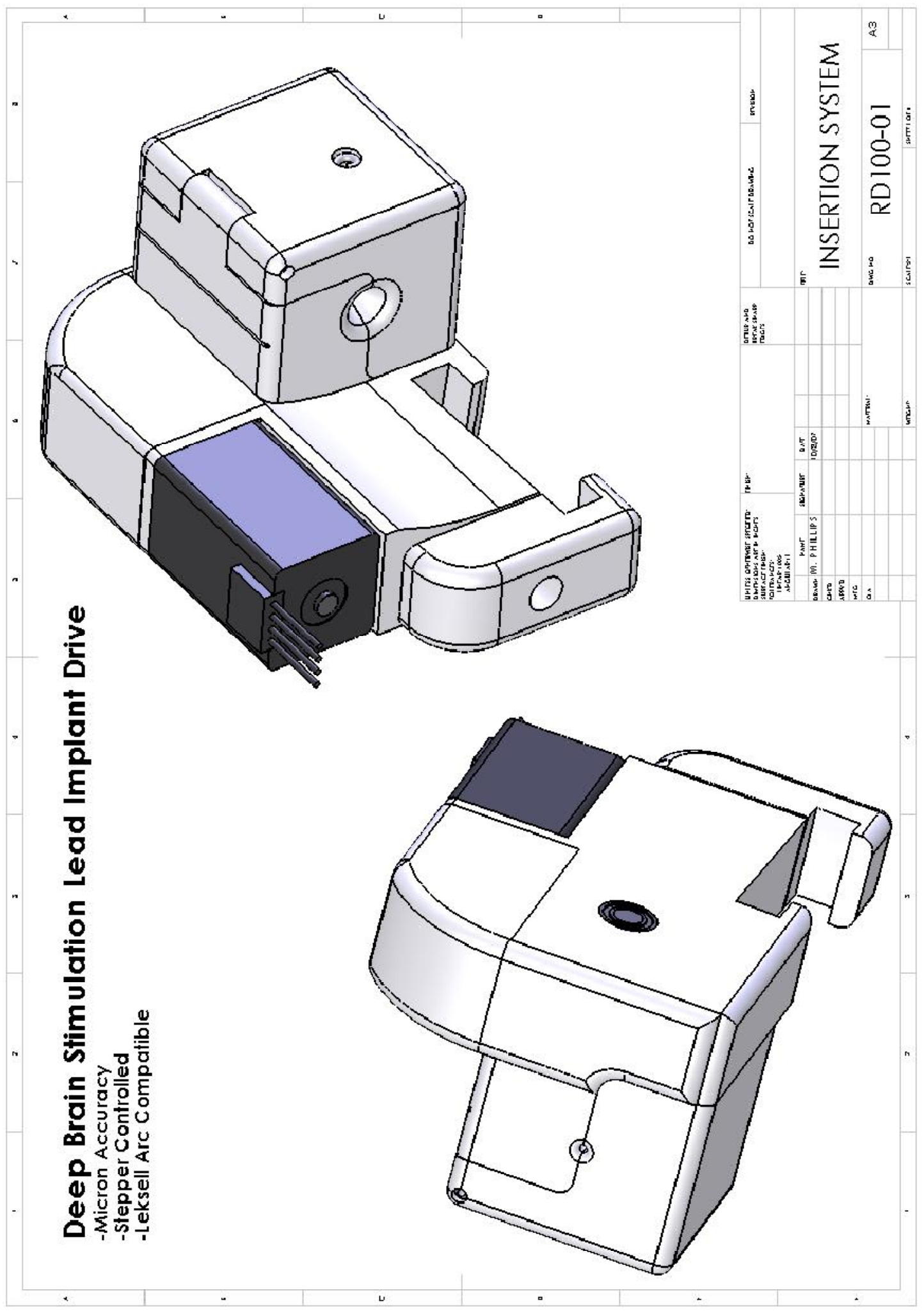




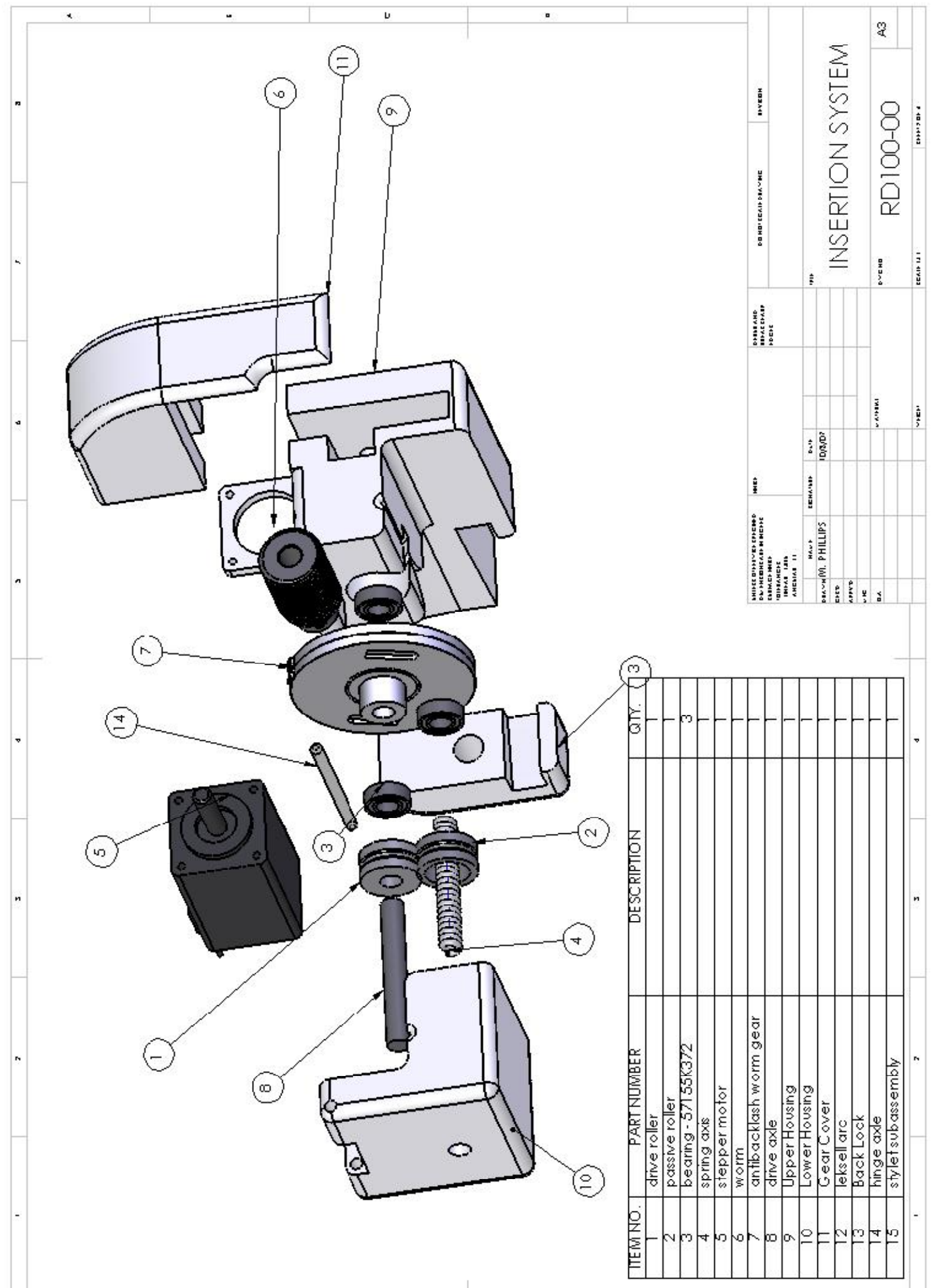




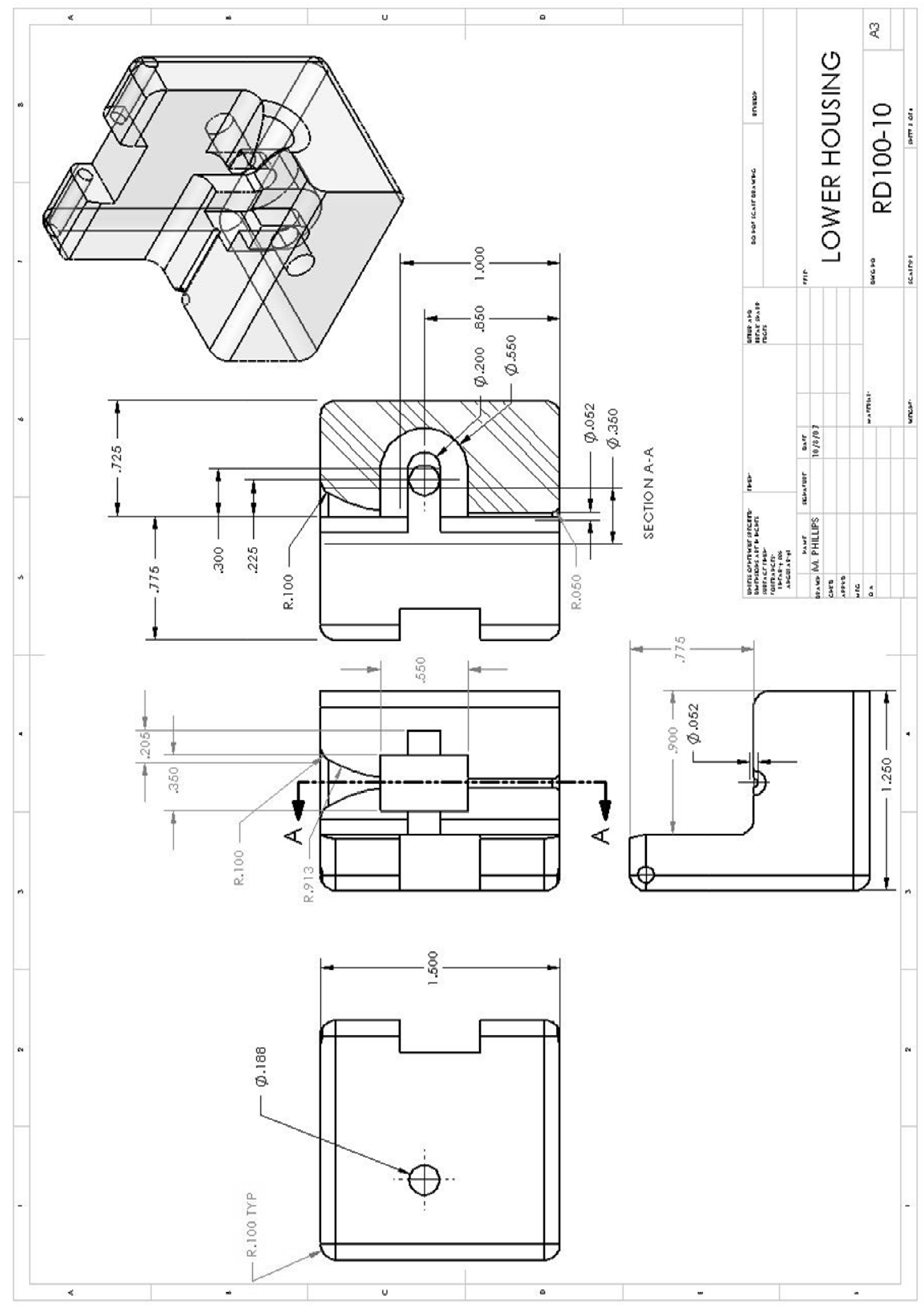




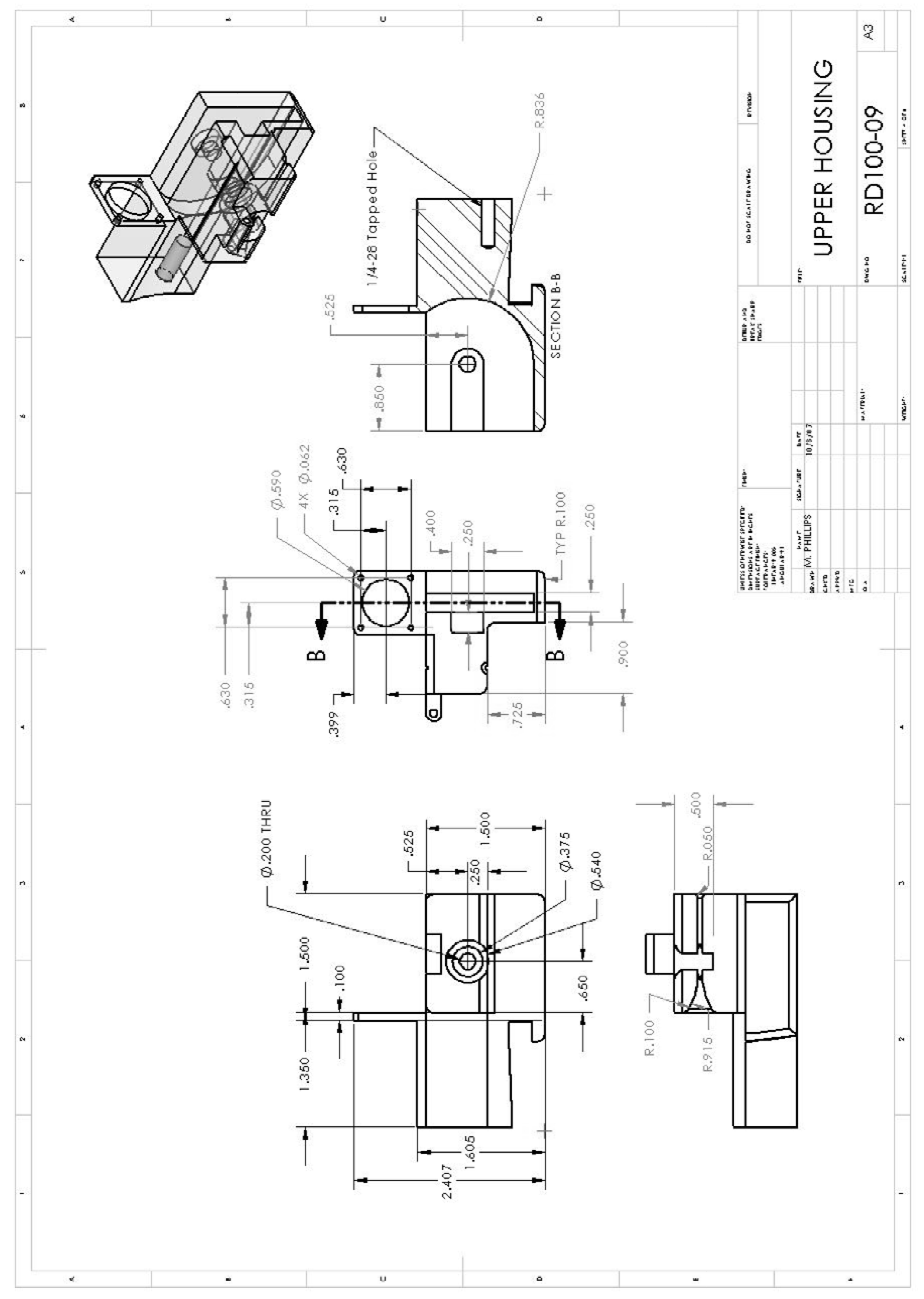




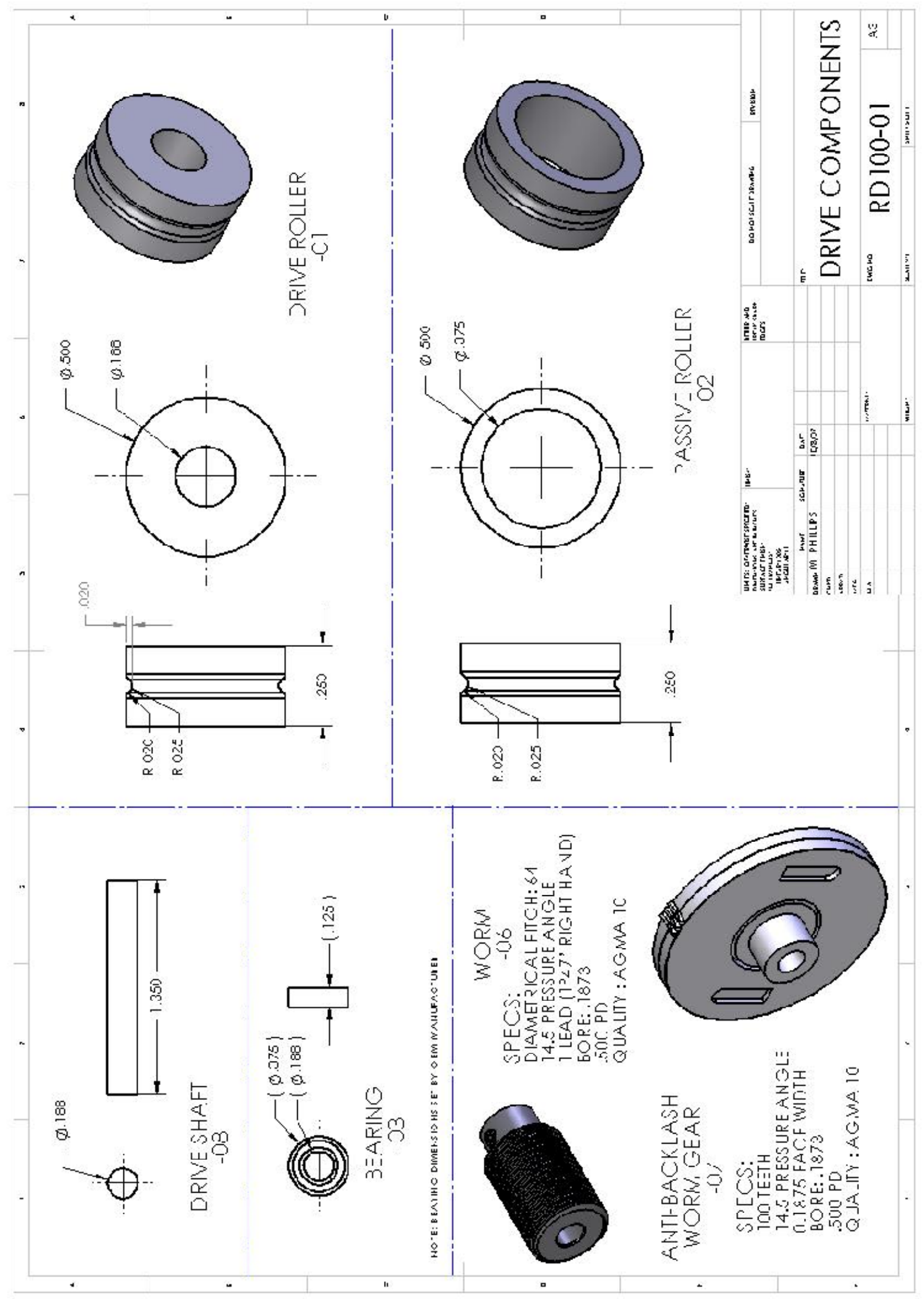




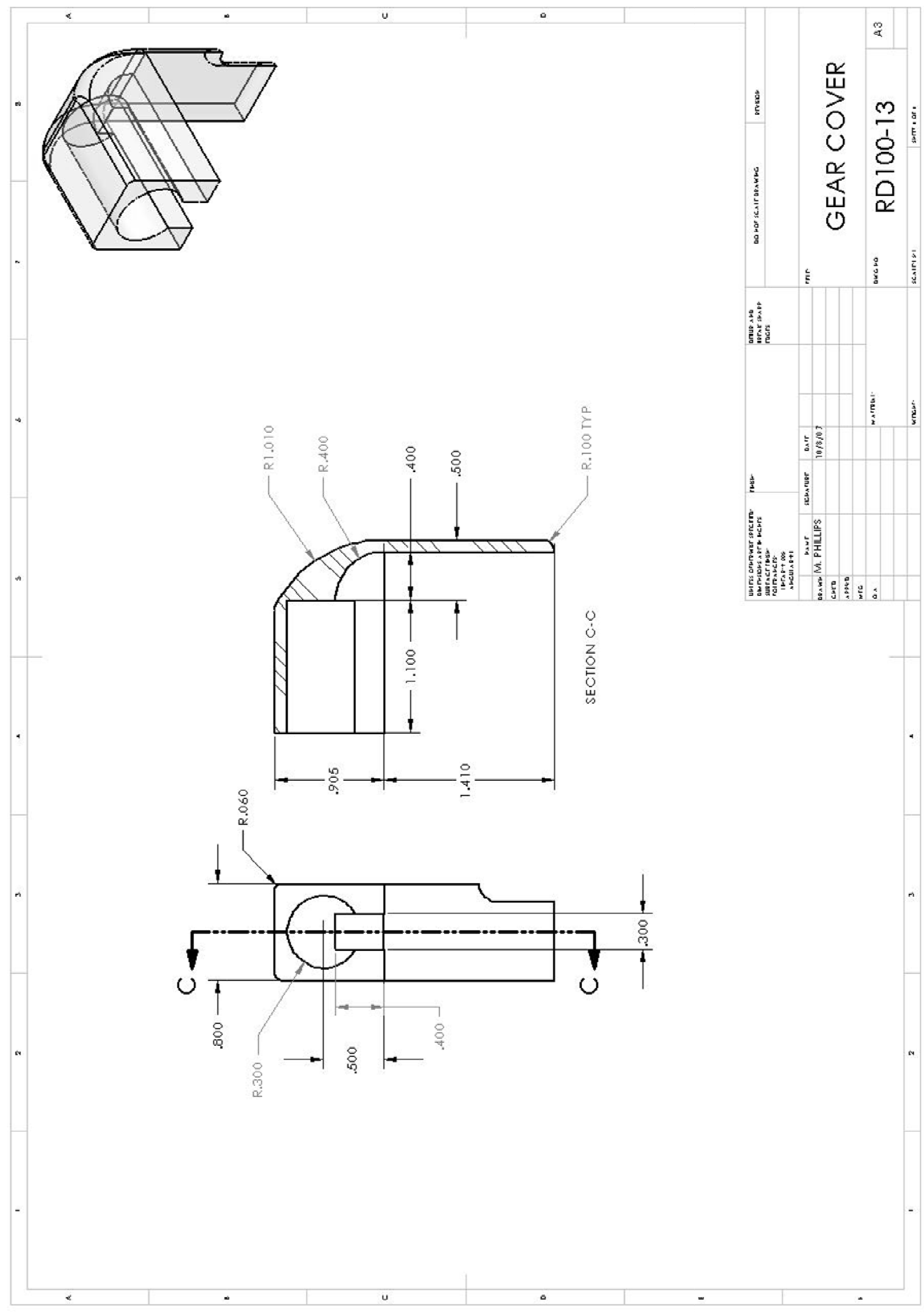




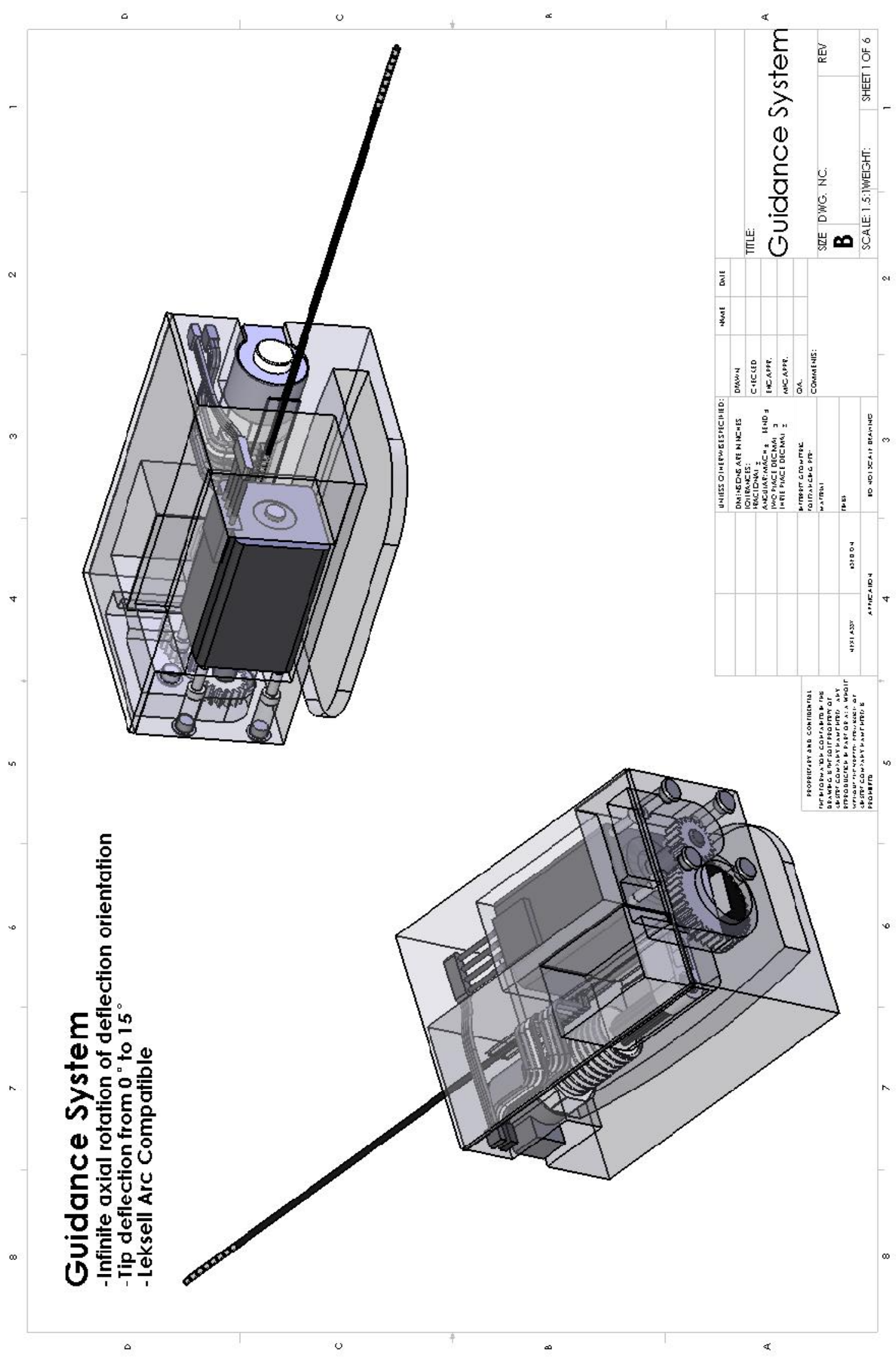




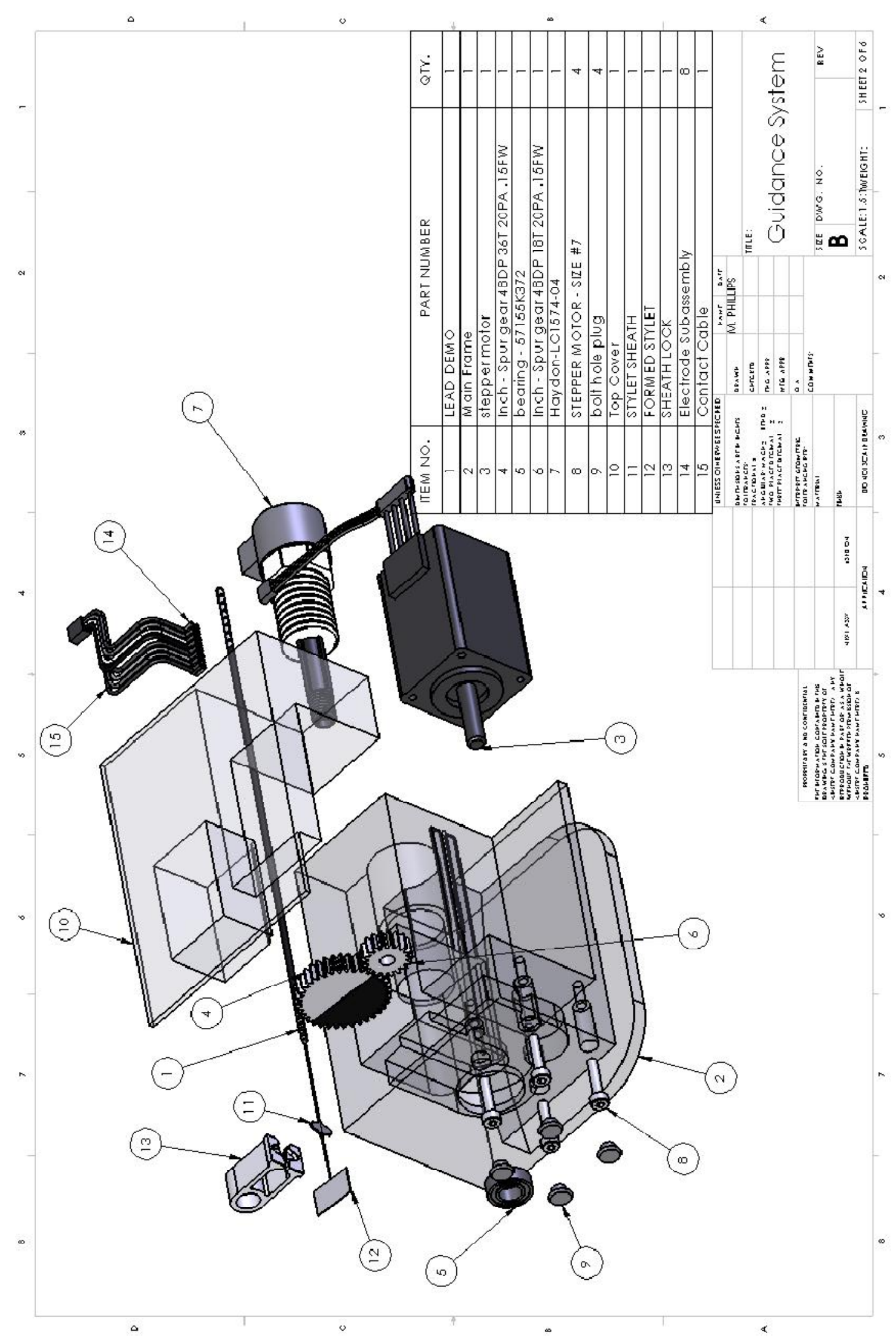




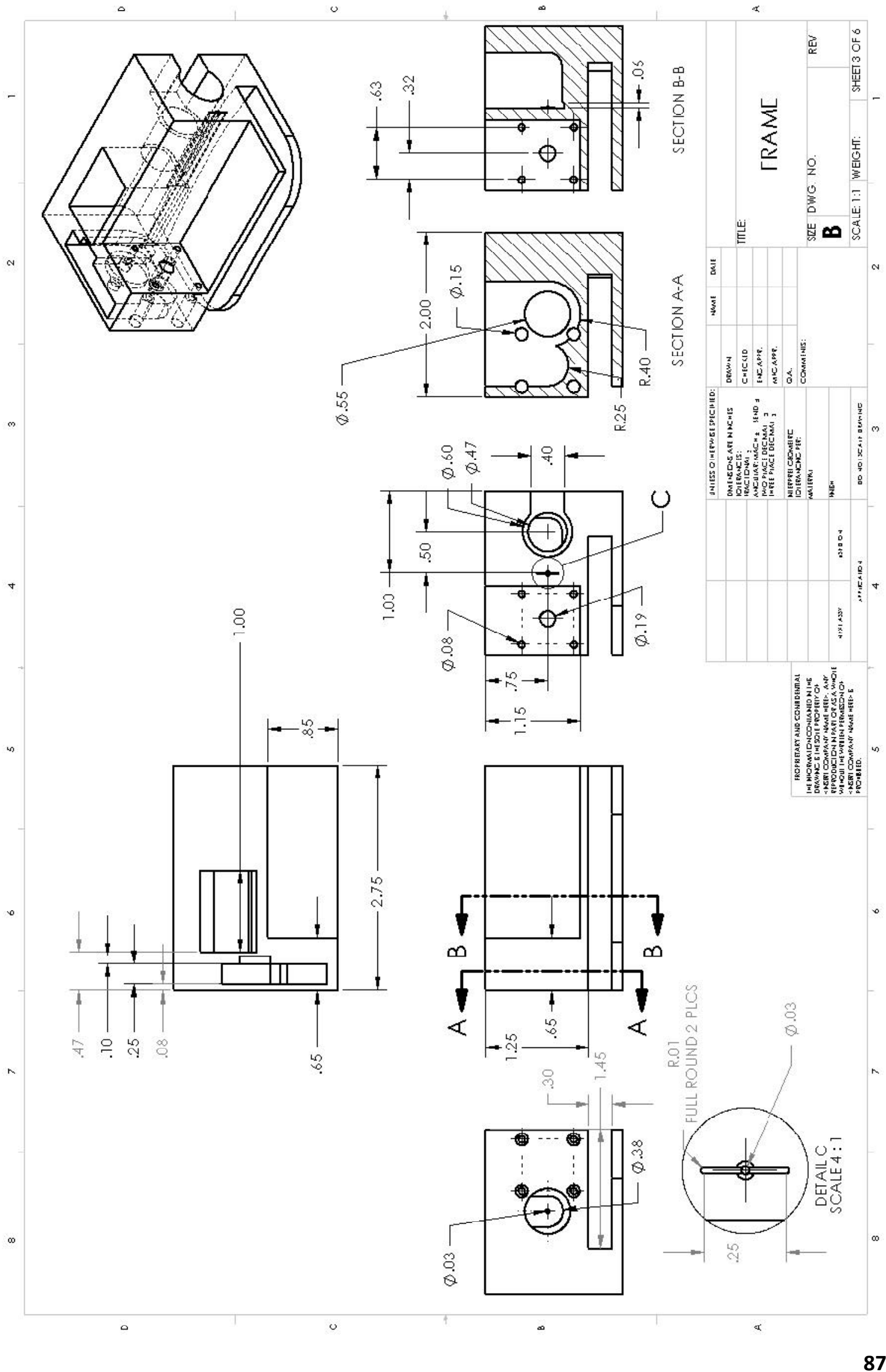




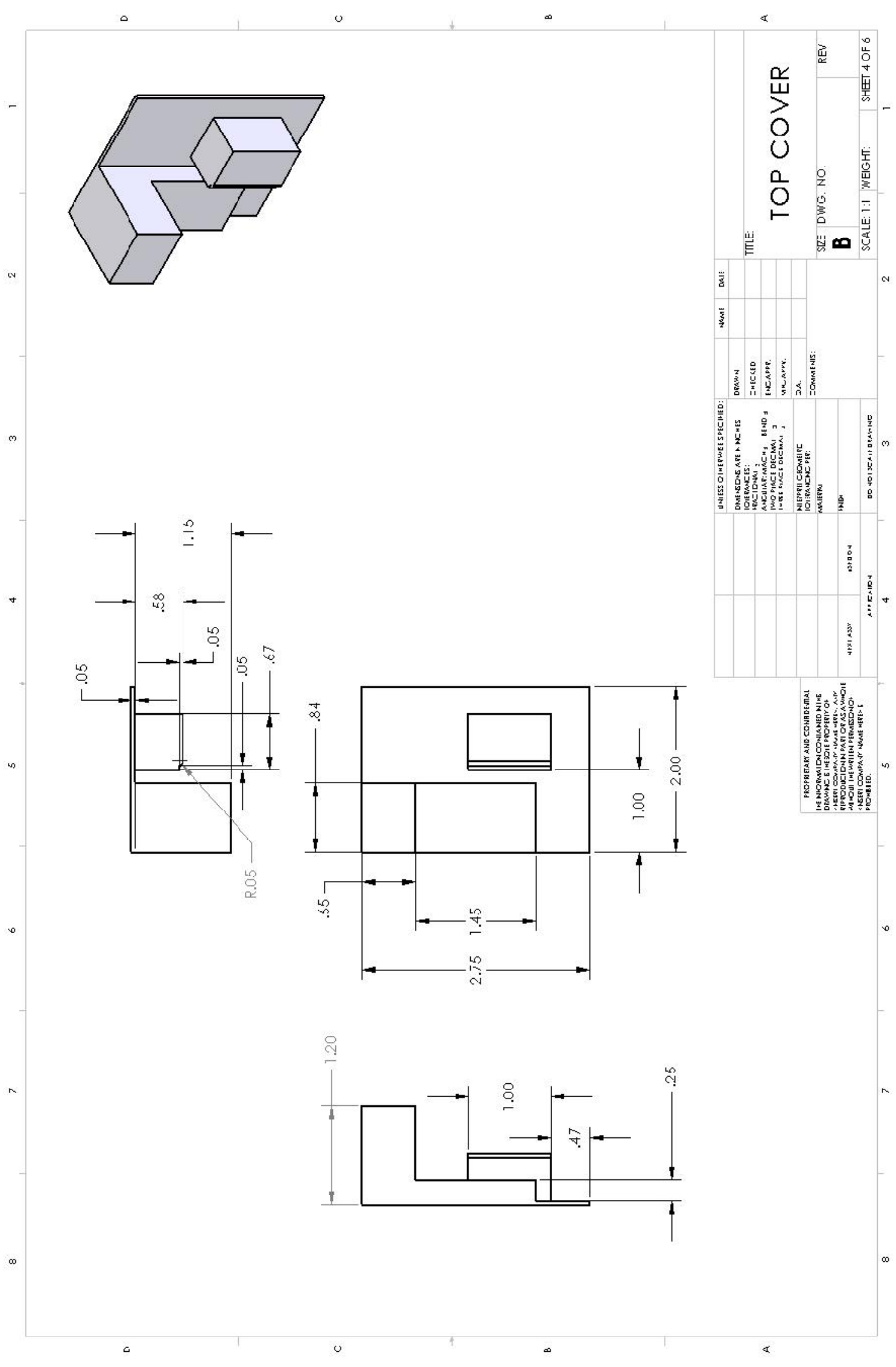




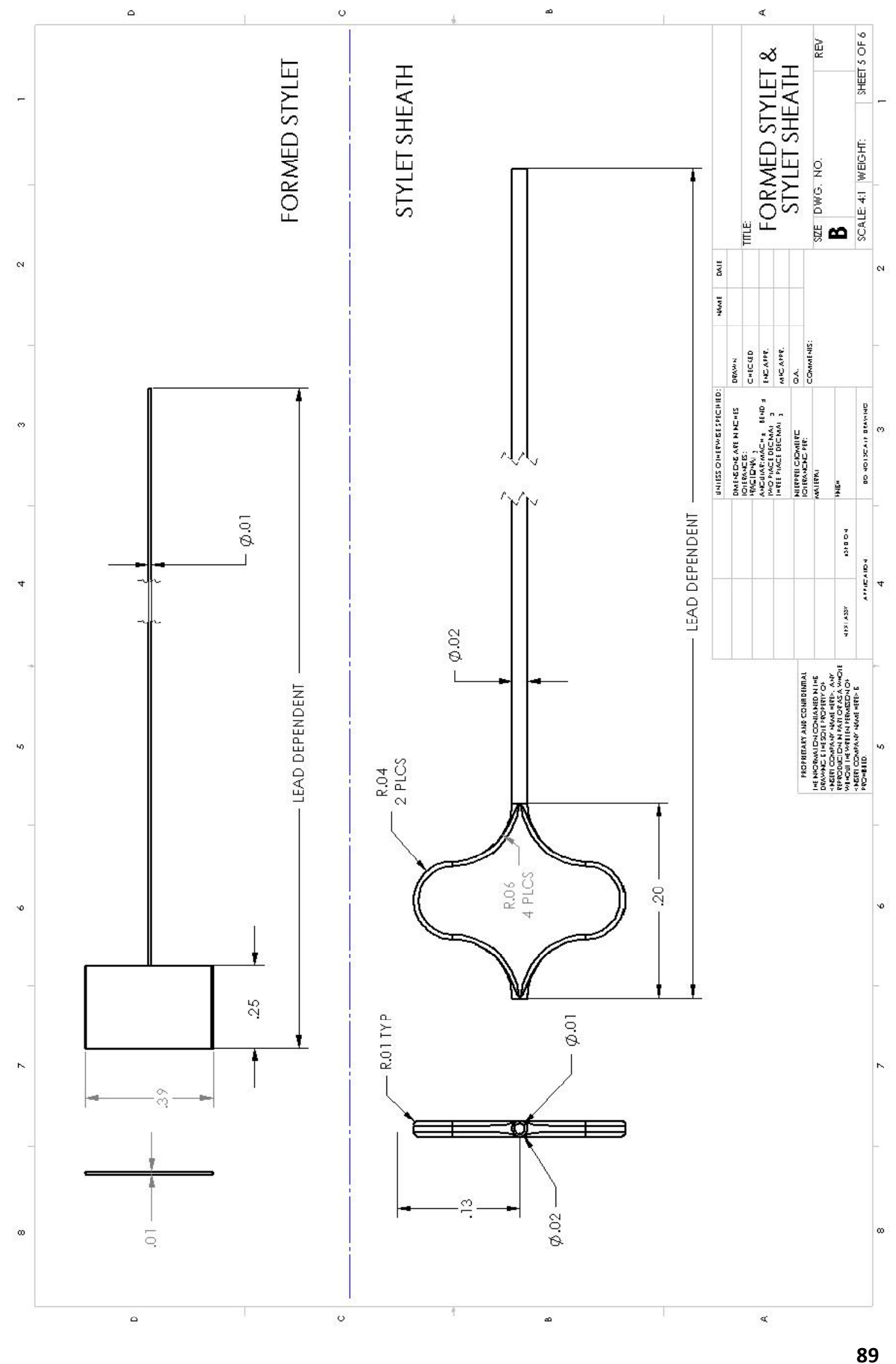




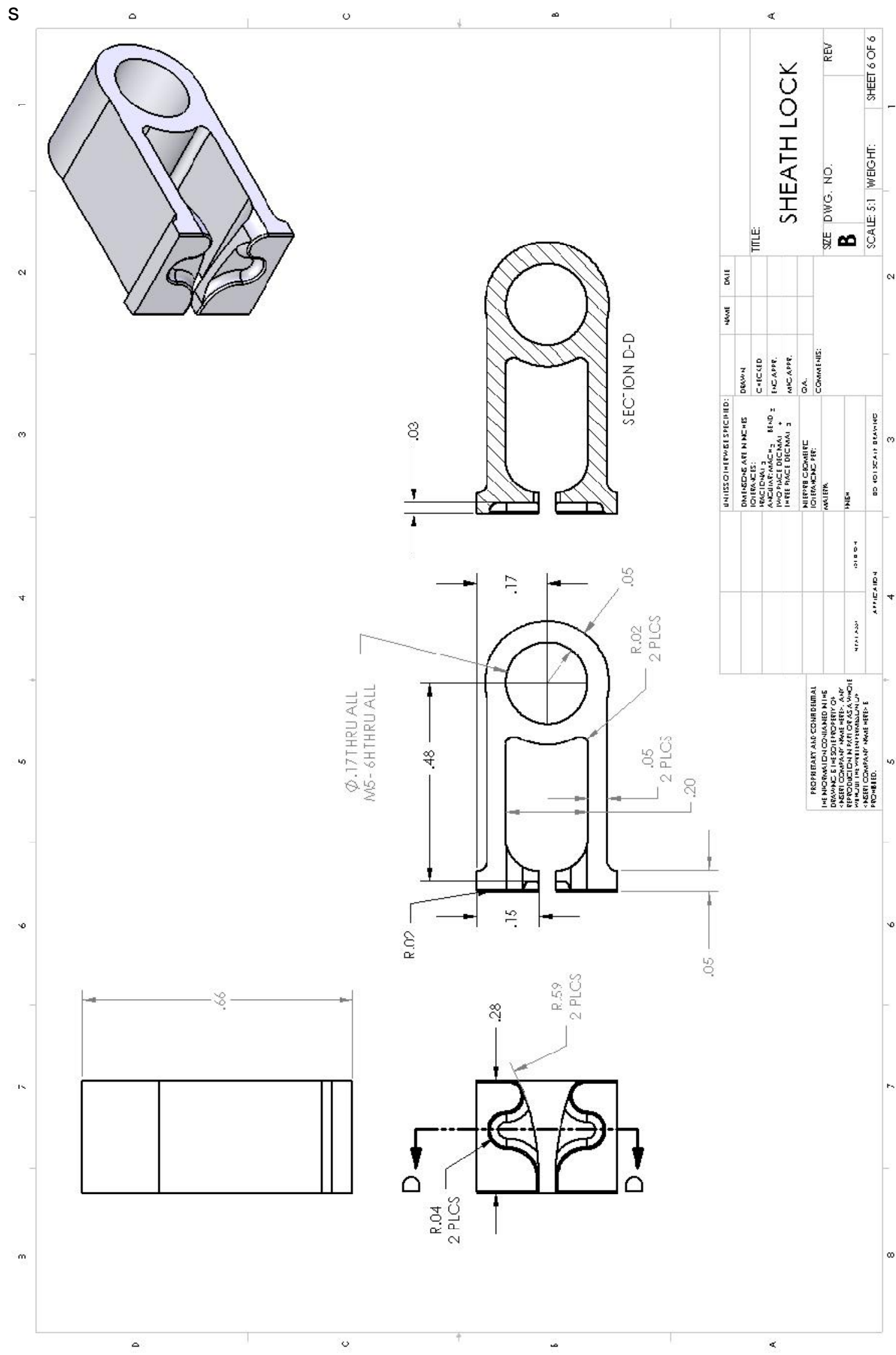




\section{Bibliography}

3D Connexion (A Logitech Company). Space Navigator Datasheet. March 24, 2008.

http://www.3dconnexion.com/docs/SpaceNavigator_Datasheet.pdf (accessed July 31, 2008).

anonymous. Incertion of electrode during parkinson surgery.

Berk, C., J. Carr, M. Sinden, J. Martzke, and C. Honey. "Thalamic deep brain stimulation for the treatment of tremor due to multiple sclerosis." Journal of Neurosurgery, 2002: 815-820.

Bilston, L., Z. Liu, and N. Phan-Thien. "Linear viscoelastic properties of bovine brain tissue in shear." Biorheology 34, no. 6 (1997): 377-85.

Butson, C, S. Cooper, J Henderson, and C. McIntyre. "Patient-Specific Analysis of the Volume of Tissue Activated During Deep Brain Stimulation." Neuroimage, January 2007: 661-670.

Butson, C., C. Maks, and C. Mclntyre. "Sources and effects of electrode impedance during deep brain stimulation." Clinical Neurophysiology, February 2006: 477-54.

FDA. Design Control Guidance For Medical Device Manufacturers. March 11, 1997.

http://www.fda.gov/medicaldevices/deviceregulationandguidance/guidancedocuments/ucm07 0627.htm (accessed 10 10, 2010).

Glezer, S., and I. Blinkov. The Human Brain in Figures and Tables. A Quantitative Handbook. New York: Plenum Press, 1968.

Henry, S., D. McAllister, M. Allen, and M. Prausnitz. "Microfabricated Microneedles: A novel approach to transdermal drug delivery." Journal of Pharmaceutical Sciences, 1998: 922-925.

Junqueira, L., and J. Carneiro. Basic Histology: Text and Atlas, 10th ed. McGraw-Hill/Appleton \& Lange, 2002.

Kopell, B., B. Greenberg, and A. Rezai. "Deep Brain Stimulation for Psychiatric Disorders." Journal of Clinical Neurophysiology, 2004: 51-67.

Leksell. Leksell Stereotactic System ${ }^{\circledR} .2008$.

http://www.elekta.com/healthcare_international_leksell_stereotactic_system.php (accessed July 04, 2008).

Mayberg, H., et al. "Deep brain stimulation for treatment-resistant depression." Neuron, Volume, 45 Issue 5, 2005: 651-660.

Medtronic Inc. Medtronic Deep Brain Stimulation. 2010.

http://professional.medtronic.com/interventions/deep-brain-stimulation/presentations-anddownloads/index.htm (accessed May 29, 2010).

Nangiana, J., J. Adler, and S. Chang. "Image-Guided Stereotactic Radiosurgery." In Intracranial Stereotactic Radiosurgery, by Lunsford L. and J. Sheehan, 21-28. Thieme, 2009.

National Institute of Neurological Disorders and Stroke. Brain Basics: Know Your Brain. August 18, 2010. http://www.ninds.nih.gov/disorders/brain_basics/know_your_brain.htm (accessed October 16, 2010). 
-. National Institute of Neurological Disorders and Stroke. May 09, 2007.

http://www.ninds.nih.gov/disorders/deep_brain_stimulation/deep_brain_stimulation.htm (accessed June 24, 2007).

National Instruments. LabVIEW. 2010. http://www.ni.com/labview/.

Nuttin, B., P. Cosyns, H. Demeulemeester, J. Gybels, and B. Meyerson. "Electrical stimulation in anterior limbs of internal capsules in patients with obsessive-compulsive disorder." Lancet, Volume 354, Issue 9189, 1999: 1526-1526.

Oscar-Berman, M., and K. Marinlovic. "Alcoholism and the brain: An overview." Alcohol Research \& Health, 2003: 125-133.

Redler, K., C. Baxi, E. Hoffmann, and K. Schaubel. "Use of a Thermal Analogy to Find Electrical Resistances of the Electrical Breaks in the TPX Passive Stabilization Systems." Fusion Engineering 2 (1995): 1299-1302.

Rengachary, S., and R. Ellenbogen. Principles of Neurosurgery. Edinburgh: Elsevier Mosby, 2005.

Schawlb, J., and C. Hamani. "The History and Future of Deep Brain Stimulation."

Neurotherapeutics: The Journal of the American Society for Experimental NeuroTherapeutics, 2008: 3-13.

Sommer, M. "The role of the thalamus in motor control." Current Opinion in Neurobiology, August 2003: 663-670.

Speigal, Wycis, Marks, and Lee. "Stereotactic apparatus for operations on the human brain." SCIENCE, 1947: 106:349-50.

St Jude Medical CRMD. Locator ${ }^{T M}$ Plus Implant Tool. 2010.

http://www.sjmprofessional.com/Products/Intl/ICD-Systems/Locator-Plus-Implant-Tool.aspx (accessed October 09, 2010).

Szeifert, G, D. Atteberry, D. Kondziolka, and L. Lunsford. "How Brain Tumors Respond to Stereotactic Radiosurgery." In Intracranial Stereotactic Radiosurgery, by Lunsford L. and J. Sheehan, 13-20. Thieme, 2009.

U.S. Department of Health and Human Services. "FDA APPROVES IMPLANTED BRAIN STIMULATOR TO CONTROL TREMORS." August 4, 1997.

http://www.fda.gov/bbs/topics/NEWS/NEW00580.html (accessed June 24, 2007).

Walkup, J. TSA Medical and Scientific Advisors. 2005.

http://web.archive.org/web/20051122154536/http://tsa-usa.org/news/DBS-Statement.htm.

WebMD. WebMD. 2002. http://www.webmd.com/multiple-sclerosis/guide/deep-brainstimulation (accessed June 10, 2008).

Young, J. Nerve Tissue. 2000.

http://training.seer.cancer.gov/module_anatomy/unit5_2_nerve_tissue.html (accessed June 10, 2008). 